Ana Cláudia Aoki Santarosa

\title{
Caracterização paleoceanográfica de um testemunho da Bacia de Santos com base em foraminíferos planctônicos durante o Holoceno
}

\author{
Dissertação apresentada ao Instituto \\ Oceanográfico da Universidade de \\ São Paulo, como parte dos requisitos \\ para obtenção do título de Mestre em \\ Ciências, Programa de Oceanografia \\ Química e Geológica \\ Orientador: Prof. Dr. Felipe A.L. Toledo
}

São Paulo

2010 
Universidade de São Paulo

Instituto Oceanográfico

\title{
Caracterização paleoceanográfica de um testemunho da Bacia de Santos com base em foraminíferos planctônicos durante o Holoceno
}

\begin{abstract}
Ana Cláudia Aoki Santarosa
Dissertação apresentada ao Instituto Oceanográfico da Universidade de São Paulo, como parte dos requisitos para obtenção do título de Mestre em Ciências, Programa de Oceanografia Química e Geológica
\end{abstract}

Julgada em__/_/__ por

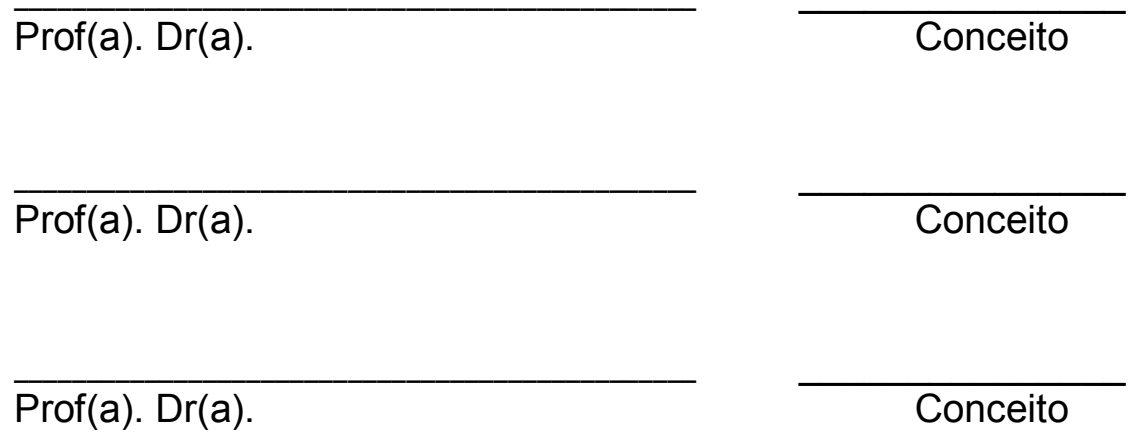




\section{SUMÁRIO}

Lista de Figuras ........................................................................................................... iii

Lista de Tabelas.............................................................................................

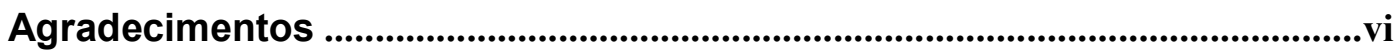

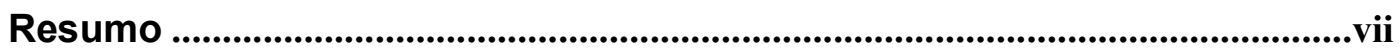

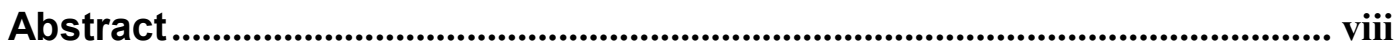

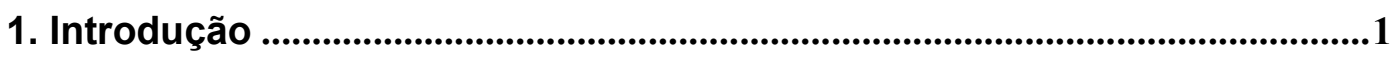

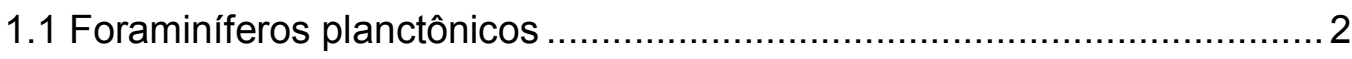

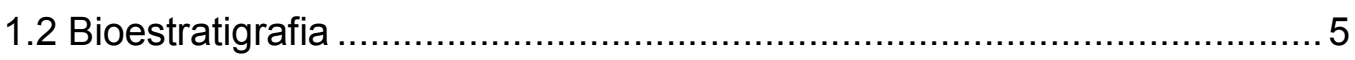

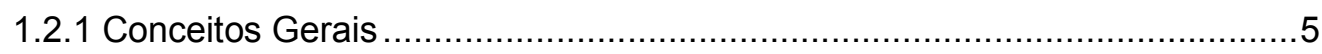

1.2.2 Bioestratigrafia do Pleistoceno/Holoceno.........................................6

1.3 Isótopos de oxigênio: pressupostos teóricos ................................... 9

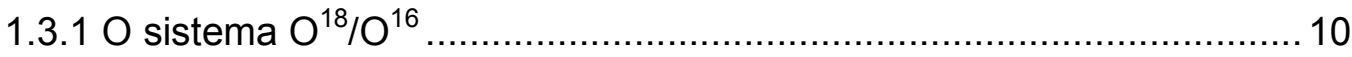

2. Motivação ................................................................................................11

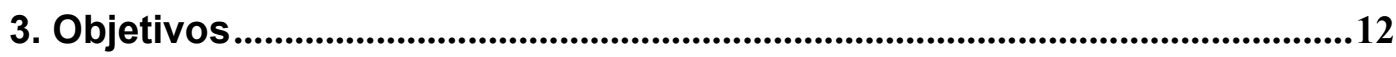

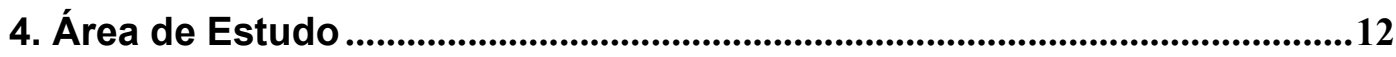

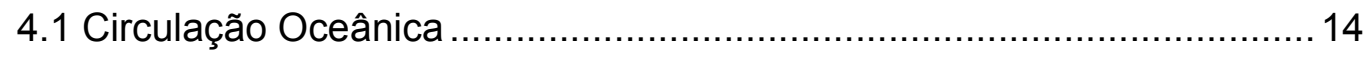

4.1.1 Transporte Meridional de calor ................................................. 17

4.2 Circulação Atmosférica ........................................................... 19

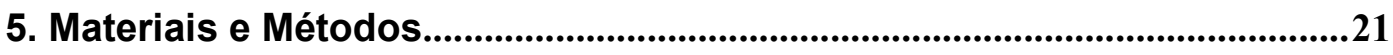

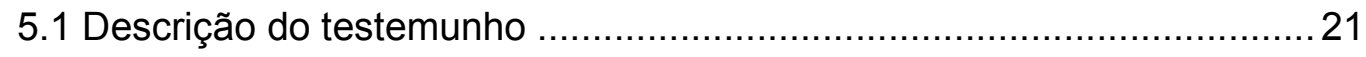




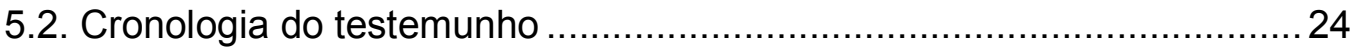

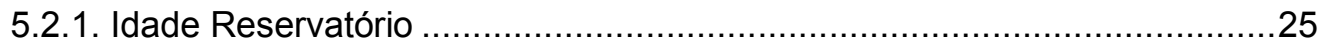

5.3. Preparação das amostras de Foraminíferos Planctônicos .......................26

5.4. Preparação para a análise de isótopos de oxigênio..................................2 27

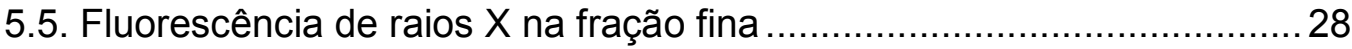

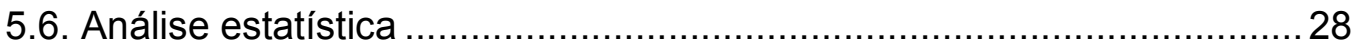

5.7. Razão Foraminiferos Planctônicos/Bentônicos (FP/FB) ……………...... 29

6. Resultados e Discussões.....................................................................................30

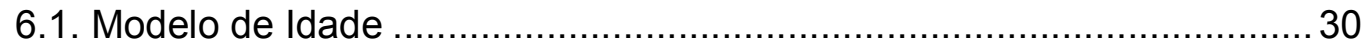

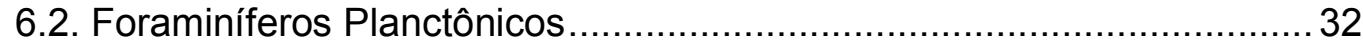

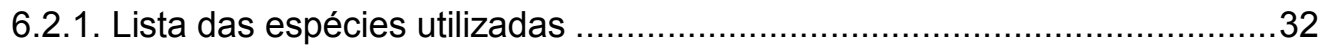

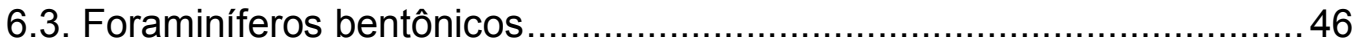

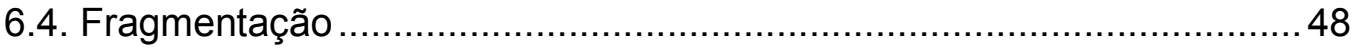

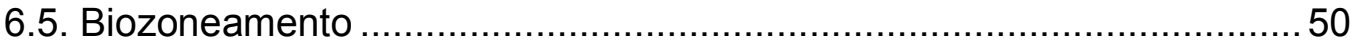

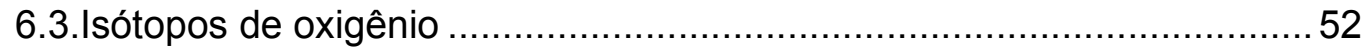

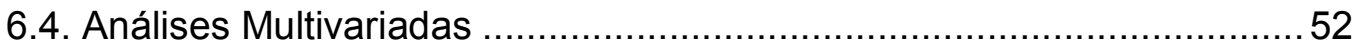

6.4.1. Análise de Agrupamentos...................................................................52

6.4.2. Análise de Componentes Principais .......................................................54

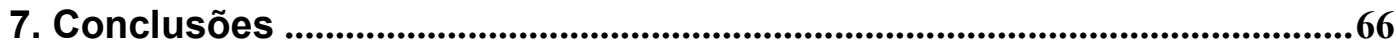

8. Referências Bibliográficas ............................................................................67

ANEXOS …......................................................................................................82 


\section{Lista de Figuras}

Figura 1: Distribuição das principais espécies de foraminíferos planctônicos recentes nas zonas biogeográficas, mostrando sua relação com a temperatura (Boersma, 1978).

Figura 2: Localização da área de estudo e coordenadas do testemunho analisado

Figura 3: Esquema geral da circulação superficial do Atlântico Sul (Modificado de Peterson \& Stramma, 1991)

Figura 4: Transecto latitudinal de temperatura média anual $(A)$ e salinidade $(B)$ para a região do Oceano Atlântico sul. Estão identificadas as seguintes massas de água: AT, Água Tropical; ACAS, Água Central do Atlântico Sul; AIA, Água Intermediária Antártica e ASA, Água Superficial Antártica. (modificado de Chiessi et al., 2007)

Figura 5: Média anual do transporte meridional de calor entre os oceanos. Os números indicam quantidade em unidade de $10^{13} \mathrm{~W}$. Adaptado de Hastenrath (1980).

Figura 6: (a) e (b) Média mensal de precipitação, segundo CMAP (Xie and Arkin, 1997) e vetores de vento a $925 \mathrm{hPa}$ para Janeiro e Julho. (c) e (d) Média de precipitação e linhas de corrente a $300 \mathrm{hPa}$ para Janeiro e Julho. Adaptado de Garreaud et al. (2009).

Figura 7: Descrição litofaciológica dos sedimentos recuperados e fotografia do testemunho KF-02. Biozonas de acordo com Ericson e Wollin (1968).

Figura 8: Idades reservatório para a porção sul do Oceano Atlântico (figura gerada no site http://reservoirage.palmod.uni-bremen.de)

Figura 9: Correlação entre a curva padrão isotópica de Martinson et al., 1987 e a curva de isótopos de oxigênio em G.ruber (white) feita com o programa AnalySeries (Paillard et al., 1996).

Figura 10: Datações efetuadas no testemunho e sua relação com a profundidade .....31

Figura 11- Freqüências relativas das espécies plexo G. menardii, G. ruber (white e pink), G. bulloides, G. sacculifer (com saco e sem saco), G. conglobatus ao longo do testemunho KF2. Áreas sombreadas representam os intervalos onde foram observadas variações significativas na abundância das assembléias (aproximadamente 8 e 3 mil anos A.P.)

Figura 12- Freqüências relativas das espécies G. truncatulinoides, Orbulina universa, G. crassaformis, G. glutinata, G. inflata N. dutertrei e Pulleniatina obliquiloculata ao longo do testemunho KF2. . Áreas sombreadas representam os intervalos onde foram observadas variações significativas na abundância das assembléias (aproximadamente 8 e 3 mil anos A.P.)

Figura 13: Abundância relativa do Plexo G. menardii. 


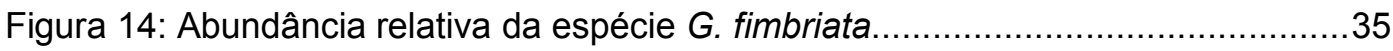

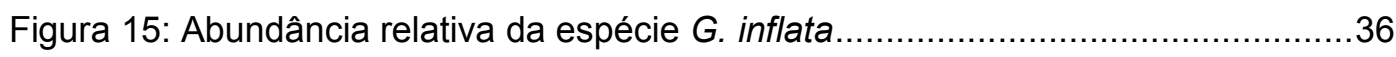

Figura 16: Abundância relativa da espécie N. dutertrei ..............................................37

Figura 17: Abundância relativa da espécie G. truncatulinoides (dextral) .....................38

Figura 18: Abundância relativa da espécie G. ruber (white) …................................39

Figura 19: Abundância relativa da espécie G. ruber (pink) .................................40

Figura 20: Abundância relativa da espécie G. bulloides .....................................41

Figura 21: Abundância relativa da espécie G. sacculifer (com saco) .......................42

Figura 22: Abundância relativa da espécie G. sacculifer (sem saco) .......................42

Figura 23: Abundância relativa da espécie G. glutinata.........................................43

Figura 24: Abundância relativa da espécie Orbulina universa ................................44

Figura 25: Abundância relativa da espécie G. conglobatus ....................................45

Figura 26: Abundância relativa da espécie Pulleniatina obliquiloculata .....................46

Figura 27: Abundância relativa de foraminíferos bentônicos .................................47

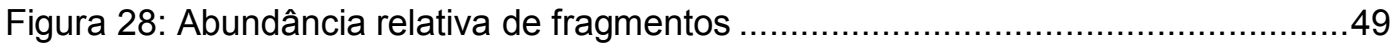

Figura 29: Gráfico de dispersão com regressão linear da abundância relativa de G. ruber (white+pink) e G. sacculifer (com saco e sem saco) e índice de

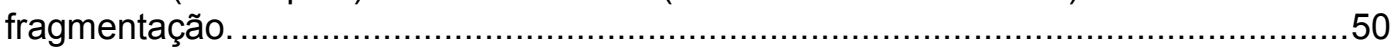

Figura 30: Biozoneamento proposto por Ericson \& Wollin (1968), com base na curva de abundância relativa do plexo Globorotalia menardii e na espécie

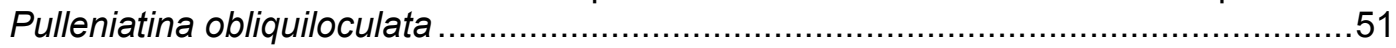

Figura 31: Resultados da análise da composição isotópica das testas da espécie Globigerinoides ruber (white). A escala de $\delta^{18} \mathrm{O}$ está invertida, de acordo com o convencionado em estudos paleoceanográficos

Figura 32: Dendograma da análise de agrupamentos modo- $R$, pelo método de Ward do KF- 02, com os 3 principais grupos identificados ...................................53

Figura 33: Histograma demonstrando a contribuição das espécies de ......................57

Figura 34: Projeção das componentes principais 1 e 2, correlacionando as espécies de foraminíferos planctônicos......................................................... 57

Figura 35: variação das cargas fatoriais das componentes principais 1 e 2 ao

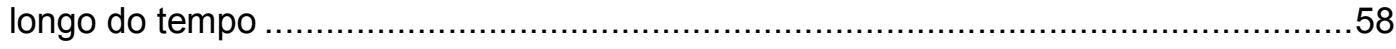


Figura 36: Curva paleoclimática obtida após aplicação do método de componentes principais nas assembléias de foraminíferos planctônicos do testemunho KF 02

Figura 37: Mecanismo atmosférico inferido por Ledru et al., 2002 a partir de estudos palinológicos na Lagoa do Caiçó $(A)$ para explicar maior influência de advecções polares árticas em regiões tropicais da América do Sul $(B)$ durante o Younger Dryas (YD). L representa Laurentide Ice Sheet durante YD.

Figura 38: Variações dos teores de $\mathrm{Fe} / \mathrm{Ca}$ e Ti/Ca para o testemunho KF-02, realizados por Bariani (2009)

Figura 39: Curva paleoclimática, $\delta^{18} \mathrm{O}, \mathrm{CP} 1$ (Temperatura), CP2 (camada de mistura) para o testemunho KF 02. No detalhe, zoom dos últimos 724 anos

\section{Lista de Tabelas}

Tabela 1: Amostras selecionadas para datação com radiocarbono e Idades Calendário obtidas

Tabela 2: Autovalores e porcentagens das variâncias explicadas por cada uma das componentes separadamente e a porcentagem cumulativa...

Tabela 3: Resultado da análise de Componentes Principais modo- $\mathrm{R}$ 56 


\section{Agradecimentos}

À CAPES pelo apoio financeiro

Agradeço especialmente ao meu orientador, Prof. Dr. Felipe Toledo, por todo conhecimento que me passou, pela paciência e atenção especial, estando sempre disposto a esclarecer minhas dúvidas.

À Profa. Dra. Karen, pelas sugestões ao meu trabalho, incentivo, esclarecimentos e ajuda com as fotografias. Obrigada pela convivência sempre carinhosa e bem humorada!

A toda equipe do LaPAS pelo apoio, especialmente ao Marcus pela ajuda gráfica, à Maria pela forma sempre atenciosa e prestativa com as minhas dúvidas e à Louise pelas boas risadas!

Não poderia deixar de dedicar um parágrafo a 3 garotas muito especiais, que me ajudaram muito, em todos os sentidos: Luisa, Sayuri e Adriana. Obrigada pelas palavras de incentivo, pelo conhecimento, pelo tempo que vocês pararam para me ouvir e me ajudar. Sem a companhia diária de vocês, tudo seria mais difícil. Foi muito boa a convivência, vou sentir falta!

Aos meus pais por todo carinho, incentivo e amor incondicional...

As minhas queridas irmãs e melhores amigas, Verônica, Vanessa e Rossana, por todo apoio e amizade. Tenho muita sorte de tê-las por perto, vocês são muito especiais...

Ao meu melhor amigo Tom, pelo companheirismo, apoio, amor, e paciência.

A todos os professores e funcionários do IO, que de alguma forma contribuíram para a conclusão desse trabalho, especialmente Cidinha, Claudinha, Dona Rai e Wagner, pelo atendimento sempre atencioso na biblioteca; à Ana Paula e Silvana, da Secretaria da Pós e ao Sr. Pedro da gráfica. 


\section{Resumo}

Para o desenvolvimento deste estudo, foi utilizado um testemunho de alta resolução coletado no talude da Bacia de Santos, em que foram realizadas análises de foraminíferos planctônicos e isótopos de oxigênio. Os resultados foram complementados por dados de razões de $\mathrm{Fe} / \mathrm{Ca}$ e $\mathrm{Ti} / \mathrm{Ca}$ e permitiram a compreensão do cenário paleoceanográfico no setor oeste do Atlântico Sul nos últimos 15 mil anos. Condições mais frias foram encontradas no início do registro até aproximadamente 8 mil anos A.P., com predomínio da fauna fria (G. truncatulinoides, N. dutertrei, e G. inflata) e valores mais altos de $\delta{ }^{18} \mathrm{O}$. Maior produtividade também é sugerida pela componente principal 2 (CP2), relacionada à camada de mistura e caracterizada pela assembléia G. ruber (white) e G. sacculifer. As razões de $\mathrm{Fe} / \mathrm{Ca}$ e Ti/Ca indicam maior aporte de terrígenos pela pluma do Rio da Prata para o ambiente oceânico, provavelmente contribuindo para fertilização das águas superficiais. A partir de 8 mil anos A.P. observa-se aumento dos valores da curva paleoclimática e diminuição progressiva dos valores de $\delta{ }^{18} \mathrm{O}$. A CP2 apresenta valores máximos entre 10 e 5 mil anos A.P., indicando uma coluna de água mais quente e altamente estratificada. Neste período, apresentam-se os mínimos de razões de $\mathrm{Fe} / \mathrm{Ca}$ e $\mathrm{Ti} / \mathrm{Ca}$, indicando um período mais seco, relacionado ao mínimo de insolação de verão no hemisfério sul e posicionamento da ZCIT mais ao norte. A partir de 5 mil anos A.P. até o final do registro, observa-se novamente menores valores da $\mathrm{CP} 2$ e razões crescentes $\mathrm{Fe} / \mathrm{Ca}$ e $\mathrm{Ti} / \mathrm{Ca}$, indicando condições mais úmidas e de maior produtividade no Holoceno superior.

Palavras- chave: Paleoceanografia, Holoceno, Foraminíferos Planctônicos, Bacia de Santos, Análise de Componentes Principais. 


\section{Abstract}

For this study, faunal changes in foraminifer's assemblages and oxygen stable isotopes were carried out on a high- resolution core retrieved from the slope of Santos Basin. The results, complemented with $\mathrm{Fe} / \mathrm{Ca}$ and $\mathrm{Ti} / \mathrm{Ca}$ ratios enabled the understanding of paleoceanografic changes occurred in the last $15 \mathrm{Kyr}$. Cold conditions were recognized in the late deglaciation until 8 mil Kyr B.P., characterized by the cold assemblage (G. truncatulinoides, N. dutertrei, and G. inflata) and higher values of $\delta{ }^{18} \mathrm{O}$. The low values of principal component 2 (PC 2 ), related to the mixed layer and dominated by the species G. ruber (white) and G. sacculifer suggest enhanced surface productivity. The $\mathrm{Fe} / \mathrm{Ca}$ and $\mathrm{Ti} / \mathrm{Ca}$ ratios on the sedimentary record indicate a high terrigenous input from the Plata Plume outflow in the oceanic environment, which probably contributed to the fertilization of superficial waters. From $8 \mathrm{Kyr}$ B.P., an increase in the paleoclimatic curve values and gradual reduction in the $\delta{ }^{18} \mathrm{O}$ were observed in the data. The PC 2 yields maximum values between 10 and $5 \mathrm{Kyr}$ B.P., indicating warm and highly stratified water-column conditions. In this period, low $\mathrm{Fe} / \mathrm{Ca}$ and $\mathrm{Ti} / \mathrm{Ca}$ ratios point out dryer conditions, related to the low peak austral summer insolation and the ITCZ located farther north. From 5 mil Kyr B.P. decreasing PC 2 values and increasing $\mathrm{Fe} / \mathrm{Ca}$ and $\mathrm{Ti} / \mathrm{Ca}$ ratios may be a sign of more productivity and humid conditions in the late Holocene. 


\section{Introdução}

O Holoceno foi previamente visto como um período de clima estável, com pequenas evidências de mudanças climáticas abruptas que caracterizam períodos glaciais. Atualmente sabe-se que este não foi um período uniformemente quente (Bond et al, 1997; Bianchi \& McCave, 1999; KlitgaardKristensen, 2001). Estudos realizados a partir de testemunhos de gelo em altas latitudes e de sedimentos marinhos mostram que o clima no Holoceno também foi instável, tendo sido pontuado por diversos eventos de resfriamento, de baixa amplitude e de escala milenar, com oscilações de 1500 anos, aproximadamente. O mais recente desses eventos de resfriamento foi a Pequena Idade do Gelo, ocorrido entre 1300 e 1870 A.D.(deMenocal, 2000)

O evento climático mais notável ocorrido durante o período de deglaciação foi o Younger Dryas, há aproximadamente 13000 anos e com duração média de 1500 anos. Este período de transição entre o Último Máximo Glacial (UMG) e o Holoceno, marca um resfriamento anômalo do clima. A origem da retomada do aquecimento do planeta é incerta. Diversos processos conduziram a esse evento e podem ter atuado de forma conjunta, fortalecendose mutuamente: uma tendência astronômica para verões mais quentes; uma restauração da circulação termohalina interglacial e um aumento na concentração de gases estufa (Bigg, 1996).

O clima do planeta também já esteve mais quente. Entre 9000 e 5000 anos A.P as temperaturas globais estavam cerca de $1^{\circ} \mathrm{C}$ mais altas, com significantes variações regionais no período conhecido como Ótimo Climático. A origem desse aquecimento foi provavelmente astronômica (o Hemisfério Norte recebia $8 \%$ mais de radiação solar durante o verão do que atualmente). Ao mesmo tempo, foram observadas pequenas variações de larga-escala na circulação oceânica, bem como nas propriedades físico- químicas das águas superficiais. (Bigg, 1996).

Os mecanismos por trás dessas variabilidades climáticas permanecem incertos (Farmer et al 2005). Entender a maneira como elas ocorrem é particularmente importante devido ao seu caráter natural, recorrente e global. Experimentos recentes com modelos climáticos prevêem um aumento de temperatura de aproximadamente $3^{\circ} \mathrm{C}$ durante o próximo século, e $\mathrm{O}$ 
aquecimento em altas latitudes no Hemisfério Norte pode ser duas vezes maior que a média global, dependendo das futuras emissões de gases estufa (IPCC, 2007). Para melhorar as previsões climáticas futuras, particularmente em escalas regionais, é necessário melhor entendimento dessas variações, baseadas em registros do passado (Hald et al, 2007).

Informações importantes para a reconstrução da história climática do planeta são preservadas também em sedimentos marinhos através das assembléias de microfósseis, da matéria orgânica e da composição isotópica e elementar das carapaças carbonáticas e de outros componentes sedimentares. Estas propriedades têm uma relação direta com os parâmetros ambientais (como temperatura) e respondem sistematicamente às suas variações ao longo do tempo. São conhecidas como proxies e podem ser definidos como descritores mensuráveis das variáveis desejadas que não são observadas. A composição isotópica de oxigênio da calcita dos foraminíferos planctônicos, por exemplo, é amplamente conhecida como indicadora de temperatura/salinidade e volume de gelo global, enquanto a composição das assembléias evidencia características dos parâmetros ambientais locais, como temperatura superficial marinha, salinidade, produtividade e estrutura da coluna de água (Wefer et al., 1999; Henderson, 2002).

A temperatura da superfície do mar (TSM) é provavelmente o mais importante parâmetro para descrever as condições dos oceanos passados e é crucial para modelagens climáticas. Os proxies utilizados para estimativas de temperatura, além dos citados no parágrafo acima incluem a proporção de magnésio ou estrôncio e cálcio em testas de foraminíferos e taxa de certas moléculas orgânicas, por exemplo, alquenonas produzidas por cocolitoforideos (Wefer et al, 1999).

\subsection{Foraminíferos planctônicos}

Os foraminíferos planctônicos recentes compreendem um grupo de protozoários livre-natantes com uma distribuição muito ampla nos ambientes marinhos, tanto batimétrica quanto geográfica. Eles vivem principalmente na zona eufótica, mas podem migrar verticalmente até centenas de metros de

profundidade, e são encontrados em diversos regimes oceânicos incluindo 
águas tropicais, subtropicais e massas de água polares (Hemleben et al., 1989).

A grande maioria dos foraminíferos modernos é de hábito bentônico; há aproximadamente 45 espécies planctônicas, que habitam regiões da coluna de água da superfície a profundidades de 1000 metros, sendo que as maiores concentrações são encontradas em profundidades menores que 100 metros (Bé, 1977, Hemleben et al., 1989). Além de sua maior diversidade, as espécies bentônicas possuem um registro geológico muito mais antigo. Os primeiros fósseis datam do Cambriano, enquanto os fósseis mais antigos de foraminíferos planctônicos são do período Jurássico (Sen Gupta, 1999)

As condições físico-químicas do meio marinho, como temperatura, salinidade, densidade e disponibilidade de nutrientes, exercem grande influência nos processos biológicos dos organismos, desde o desenvolvimento do indivíduo à dinâmica de grandes sistemas. Obtendo informações sobre como o meio modifica o fenótipo (tamanho, forma, etc) de determinado organismo e como ele controla sua distribuição espacial e temporal, nós estamos aptos a usar os registros fósseis de tais organismos para reconstruir paleoambientes e suas variações ao longo do tempo. Os foraminíferos planctônicos fósseis estão entre os mais importantes instrumentos para a extração de informações de caráter paleoceanográfico. As propriedades físicoquímicas de suas testas fornecem diversos paleoproxies incluindo o registro de sinais isotópicos e aspectos da abundância taxonômica e morfologia das testas que são controlados ecologicamente (Kucera et al., 2005). Além disso, os foraminíferos planctônicos possuem ocorrência global e uma excelente preservação no registro fossilífero.

A distribuição geográfica dos foraminíferos planctônicos vivos nas águas superficiais e consequentemente àquela nas assembléias fósseis do registro geológico está relacionada, principalmente, à temperatura da água superficial onde vivem (figura 1) (Bé, 1977).

Os foraminíferos planctônicos raramente são encontrados em águas costeiras, sobretudo em locais onde há extensa plataforma continental. Isso se deve a sua preferência por águas límpidas, sem material em suspensão e com salinidade normal. Além disso, as profundidades da plataforma, especialmente da interna, não são suficientes para suas migrações verticais ontogenéticas, 
necessárias para sua reprodução. Em áreas costeiras, os foraminíferos planctônicos comumente são raros e os poucos exemplares presentes se caracterizam por tamanhos menores e pouco desenvolvidos (Boltovskoy, 1981).

Diversos estudos têm sido realizados sobre estimativas de mudanças climáticas, utilizando a variação na composição das assembléias de foraminíferos (CLIMAP, 1976; Toledo, 2000; Klitgaard- Kristensen et al., 2001; de Abreu et al., 2005; Kucera et al, 2005; Toledo et al, 2005). Os estudos das oscilações climáticas ocorridas durante $\bigcirc$ Quaternário baseiam-se primariamente na bioestratigrafia de determinados microfósseis planctônicos, entre os quais, os foraminíferos (Vicalvi, 1997).

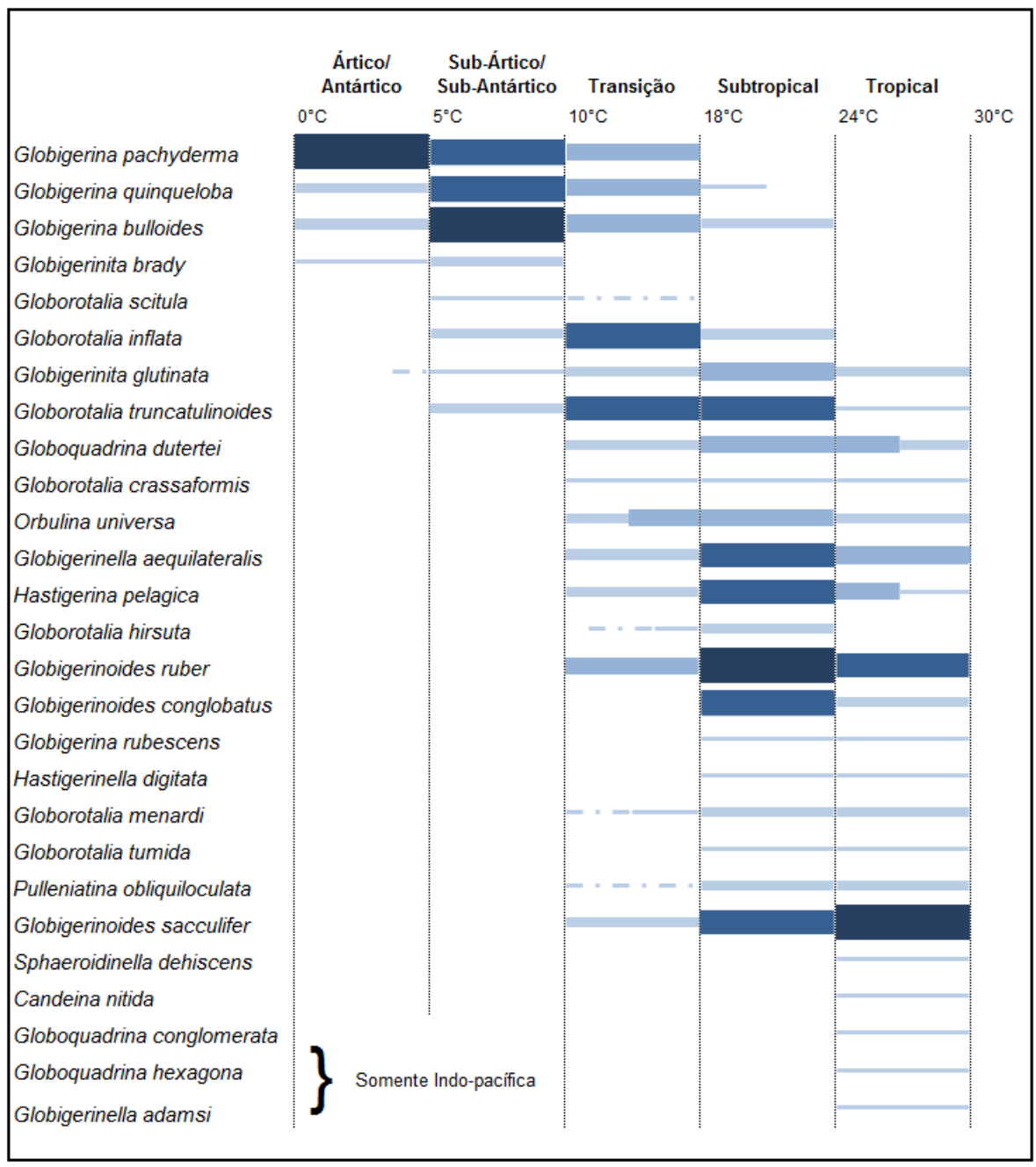

Figura 1: Distribuição das principais espécies de foraminíferos planctônicos recentes nas zonas biogeográficas, mostrando sua relação com a temperatura (Boersma, 1978). 


\subsection{Bioestratigrafia}

\subsubsection{Conceitos Gerais}

De acordo com o Código Estratigráfico Norte- Americano (NACSN, 2005), a bioestratigrafia estuda a distribuição dos fósseis no registro estratigráfico e classifica os estratos em unidades bioestratigráficas (biozonas) baseados em seu conteúdo fossilífero. Este ramo da estratigrafia é largamente utilizado para correlacionar seções estratigráficas e suas preferências paleoambientais para fornecer informações sobre o contexto deposicional.

A definição de uma biozona pode ser baseada na identificação de um ou mais táxons, suas abundâncias relativas, feições morfológicas específicas ou variações em outras características relacionadas ao conteúdo e à distribuição dos fósseis nos estratos. O conteúdo fóssilifero deve ser bem característico a ponto de permitir que uma zona seja diferenciada daquelas que Ihes são imediatamente adjacentes.

Como os microfósseis são mais abundantes do que os macrofósseis, os zoneamentos estabelecidos com base nos primeiros têm, em geral, maior aplicação do que aqueles estabelecidos pelos últimos. Para que tais zoneamentos tenham ampla distribuição e possam ser empregados em várias regiões do mundo, buscam-se utilizar principalmente microfósseis que apresentam ampla distribuição geográfica e que sejam cosmopolitas. Assim, geralmente os microfósseis marinhos de hábito planctônicos são, por excelência, os mais empregados.

Dentre os tipos de biozonas, destaca-se pela maior objetividade, no que se refere à identificação de seus limites, o tipo de zona de intervalo. De acordo com o NASC (1983), uma zona desse tipo tem como elementos definidores dois eventos biológicos distintos, que definem dois biorizontes. Desse modo, uma zona de intervalo seria um corpo de rocha situado entre os dois bioeventos, que se relacionam principalmente ao surgimento ou à extinção de entidades taxonômicas. Secundariamente, inícios ou fins de acmes (predominância de um determinado táxon) também podem ser empregados.

Outro tipo de biozona que tem certa aplicação é a zona de abundância ou zona de acme. Refere-se essa biozona a um corpo de rocha caracterizado por uma relativa abundância de uma ou mais entidades taxonômicas. Todavia, 
zonas de acme costumam ter aplicação mais restrita (local/regional), pois estão relacionadas a certas condicionantes ecológicas que propiciaram a predominância exagerada de umas poucas entidades taxonômicas durante o tempo de deposição dos sedimentos que compõe uma seção. Em regiões com fenômeno de ressurgência, zonas de abundancia podem ser estabelecidas mais de uma vez. Biozonas desse tipo são geralmente referenciadas como ecozonas (Antunes \& Melo, 2001).

\subsubsection{Bioestratigrafia do Pleistoceno/Holoceno}

Em alguns intervalos específicos de tempo, o desaparecimento local de determinadas espécies pode ser relacionado às variações nos eventos climáticos. Esta relação aparecimento/desaparecimento é a mais utilizada nos estudos dos foraminíferos planctônicos no Quaternário, pois devido ao seu curto período de duração não se observa evolução nas espécies de foraminíferos planctônicos, sendo que a maneira que diversos autores encontraram para subdividi-lo foi com relação às mudanças ambientais, às quais alguns foraminíferos são sensíveis (Ericson \& Wollin, 1968; Kennett \& Huddlestun, 1972; Prell \& Damuth, 1978; Thunnel \& Reynolds, 1984). Sendo assim, algumas assembléias são típicas de águas frias, relacionadas aos episódios glaciais, e outras são típicas de águas quentes, relacionadas aos episódios interglaciais.

Observando as variações de freqüência de algumas espécies de foraminíferos planctônicos em amostras estudadas da região da Bacia de Campos, Costa \& Toledo (2003) obtiveram uma boa correlação bioestratigráfica entre os testemunhos amostrados. Uma alta proporção desta boa correlação bioestratigráfica está relacionada a oscilações paleoclimáticas e refletem rápidas mudanças nas condições de massa d'água na porção oeste do Oceano Atlântico Sul, durante o Quaternário superior.

Um dos trabalhos pioneiros de zoneamento bioestratigráfico do Pleistoceno/Holoceno foi realizado na segunda metade do século $X X$, por Ericson \& Wollin (1968) com amostras provenientes de 10 testemunhos, coletados no Golfo do México, Mar do Caribe e Oceano Atlântico, pertencentes à coleção do Lamont Geological Observatory. Este biozoneamento constitui-se 
de 10 biozonas identificadas com letras do alfabeto no sentido inverso (de $Q$ a $Z$ ), onde $Z$ é a biozona mais nova e corresponde ao Holoceno e $Q$ a mais antiga, correspondendo ao início do Pleistoceno. Os intervalos onde está presente o plexo Globorotalia menardii são considerados interglaciais e a sua ausência identifica intervalos glaciais. Porém, cabe salientar que não é a simples presença/ausência desta espécie que funciona como marcador das oscilações climáticas. Muita informação é perdida quando somente o plexo $G$. menardii é utilizado em estudos climáticos, porque estas espécies estão essencialmente ausentes durante o período glacial. Um estudo quantitativo deve ser efetuado em relação a esta espécie, bem como o uso da freqüência de outras espécies planctônicas indicadoras de águas mais quentes ou mais frias (Toledo, 2000).

O termo utilizado "plexo" se refere a um grupo de espécies e/ou subespécies de morfologia e ecologia semelhantes (sensu Vicalvi, 1997, 1999). A expressão "plexo G. menardii" inclui os táxons Globorotalia menardii menardii, G. menardii cultrata, G. fimbriata (presente somente no Holoceno), G. flexuosa e G. tumida tumida, formando o principal grupo indicador de águas quentes. O "plexo Pulleniatina" compreende o conjunto das espécies Pulleniatina primalis, $P$. obliquiloculata e $P$. finalis.

As principais espécies indicadoras de águas quentes são a Globorotalia menardii e Pulleniatina obliquiloculata, enquanto que as principais formas indicadoras de águas temperadas/frias são Globorotalia inflata e Globigerina falconensis. A maioria das espécies de foraminíferos planctônicos tem tolerância a temperaturas intermediárias (Prell \& Damuth, 1978).

Um datum muito utilizado no Quaternário é o aparecimento e desaparecimento de $P$. obliquiloculata ao longo dos últimos 175 mil anos (Prell \& Damuth, 1978). A espécie $P$. obliquiloculata é típica de águas quentes, muito sensível às mudanças de temperatura e de salinidade (Jones, 1967; Parker, 1967; Bé \& Tolderlund, 1971; Cifelli \& Beniér, 1976). Estes autores observaram que esta espécie desapareceu e reapareceu periodicamente nos últimos 175.000 anos, nos sedimentos quaternários do Atlântico equatorial, no Golfo do México e Caribe. Vicalvi (1997) observou em amostras de testemunhos da região sudeste da costa brasileira, o desaparecimento de $P$. obliquiloculata, na metade superior da zona $Y$, aproximadamente entre 42 e 45 mil anos A.P. Este 
bio-horizonte divide a Zona $\mathrm{Y}$ aproximadamente ao meio e é diácrono, com idades variando de aproximadamente 60 mil anos A.P. no Golfo do México, para 50 mil anos A.P. no Caribe Ocidental até 35 mil A.P. para o Atlântico Equatorial. Esse diacronismo deve-se a mudanças climáticas e ambientais no Oceano Atlântico.

De acordo com Vicalvi (1997 e 1999), as subdivisões do Pleistoceno são baseadas em episódios adicionais de aparecimentos e desaparecimentos de determinadas espécies de foraminíferos planctônicos, representando simplesmente eventos migracionais não evolucionários ou a resposta a mudanças climáticas, comumente de significado regional. Um exemplo disto é o caso do desaparecimento de G. m. flexuosa no final do último episódio interglacial (Kennett \& Huddlestun, 1972; Thunnel, 1984) e dos desaparecimentos de reaparecimentos de $P$. obliquiloculata nos últimos 175 mil anos (Bé et al., 1976; Prell \& Damuth, 1978).

A partir das zonas propostas por Ericson \& Wollin (1968) e de seus estudos com foraminíferos na Bacia de Campos publicados em Vicalvi (1997), Vicalvi (1999) reconheceu 18 distintas subzonas de foraminíferos planctônicos, desde a parte superior da Zona $\mathrm{W}$ até o presente (Zona Z). A variação percentual do plexo G. menardii em relação à fauna total de foraminíferos planctônicos permitiu a subdivisão da Zona $X$ (último episódio interglacial) em onze subzonas (X11 a X1) e a divisão da Zona Z (pós-glacial) em duas subzonas (Z2 e Z1). O controle da freqüência do plexo Pulleniatina fundamentou a divisão da Zona Y (último episódio glacial) em cinco subzonas (Y5 aY1) (Vicalvi, 1999).

Para reconstruir a história paleoclimática do testemunho, foram utilizadas as freqüências de espécies de foraminíferos planctônicos, indicadoras de águas mais quentes ou mais frias:

1. Globorotalia menardii (Parker, Jones e Brady)

2. Globorotalia tumida (Brady)

3. Globorotalia fimbriata (Brady)

4. Globorotalia flexuosa (Koch)

6. Globorotalia inflata (d'Orbigny)

7. Globorotalia truncatulinoides (d'Orbigny)

8. Globigerinoides conglobatus (Brady) 


\section{Globorotalia crassaformis (Galloway e Wisslweer)}

10. Neogloboquadrina dutertrei (d'Orbigny)

As espécies listadas de 1 a 4 compõem o grupo das menardiformes e são indicadoras de águas quentes, enquanto $G$. inflata e $G$. truncatulinoides são indicadoras de águas temperadas/ frias. As demais espécies, numeradas de 8 a 10, são numericamente menos comuns na região estudada. Porém foram selecionadas porque são predominantes em alguns intervalos ao longo de testemunhos previamente estudados por Costa \& Toledo (2003) da região. No presente estudo, pretende-se fazer uma caracterização da fauna do testemunho e observar a variação das freqüências relativas dessas espécies.

\subsection{Isótopos de oxigênio: pressupostos teóricos}

Nas últimas décadas, isótopos de oxigênio se tornaram ferramenta indispensável para estudos de geoquímica relacionados com reconstruções das condições dos oceanos do passado. A composição isotópica das testas de foraminíferos planctônicos tem um papel fundamental no estabelecimento de condições climáticas pretéritas, pois ela é função da temperatura do ambiente e da composição isotópica da água na qual ocorreu o processo de calcificação. Logo, a partir desse conhecimento, é possível obter importantes informações desses paleoambientes.

Emiliani (1955) utilizou pela primeira vez os registros isotópicos de testemunhos de mar profundo como uma ferramenta para apontar uma série de ciclos de temperatura/clima durante o Pleistoceno (Rohling \& Cooke, 1999). Seu trabalho desde então é a base para estudos da teoria astronômica de sucessões glaciais- interglaciais (Teoria de Milankovitch), reconstrução de mapas sinóticos dos oceanos desse período, determinação da escala de tempo de glaciações e deglaciações, bem como o volume da massa de gelo formado durante períodos glaciais (e assim de variações do nível relativo do mar) e estudos de mudanças climáticas (Berger, 1981). 
A estratigrafia isotópica é de extrema importância para a interpretação dos registros climáticos e para correlação entre testemunhos da mesma área e/ou outras áreas para determinação de padrões regionais.

\subsubsection{0 sistema $0^{18} / 0^{16}$}

O elemento oxigênio está presente na natureza em três formas isotópicas: ${ }^{16} \mathrm{O},{ }^{17} \mathrm{O}{ }^{18} \mathrm{O}$, com abundâncias naturais relativas de $99.76 \%, 0.04 \%$ e $0.20 \%$, respectivamente. Para estudos em paleoceanografia, porém, somente ${ }^{16} \mathrm{O}$ e ${ }^{18} \mathrm{O}$ são analisados, devido às maiores abundâncias e à maior diferença de massa entre esses dois isótopos.

Todos os isótopos de um dado elemento contêm mesmo número de prótons e elétrons e mesmo arranjo da eletrosfera, o que implica em comportamentos químicos similares. Porém, o número diferente de nêutrons no núcleo impõe diferenças nas propriedades físico-químicas dos mesmos. As moléculas vibram com uma freqüência fundamental que depende da massa do isótopo da qual ela é composta. As diferenças resultantes na dissociação de energia de isótopos leves e pesados implicam em ligações mais fracas formadas com isótopos mais leves. Assim, como regra geral, moléculas constituídas por isótopos mais leves reagem mais facilmente do que as constituídas por isótopos mais pesados (Cooke \& Rohling,2001).

A partição dos isótopos entre substâncias com composições isotópicas diferentes é conhecida como fracionamento e esse processo é essencialmente dependente da temperatura (Lea, 2003).

A razão ${ }^{18} \mathrm{O}:{ }^{16} \mathrm{O}$ no ambiente é de aproximadamente 1:500, ou seja apenas $0.2 \%$ do oxigênio que circula é ${ }^{18} \mathrm{O}$ (Lowe \& Walker, 1997). As taxas dos isótopos de oxigênio são medidas não como valores absolutos, mas em termos de desvio relativo $\left(\delta^{18} \mathrm{O}\right.$ por mil, equação 1$)$ a 2 padrões arbitrários: PDB (concha de belemnite da Formação PeeDee, Carolina do Norte), para análises em carbonato, e SMOW (Standard Mean Ocean Water), para análises de água, gelo e neve (Craig, 1961).

$$
\delta^{18} \mathrm{O}(\%)=10^{3} \mathrm{X}\left[\left({ }^{18} \mathrm{O} /{ }^{16} \mathrm{O}\right)_{\text {amostra }}-\left({ }^{18} \mathrm{O} /{ }^{16} \mathrm{O}\right)_{\text {padrão }} /\left({ }^{18} \mathrm{O} /{ }^{16} \mathrm{O}\right)_{\text {padrão }} \quad \text { equação } 1\right.
$$


Valores positivos de $\delta^{18} \mathrm{O}$ representam enriquecimento na amostra em isótopo pesado $\left({ }^{18} \mathrm{O}\right)$ com relação ao padrão, enquanto valores negativos refletem depleção de isótopo pesado.

A razão ${ }^{18} \mathrm{O}:{ }^{16} \mathrm{O}$ nas águas oceânicas tem variado ao longo do tempo geológico durante os ciclos glaciais e interglaciais de uma forma quase cíclica (Martinson et al, 1987), como resultado do fracionamento natural dos isótopos de oxigênio durante a evaporação da água na superfície marinha. Durante esse processo físico, altamente dependente da temperatura, há preferência na remoção da molécula mais leve $\left(\mathrm{H}_{2}{ }^{16} \mathrm{O}\right)$ para a atmosfera. Dessa forma, os oceanos ficam relativamente enriquecidos em $\mathrm{H}_{2}{ }^{18} \mathrm{O}$ (o que equivale a um sinal isotopicamente mais positivo) e o vapor apresenta maiores quantidades de isótopos leves. Através da circulação atmosférica, esse vapor é levado em direção aos pólos onde precipita na forma de neve, aprisionando grandes quantidades de $\mathrm{H}_{2}{ }^{16} \mathrm{O}$ nas geleiras em períodos glaciais. Contrariamente, $\mathrm{O}$ derretimento dessas massas de gelo libera no oceano grandes volumes de água enriquecida em $\mathrm{H}_{2}{ }^{16} \mathrm{O}$, resultando em razões isotópicas mais leves ou valores de $\delta^{18}$ O mais negativos (Lowe \& Walker, 1997).

\section{Motivação}

Os foraminíferos planctônicos têm sido amplamente utilizados nos estudos de construções paleoclimáticas e paleoceanográficas (Naidu \& Malmgren, 1996; Vicalvi, 1997; Mulitza et al., 1997; Giraudeau et al., 2001). A análise da fauna fossilífera e das variações de freqüências relativas de determinadas espécies de foraminíferos fornece de forma rápida e simples uma estimativa confiável de mudanças climáticas do passado. Apesar do grande número de publicações realizadas por instituições de pesquisas no Hemisfério Norte, o setor oeste do Atlântico Sul carece de estudos nesse domínio. Ainda, estudos do Holoceno em sedimentos de mar profundo têm sofrido com as baixas resolução estratigráfica e conservação do topo do testemunho durante a amostragem no campo. Dessa forma, o presente trabalho procurou contribuir com um estudo detalhado das variações paleoceanográficas ocorridas ao longo dos últimos 15 mil anos a partir de um testemunho de alta resolução estratigráfica coletado na Bacia de Santos. 


\section{Objetivos}

- Identificar a fauna de foraminíferos planctônicos do testemunho estudado;

- Realizar análise quantitativa dos foraminíferos planctônicos ao longo do testemunho e inferir mudanças paleoceanográficas associadas;

- Estabelecer a cronologia do testemunho com (carbono) $\mathrm{C}^{14}$;

- Estabelecer a estratigrafia isotópica do testemunho a partir da análise química de testas do foraminífero planctônico Globigerinoides ruber e comparar os resultados com as curvas de abundância das principais espécies de foraminíferos planctônicos;

- Comparar os resultados obtidos com os dados de fluorescência de Raios X (FRX) realizados neste testemunho.

\section{4. Área de Estudo}

A Bacia de Santos está localizada na margem sudeste do Brasil e apresenta um contexto evolutivo do tipo margem passiva, formada por esforços distensionais durante a separação do continente sul- americano e a África (ruptura do Gondwana) no Cretáceo inferior. Ao longo do tempo foi moldada pela geometria das descontinuidades do embasamento cristalino (Gonzaga, 2005).

A região de estudo (figura 2) está situada entre os paralelos $23^{\circ}$ et $28^{\circ}$ sul. O limite ao norte dá-se pelo alto estrutural de Cabo Frio, que o separa da Bacia de Campos, e ao sul, pela plataforma de Florianópolis que a separa da Bacia de Pelotas. A bacia de Santos cobre uma superfície de $206000 \mathrm{~km}^{2}$ até a isóbata de 2000 metros. Sua espessura sedimentar pode atingir em torno de 12 $\mathrm{km}$ nas partes mais profundas (Moreira et al., 2001). 


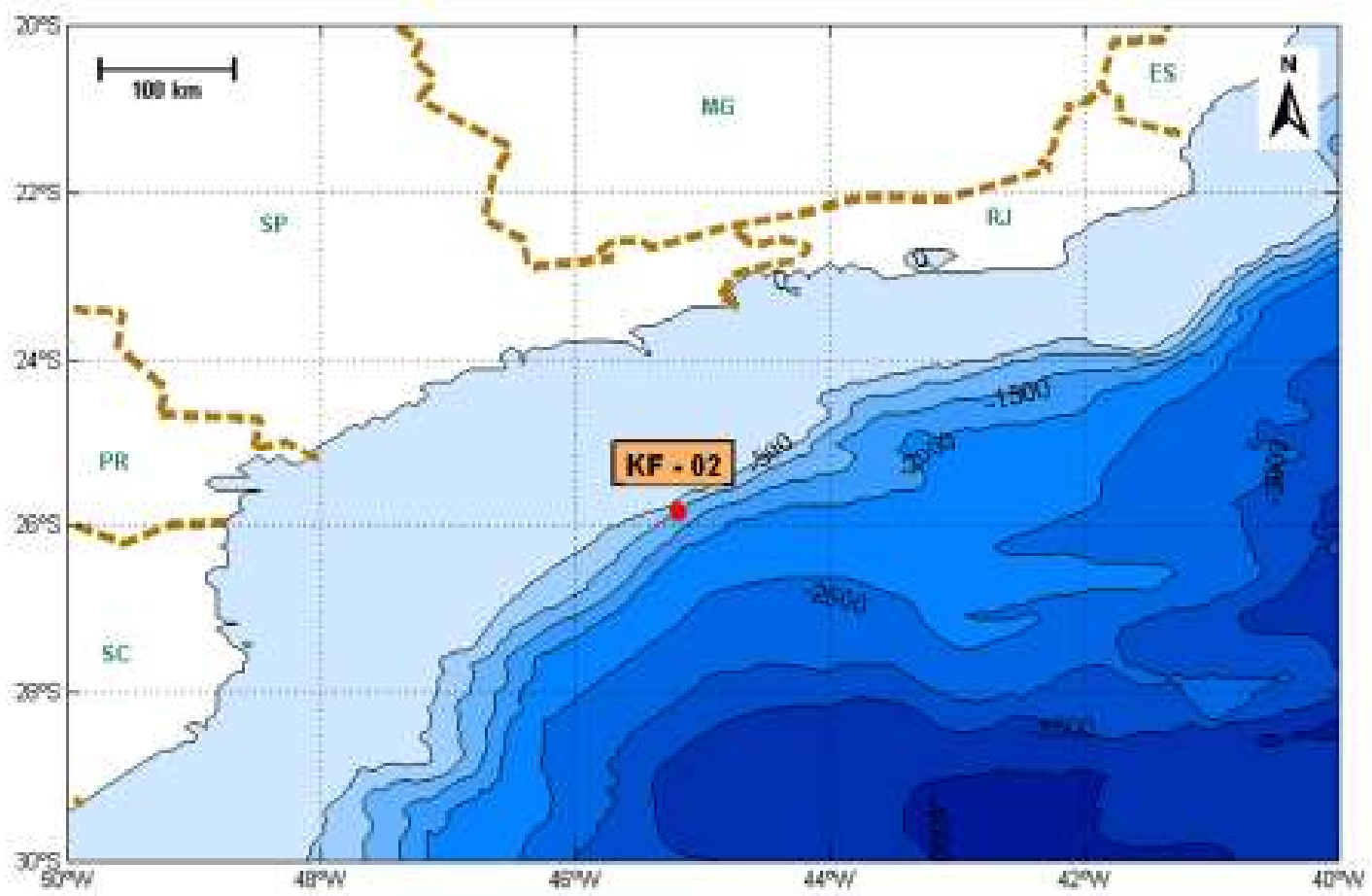

Figura 2: Localização da área de estudo e coordenadas do testemunho analisado

A região sudeste é descrita por Zembruscki (1979) como sendo uma margem caracterizada por províncias normalmente amplas, de gradientes suaves, cuja quebra da plataforma se dá de maneira não abrupta. O talude apresenta baixo declive, de perfil ligeiramente côncavo, tratando-se de margem continental com enquadramento típico numa categoria genérica de deposicional (tipo III- Secundária), na classificação de Fairbridge (1966). A largura máxima da plataforma localiza-se no setor do Embaiamento de São Paulo, aproximadamente na altura de Santos, com $230 \mathrm{~km}$ de extensão. No Embaiamento, a quebra da plataforma ocorre entre 120 e $180 \mathrm{~m}$ de profundidade e o talude continental apresenta uma largura aproximada de 70 $\mathrm{km}$ em sua porção mediana, com uma declividade entre $1^{\circ}$ e $2^{\circ}$.

O alinhamento da Serra do Mar em relação à linha de costa atual reflete o tamanho reduzido da planície costeira e a orientação das isóbatas. Como conseqüência do soerguimento da Serra do Mar na porção sudeste do Brasil, a maior parte das bacias de drenagem da plataforma continental sudeste fluem em direção ao interior do Brasil, alimentando a bacia de drenagem do Rio Paraná-La Plata. Dessa forma, um pequeno número de rios 
drena diretamente para o mar na plataforma continental sudeste (Emílson, 1961; Mahiques et al., 2004). Sendo assim, os processos sedimentares em margens passivas com descargas fluviais limitadas, são controlados principalmente pelo deslocamento de massas de água e correntes, taxas de produção primária, mudanças no nível relativo do mar e clima nas áreas emersas adjacentes. Todos esses fatores controlam o aporte e a redistribuição dos diferentes componentes do sedimento. (Stein, 1991; Meyers, 1994, 1997; Madureira et al., 1997).

\subsection{Circulação Oceânica}

No Oceano Atlântico Sul, a circulação de grande escala nos primeiros $1000 \mathrm{~m}$ é representada por um grande giro anticiclônico (figura 3), limitado ao norte pela Corrente Sul Equatorial e meridionalmente pela Corrente do Atlântico Sul. A borda leste desse sistema é ocupada pela Corrente de Benguela e a corrente de contorno oeste que completa o giro é a Corrente do Brasil (CB). Apesar de não fazerem parte das correntes superficiais do Giro Subtropical do Atlântico Sul, a Corrente das Agulhas, Malvinas e a Circumpolar Antártica, influenciam diretamente a configuração do Giro Subtropical do Atlântico Sul (Stramma \& England, 1999).

Das camadas superficiais até o nível da termoclina, a corrente mais importante que flui ao longo da costa brasileira é a Corrente do Brasil (CB). A $\mathrm{CB}$ se origina da bifurcação do ramo sul da Corrente Sul Equatorial (CSE), ao sul de $10^{\circ} \mathrm{S}$, e flui para sul, transportando águas quentes e salinas, meandrando por sobre a Plataforma. Em média, ao longo de sua extensão flui nos primeiros $500 \mathrm{~m}$ de coluna de água com $100 \mathrm{~km}$ de largura (Silveira et al., 2000) até a encontrar as águas frias e menos salinas da Corrente das Malvinas, que vem do sul, contornando o continente sul-americano desde sua origem como um ramo da Corrente Circumpolar Antártica. A região de encontro dessas duas correntes, localizada entre as latitudes $34^{\circ} \mathrm{S}$ e $46^{\circ} \mathrm{S}$, é denominada Zona de Confluência Brasil- Malvinas (CBM). Essa região, caracterizada por um forte contraste termohalino, é considerada uma das mais energéticas dos oceanos, de intensa atividade em meso-escala, pois o 
encontro dessas duas correntes gera uma forte estrutura frontal e uma cadeia complexa de vórtices e anéis (Gordon, 1989).

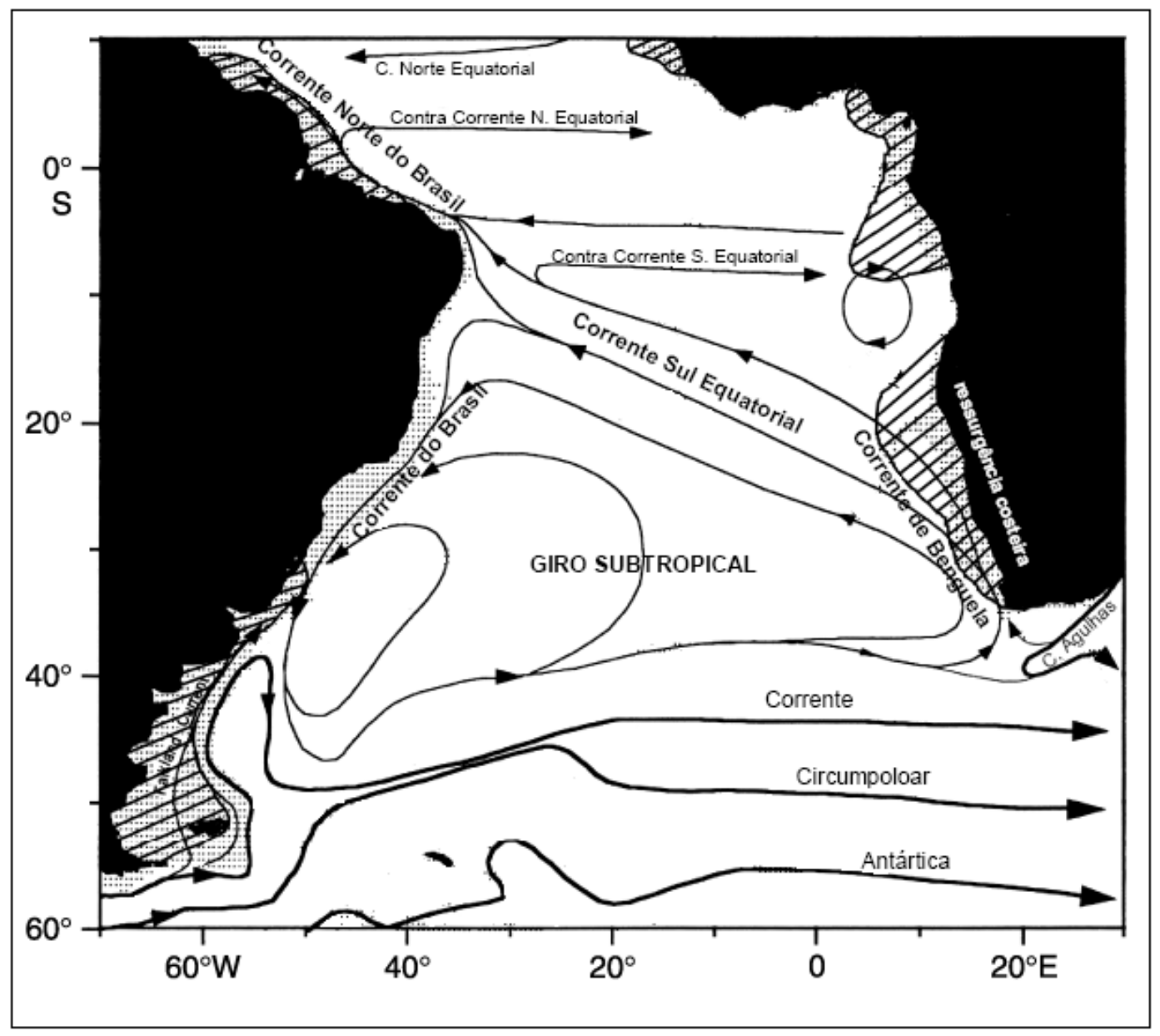

Figura 3: Esquema geral da circulação superficial do Atlântico Sul (Modificado de Peterson \& Stramma, 1991).

As amplitudes do ciclo anual da temperatura da superfície do mar (TSM) na região da CBM aumentam na direção da plataforma continental (Podestá et al., 1991). Valores mínimos de $8^{\circ} \mathrm{C}$ ocorrem em junho (inverno austral) enquanto valores máximos de TSM podem chegar a $25^{\circ} \mathrm{C}$ no núcleo da CB durante os meses de verão Austral (Goni et al., 1996). Lentini et al. (2000) estimaram que as amplitudes anuais de TSM podem variar entre $4^{\circ} \mathrm{C}$ e $13^{\circ} \mathrm{C}$ ao longo da plataforma continental no Oceano Atlântico Sudoeste. Os autores descrevem que a maior parte dessa variação é devida ao aumento do transporte da CB (CM) durante o verão (inverno), o que contribuiria para as grandes amplitudes de TSM encontradas na região adjacente ao Rio da Prata. 
A CB flui ao longo do talude continental, transportando massas de água de origens distintas: a massa de Água Tropical (AT) e a Água Central do Atlântico Sul (ACAS) (figura 4).

Emilson (1961) caracterizou a AT como uma massa de água quente e salina, com temperaturas superiores a $20^{\circ} \mathrm{C}$ e salinidades acima de 36 . Sua formação ocorre em regiões com intensa radiação solar e excesso de evaporação. A AT apresenta baixa concentração de nutrientes, estando, portanto a sua presença associada a ambientes de baixa produtividade biológica (Ciotti et al., 1995).

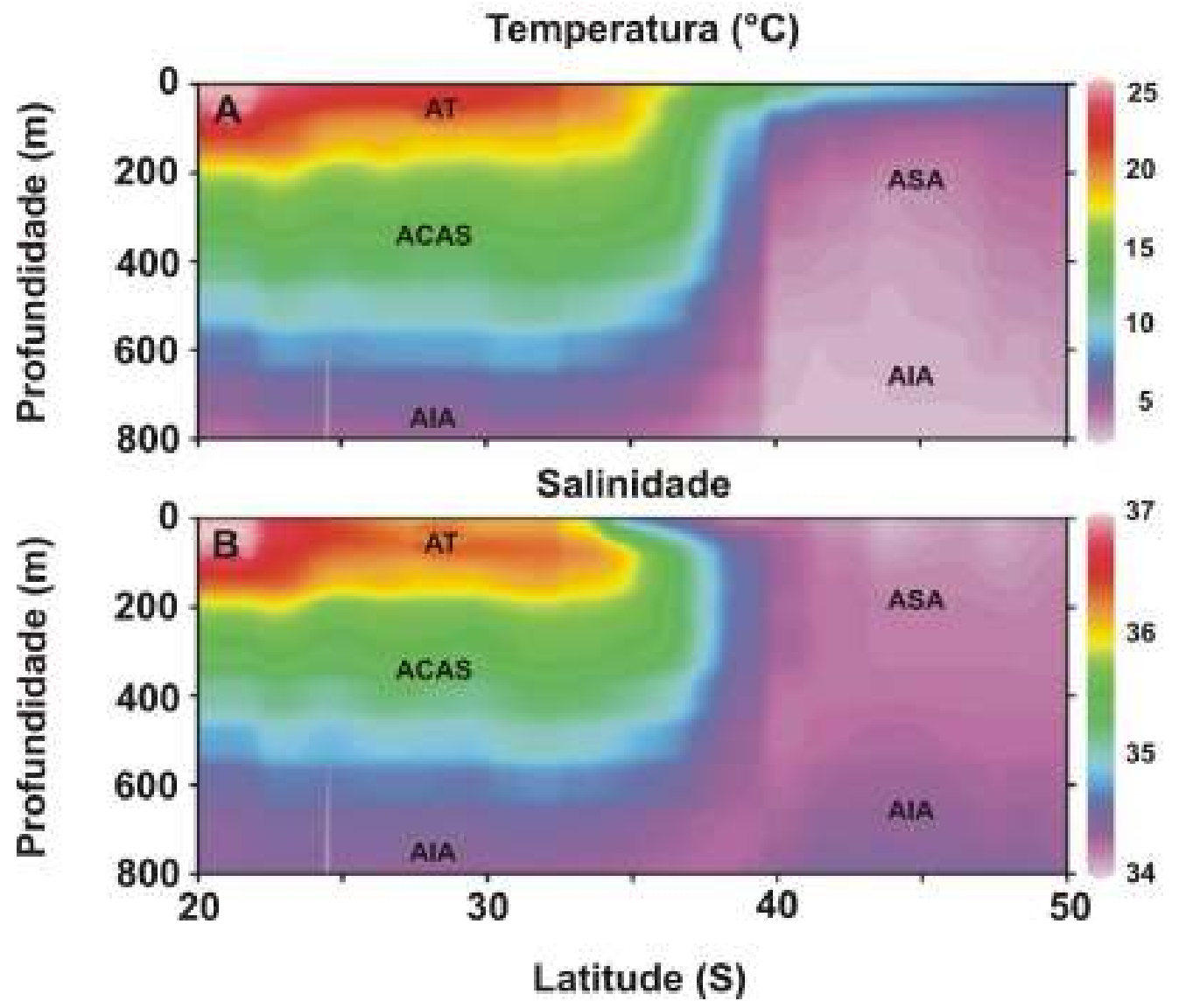

Figura 4: Transecto latitudinal de temperatura média anual $(A)$ e salinidade (B) para a região do Oceano Atlântico sul. Estão identificadas as seguintes massas de água: AT, Água Tropical; ACAS, Água Central do Atlântico Sul; AIA, Água Intermediária Antártica e ASA, Água Superficial Antártica. (modificado de Chiessi et al., 2007)

A ACAS, segundo Miranda (1985), é caracterizada por temperaturas superiores a $6^{\circ} \mathrm{C}$ e inferiores a $20^{\circ} \mathrm{C}$ e por salinidades entre 34,6 e 36 . Sua 
formação acontece na zona de confluência subtropical, como resultado da mistura entre a CB e a Corrente das Malvinas e isto, segundo Stramma \& England (1999), é o fator responsável por sua alta salinidade.

A massa de água localizada imediatamente abaixo da ACAS é a Água Intermediária Antártica (AIA). As isopicnais $\sigma \theta=27.1$ nos trópicos e $\sigma \theta=27.05$ nos subtrópicos marcam a transição entre essas duas massas de água (Stramma \& England, 1999). Segundo Sverdrup et al. (1942), a AIA é definida pelos limites termohalinos de $3^{\circ}-6^{\circ} \mathrm{C}$ para temperatura e $34,2-34,6$ para salinidade. Enquanto apresenta-se como uma corrente de contorno oeste bem definida, a AIA move- se na direção do equador ao norte de $25^{\circ} \mathrm{S}$, fluindo para o sul em $28^{\circ} \mathrm{S}$ (Muller et al., 1998). Stramma \& England (1999) centram o eixo da bifurcação da AIA ao sul de $25^{\circ} \mathrm{S}$. Esta bifurcação ocorreria próximo à latitude de Santos, mas com o eixo da divergência ocorrendo praticamente paralelo ao talude (Cirano et al., 2006).

\subsubsection{Transporte Meridional de calor}

Os processos de troca que ocorrem na interface oceano-atmosfera são de fundamental importância na geração e manutenção das circulações atmosférica e oceânica. O sistema oceano-atmosfera está, assim como todo o planeta, sujeito à radiação solar, que incide de forma desigual sobre a superfície terrestre. A intensidade dessa radiação decresce para os pólos, pois nas altas latitudes atravessa uma maior espessura da atmosfera (a "espessura aparente" é maior), a mesma radiação é espalhada por uma área maior, a refletividade (albedo) do gelo é maior e uma maior quantidade de radiação é refletida devido aos menores ângulos de incidência. Desta forma, as regiões equatoriais são mais aquecidas pelo Sol que as regiões polares (Perry \& Walker, 1977).

O balanço positivo de radiação em baixas latitudes e o negativo em altas resulta em uma rede de transferência de energia/calor das baixas para altas latitudes, através dos sistemas de ventos na atmosfera e correntes nos

oceanos. O sistema de ventos redistribui calor parcialmente por advecção de massas de ar quentes para regiões mais frias (e vice- versa) e parcialmente por transferência de calor latente. Os ventos gerados pelos gradientes de pressão 
(gradientes térmicos) aplicam tensão de cisalhamento na superfície do mar, gerando as correntes oceânicas superficiais. Ao mesmo tempo, variações de temperatura e salinidade controlam correntes oceânicas na vertical através de subsidência e ressurgência de massas d'água por diferenças de densidade, e geram as correntes profundas, dando origem à Circulação Termohalina. Estas diferenças de densidade podem ser devidas ao aquecimento ou resfriamento da água, à variação no balanço entre evaporação e precipitação ou ainda à formação de gelo e conseqüente aumento de salinidade das águas vizinhas. Deste modo, formam-se importantes fluxos de massas d'água e calor em todos os níveis de profundidade (Pickard \& Emery, 1992).

Diversas estimativas do transporte de calor pelos oceanos foram realizadas: Sellers (1966) e Emig (1967), entre outros autores, utilizaram medidas diretas do transporte de calor meridional pelas correntes marítimas e concluíram que o transporte era no sentido do equador para os pólos. Porém, estudos posteriores indicacaram que o transporte de calor no Atlântico Sul é das altas latitudes em direção ao equador (Bennett, 1978; Hastenrath, 1980; Fu, 1981; Macdonald \& Wunsch, 1996; Vellinga \& Wood, 2002). Isto é uma resposta à manifestação da estrutura tipo 'esteira transportadora' pela qual a Circulação Termohalina do oceano organiza o transporte global de calor (Gordon, 1986; Vellinga \& Wood, 2002). Neste oceano, o fluxo profundo para sul da fria Água Profunda do Atlântico Norte (APAN), de aproximadamente 15 a 20 Sv (Piola et al., 2003), é compensado por um fluxo superficial para norte de águas quentes através do mesmo. Este efetivamente transporta calor para o oceano Atlântico Norte (figura 5) e sua influencia é de extrema importância no clima da região noroeste do continente Europeu (Vellinga \& Wood, 2002; Piola, 2003).

Portanto, as variações das propriedades termohalinas das massas de água levam a alterações da circulação termohalina e, conseqüentemente, do fluxo meridional de calor (Piola et al. 2003). Uma diminuição do transporte de águas quentes através do Atlântico Sul nas camadas superficiais para norte leva também a uma diminuição do fluxo de calor pelo mesmo. 


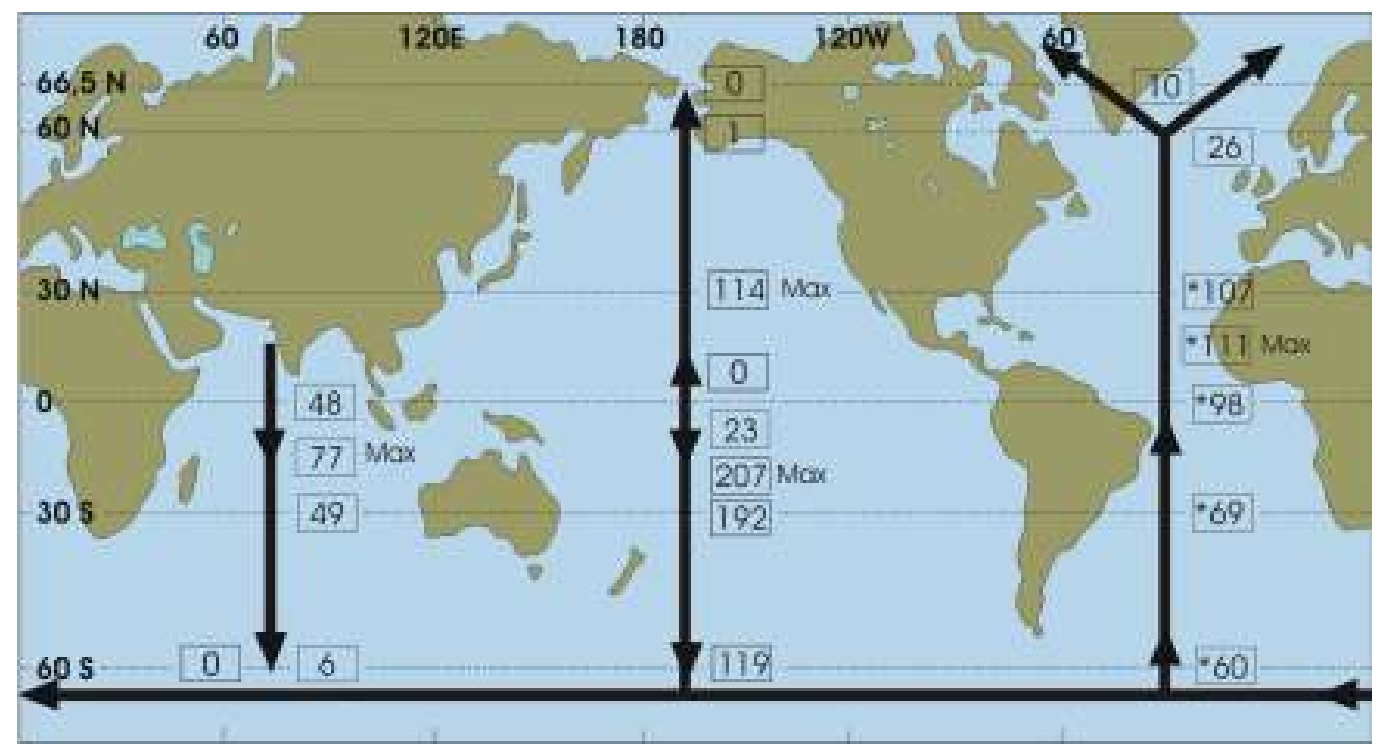

Figura 5: Média anual do transporte meridional de calor entre os oceanos. Os números indicam quantidade em unidade de $10^{13} \mathrm{~W}$. Adaptado de Hastenrath (1980).

\subsection{Circulação Atmosférica}

A circulação atmosférica na região sudeste do Brasil é dominada pelo anti- ciclone do Atlântico Sul (Alta Subtropical do Atlântico Sul - ASAS), um sistema de alta pressão permanente, localizado em torno de $30^{\circ} \mathrm{S}$ de latitude. Possui extensão vertical de mais $10 \mathrm{~km}$, da superfície oceânica à tropopausa e consiste em extensa área (alguns milhares de quilômetros) de ar subsidente seco e quente. Este sistema está associado à circulação média meridional da atmosfera, surgindo devido às células de Hadley. (Bastos \& Ferreira, 2000; Ito \& Ambrizzi, 2000). Vianello \& Alves (1991) observaram que os centros de pressão modificam-se do inverno para o verão, causando as diferenças de temperatura do ar de uma estação para outra. No verão as temperaturas sobre os continentes são maiores e os centros de alta pressão localizam-se sobre os oceanos e são mais determinados. Durante o inverno, as temperaturas são menores sobre os continentes; em conseqüência, os centros de alta pressão migram para o continente, onde o vento encontra-se consideravelmente fraco na região Sul/Sudeste. Mudanças neste padrão estão relacionadas a perturbações causadas por frentes frias polares, as quais, ao encontrar massas tropicais, produzem intensa precipitação no sul do Brasil. (Nimer, 1989; Hastenrath, 1991). 
A Zona de Convergência Intertropical (ZCIT) constitui outro elemento fundamental do clima tropical e da circulação oceânica para a região da América do Sul. Ela corresponde à zona de baixa pressão e intensa convergência de ventos (alísios provenientes de sudeste e nordeste), criando uma ascendência de massas de ar, que são normalmente úmidas sobre o oceano equatorial Ela é móvel, uma vez que se desloca durante o ano sob a ação do movimento aparente do sol, apresentando sua posição mais ao sul em março e mais ao norte em setembro, com uma diferença temporal de cerca de 50 dias (Mendonça \& Danni- Oliveira, 2007). Durante o inverno austral (figura 6), a precipitação máxima sobre o continente está localizada ao norte do equador, enquanto na parte central do continental sul americano (incluindo o sul da região amazônica) observa-se a estação seca. Ao final de outubro, ocorre uma rápida mudança na convecção em direção a sul e durante o verão austral, uma grande área de intensa precipitação se estende da bacia amazônica até o norte da Argentina. No outono, a região de máxima precipitação retorna gradualmente ao norte da América do Sul. Tal movimento de migração da precipitação tem levado muitos cientistas a descrever o clima da parte central da América do Sul como um sistema de Monções. O clima, porém não é inteiramente de monção devido aos ventos de baixo nível nunca reverterem suas direções. Durante 0 ano, a circulação de ventos sobre 0 Atlântico sopra em direção ao continente (embora com diferentes ângulos) onde a pressão é menor em relação ao oceano (Garreaud et al, 2009). 

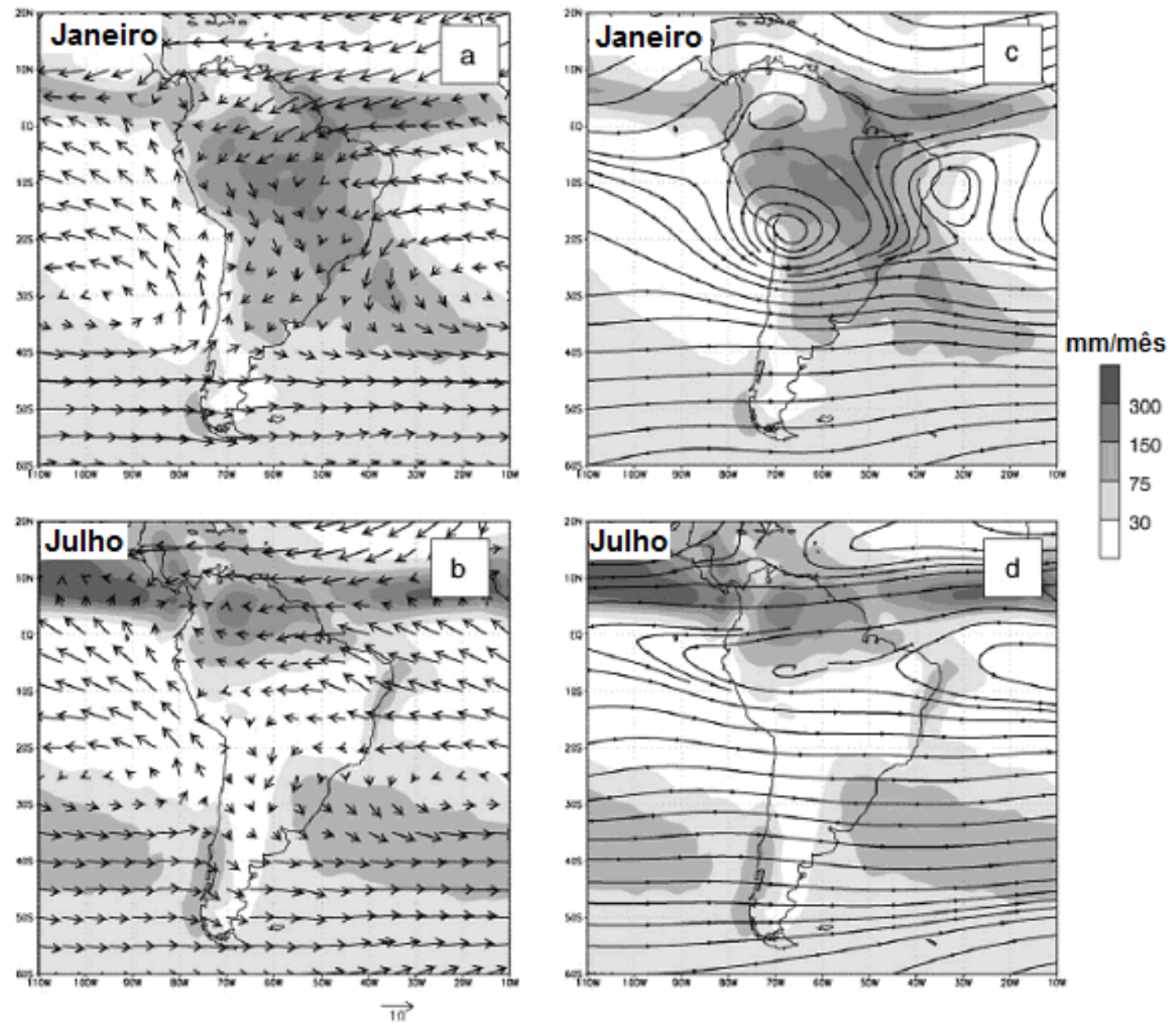

Figura 6: (a) e (b) Média mensal de precipitação, segundo CMAP (Xie and Arkin, 1997) e vetores de vento a $925 \mathrm{hPa}$ para Janeiro e Julho. (c) e (d) Média de precipitação e linhas de corrente a $300 \mathrm{hPa}$ para Janeiro e Julho. Adaptado de Garreaud et al., (2009)

\section{Materiais e Métodos}

\subsection{Descrição do testemunho}

O testemunho analisado possui 4,8 metros (figura 7 ) e foi coletado na Margem Continental Brasileira (figura 1), na Bacia de Santos, a 827 metros de profundidade, na posição $25^{\circ} 50^{\prime} 15,25^{\prime \prime}$ e e 4511'53,72”W.

Os testemunhos a pistão são coletados em um tubo que penetra sedimentos marinhos ou lacustres por métodos hidráulicos, ao invés de introduzidos por gravidade ou tração (Allaby \& Allaby, 1990). A testemunhagem foi efetuada através de um testemunhador a pistão (piston core) com peso de cabeça de $900 \mathrm{Kg}$, barrilete externo de aço de 6 metros de comprimento (20 
pés) e dotado de barrilete interno de polipropileno transparente "liner", com 2 15/16 polegadas de diâmetro interno.

A descrição dos testemunhos foi efetuada na escala 1:20, incluindo cor, granulometria e fácies. As fácies foram classificadas de acordo com a textura do sedimento e o teor estimado de $\mathrm{CaCO}_{3}$ em:

- Lama levemente carbonática (LL): possui conteúdo de carbonato entre 5 e $18 \%$;

- Lama rica em carbonato (LR): possui conteúdo de carbonato entre 18 e $30 \%$;

O modo mais simples e rápido de se determinar a idade dos sedimentos quaternários, antes da coleta das amostras, é através de estudos paralelos de abundância relativa de foraminíferos planctônicos pertencentes ao grupo Globorotalia menardii (G. menardii, G. tumida e G. flexuosa). Aproveitando-se as amostras utilizadas para verificar a composição da fração grossa, efetuou-se um controle estratigráfico preliminar no testemunho. Foram utilizadas as biozonas definidas por Ericson e Wollin (1968), onde a biozona Z superior rica em G. menardii é correspondente ao Holoceno (0 - 11 mil anos A.P.), enquanto a biozona $\mathrm{Y}$, pobre em G. menardii, está abaixo e é aproximadamente equivalente ao último período glacial (12,5 - 75 mil anos A.P.). Além disso, procurou-se verificar a presença do foraminífero plantônico Pulleniatina obliquiloculata, o qual marca um datum de aproximadamente 40 mil anos e divide a zona Y em Y1 e Y2 (Prell e Damuth, 1978).

A descrição realizada do testemunho mostrou que a maior parte do material coletado está compreendida na Biozona Z, com alta abundância do plexo do foraminífero planctônico G. menardii e presença da subespécie $G$. menardii fimbriata, que ocorre no Atlântico sul somente nos últimos 5 mil anos. Nos primeiros $300 \mathrm{~cm}$ do testemunho, observa-se lama (argila siltosa) levemente carbonática (teor de carbonato entre 5 e 18\%), de cor cinza olivácea a qual grada para uma lama cinza esverdeada rica em carbonato (com teor de carbonato entre 18 e $30 \%$ ). Abaixo dos $300 \mathrm{~cm}$ de profundidade o testemunho apresenta areia siltosa bioturbada dispersa na matriz. Esta areia fina a muito fina, que se apresentou mais concentrada entre 315 e $415 \mathrm{~cm}$ de profundidade é siliciclástica com bioclastos. Os sedimentos abaixo de $380 \mathrm{~cm}$ de 
profundidade pertencem à zona $\mathrm{Y}$, com baixas freqüências ou mesmo ausência do plexo G. menardii.
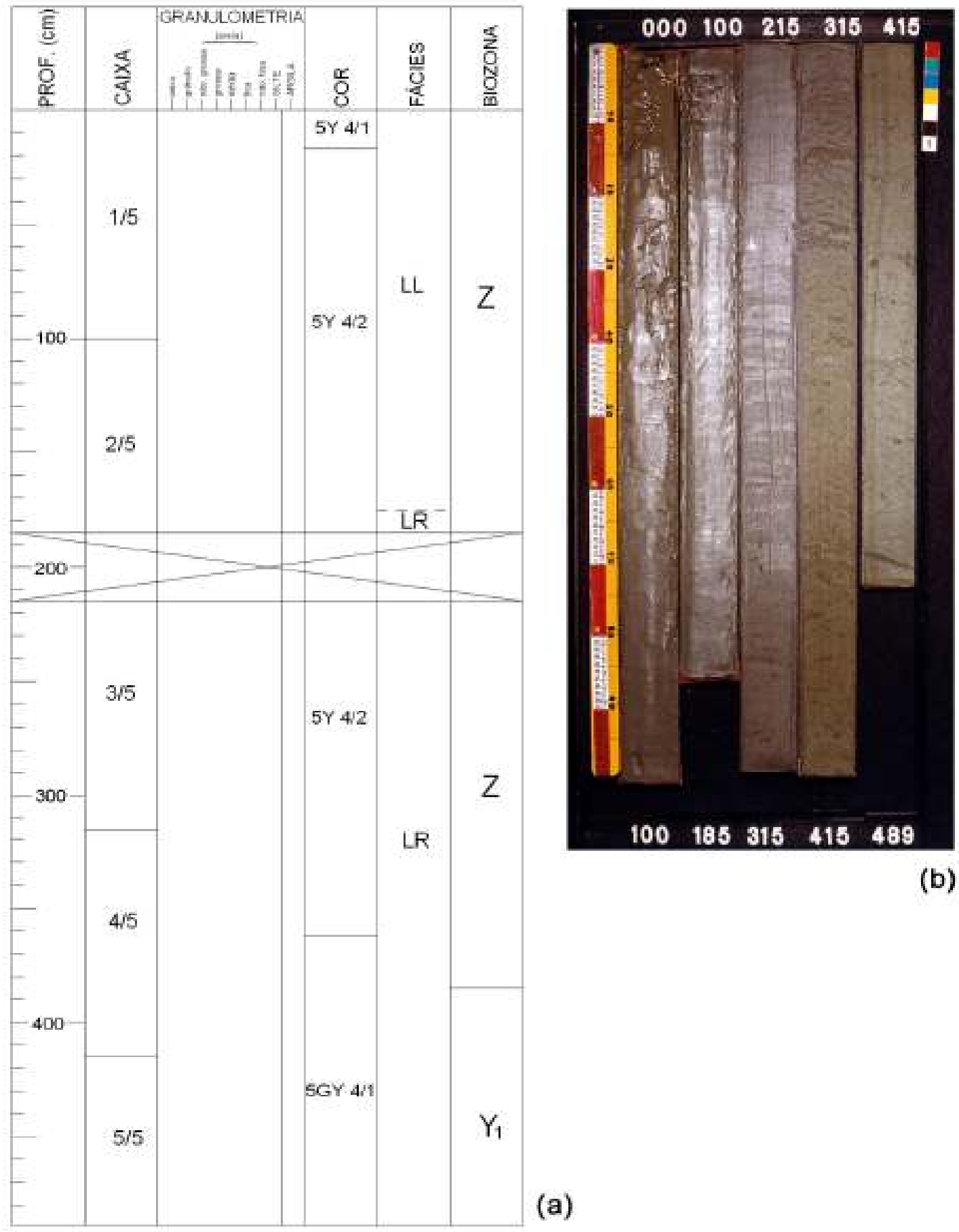

(b)

(a)

Figura 7: Descrição litofaciológica dos sedimentos recuperados e fotografia do testemunho KF-02. Biozonas de acordo com Ericson e Wollin (1968). 


\subsection{Cronologia do testemunho}

Para estudos de variações climáticas do Quaternário superior, a datação por radiocarbono ou ${ }^{14} \mathrm{C}$ tem provado ser de longe a mais útil. A técnica pode ser aplicada globalmente e tem sido utilizada para datações de turfa, madeira, ossos, conchas, paleosolos, testas, água dos oceanos, sedimentos lacustres e marinhos e $\mathrm{CO}_{2}$ atmosférico aprisionado em geleiras (Bradley, 1999).

Os princípios da técnica foram formulados na década de 40 pelo cientista americano Wiiliard Libby, que determinou os efeitos da radiação cósmica de alta energia (fluxo de raios cósmicos) na atmosfera (Lowe \& Walker, 1997). O radiocarbono ${ }^{14} \mathrm{C}$ é produzido nas camadas mais altas da atmosfera, tendo sua concentração máxima a $15 \mathrm{~km}$, por bombardeamento de nêutrons de átomos de nitrogênio da atmosfera:

$$
{ }^{14} \mathrm{~N}+{ }^{1} \mathrm{n} \rightarrow{ }^{14} \mathrm{C}+{ }^{1} \mathrm{H}
$$

Os átomos de ${ }^{14} \mathrm{C}$ são rapidamente oxidados para dióxido de carbono, se misturando na atmosfera com outras moléculas mais leves desse gás $\left({ }^{12} \mathrm{CO}_{2}\right)$. Em seguida, ocorre o seu armazenamento em diversos reservatórios globais atmosfera, bioesfera e hidrosfera, através de processos como a fotossíntese e a respiração (Lowe and Walker, 1997).

A datação por radiocarbono é baseada em 4 premissas fundamentais: 1) a produção de ${ }^{14} \mathrm{C}$ é constante ao longo do tempo; 2) a razão ${ }^{14} \mathrm{C}:{ }^{12} \mathrm{C}$ na bioesfera e hidrosfera está em equilíbrio com a razão na atmosfera; 3) a taxa de decaimento do ${ }^{14} \mathrm{C}$ pode ser estabelecida; 4) a partir da morte do organismo, considera-se a existência de um sistema fechado (Lowe and Walker, 1997).

$\mathrm{O}$ conteúdo de ${ }^{14} \mathrm{C}$ nos tecidos dos organismos está em equilíbrio com o da atmosfera devido à constante troca de novas moléculas de ${ }^{14} \mathrm{C}$, na medida em que células morrem e são substituídas. Com a morte do organismo, essa troca cessa e o conteúdo de ${ }^{14} \mathrm{C}$ diminui em função do tempo, devido ao decaimento radioativo (emissão de partícula $\beta^{-}$) e transformação desse elemento em nitrogênio. 


\subsubsection{Idade Reservatório}

As águas superficiais não estão em equilíbrio isotópico com a atmosfera devido à mistura com águas pobres em ${ }^{14} \mathrm{C}$, trazidas do fundo pela circulação oceânica. Estas tiveram por longo tempo seu conteúdo de ${ }^{14} \mathrm{C}$ diminuído, em função do decaimento radioativo e o não-reabastecimento com moléculas "novas" da atmosfera. Dessa forma, atribui-se uma idade aparente ou idade reservatório para essas águas superficiais oceânicas. Estes valores variam geograficamente (figura 8) em função de fatores como as taxas de troca isotópica entre oceano e atmosfera, cobertura de gelo e da própria circulação oceânica.

Em baixas latitudes de todos os oceanos, por exemplo, o valor médio é de aproximadamente 400 anos, ou seja, 400 anos devem ser adicionados à idade de ${ }^{14} \mathrm{C}$ de uma amostra marinha da camada de mistura para comparação com um material terrestre (Bradley, 1999). Esta diferença apresenta variação de menos de 300 anos nos giros subtropicais até mais de 1600 anos na porção mais ao sul do oceano austral e varia significantemente entre regiões de ressurgência e águas quentes (warm pools) nos trópicos.

LAS $7 .+/$ Ferret $6.08 \quad$ NOAA/PMEL

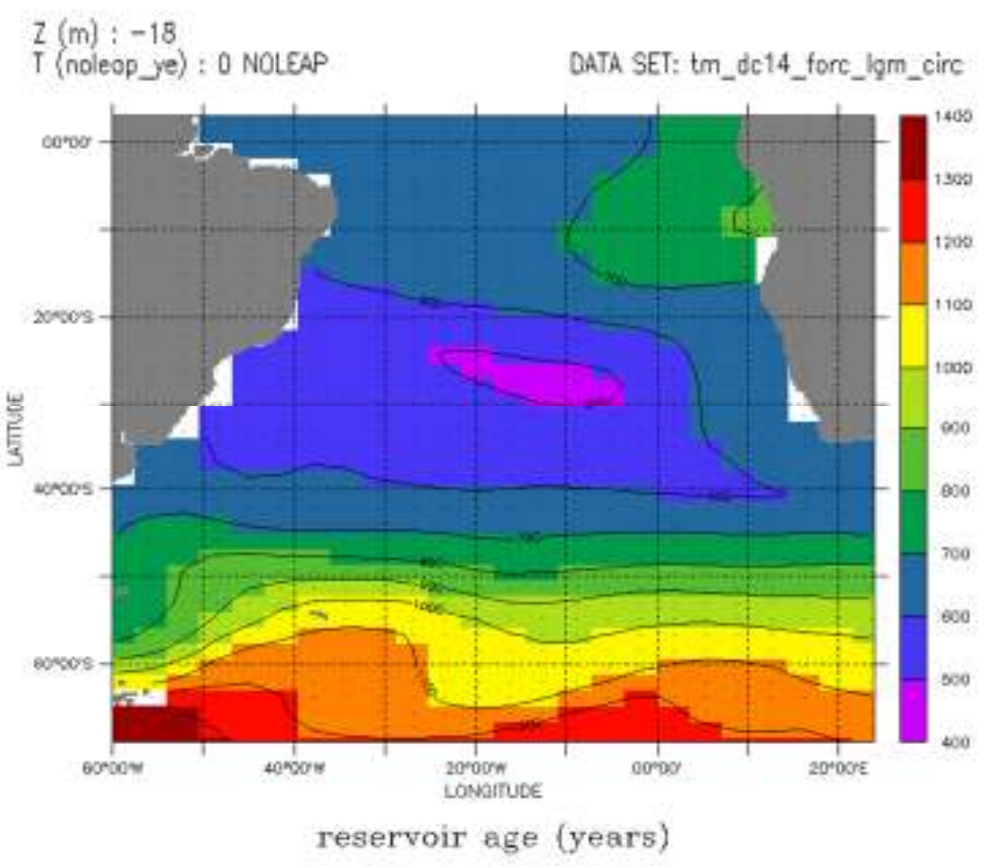

Figura 8: Idades reservatório para a porção sul do Oceano Atlântico (figura gerada no site http://reservoirage.palmod.uni-bremen.de) 
Para a realização da cronologia do testemunho KF-02, foram selecionadas 9 amostras monoespecíficas de Globigerinoides ruber (variedades white e pink) de diferentes profundidades. As análises foram efetuadas no National Ocean Science Accelerator Mass Spectrometrer Facility (NOSAMS) no Woods Hole Oceanographic Institution (WHOI), EUA.

Os valores obtidos pela datação com radiocarbono foram corrigidos adotando-se a idade reservatório de 271 anos para a região, de acordo com Butzin et al. (2005) e Cao et al. (2007). As idades estimadas para o restante do testemunho se baseiam no modelo de idade construído com o Analyseries, usando os dados de isótopos de oxigênio em G. ruber, as nove datações de ${ }^{14} \mathrm{C}$ e a curva do SPECMAP como série de referência. O modelo de idade é apresentado no item 6.1, na discussão dos resultados.

\subsection{Preparação das amostras de Foraminíferos Planctônicos}

Para a recuperação dos foraminíferos dos sedimentos, as amostras foram processadas no Laboratório de Paleoceanografia do Atlântico Sul (LaPAS) do Instituto Oceanográfico da Universidade de São Paulo. A amostragem paleontológica foi coletada com espaçamento médio de $4 \mathrm{~cm}$. As 108 amostras foram pesadas e secas em estufa. Este procedimento é efetuado para facilitar a desagregação dos sedimentos que não estão inconsolidados. Em seguida, as amostras foram lavadas com água corrente em peneira de 0,063 mm. Estas amostras, após a secagem em estufas em temperatura em torno de $50^{\circ} \mathrm{C}$, foram novamente pesadas e então armazenadas em frascos previamente etiquetados com a identificação de cada amostra. Posteriormente, na fase de triagem, o sedimento seco foi peneirado na malha de $0,150 \mathrm{~mm}$. A escolha desta malha se deve ao fato de que, de acordo com a literatura (ex. Deuser \& Ross 1989; Toledo, 2000; Costa \& Toledo 2003), a fauna de foraminíferos planctônicos mais representativa para a determinação das variações climáticas fica retida nesta malha. Segundo Toledo (2000), o uso de malhas com diâmetros maiores pode causar a perda de espécies pequenas importantes, assim como a utilização de malhas com diâmetros menores causa um falso crescimento numérico dessas mesmas espécies, além das avaliações qualitativa e quantitativa serem 
dificultadas devido ao grande número de indivíduos e à dificuldade de identificação de formas juvenis.

Nas amostras, o resíduo foi quarteado e despejado sobre uma bandeja (picktray), onde os foraminíferos planctônicos foram contados e re-quarteados até que a fração obtida ficasse com pelo menos 300 espécimes de foraminíferos planctônicos. Em seguida, procedeu-se à classificação das espécies, efetuada de acordo com Hemleben et al. (1989), contagem e subseqüente conversão dos valores absolutos em porcentagem em relação à fauna total daquela amostra.

\subsection{Preparação para a análise de isótopos de oxigênio}

A espécie de foraminífero planctônico Globigerinoides ruber é considerada um dos indicadores mais confiáveis para reconstruções paleoambientais em latitudes tropicais e subtropicais, já que vive na camada de mistura (Ravelo et al.,1990). As testas desta espécie são formadas/ calcificadas nos primeiros $25 \mathrm{~m}$ da coluna de água.

O táxon foi escolhido por ser abundante em todo o testemunho, viver próximo à superfície e, principalmente, por calcificar sua testa em equilíbrio isotópico de oxigênio com a água do mar (Deuser \& Ross, 1989, Toledo, 2000).

As análises isotópicas foram feitas ao longo de todo o testemunho, nas mesmas 108 amostras selecionadas para os estudos da fauna. Cerca de 20 exemplares da espécie Globigerinoides ruber (white) foram recuperadas de cada amostra para o procedimento. As testas selecionadas para determinação da variação isotópica do oxigênio tiveram uma preparação específica após a separação das espécies que conta com a lavagem das mesmas em aparelho de ultra- som e ataque com ácido fosfórico $100 \%$. As análises foram feitas pelo laboratório do Instituto Oceanográfico de Woods Hole, nos Estados Unidos. As razões isotópicas foram fornecidas em relação ao padrão PDB, com uma precisão de 0.07 . 


\subsection{Fluorescência de raios $X$ na fração fina}

Para auxiliar a interpretação dos resultados obtidos nesta dissertação, foram considerados os dados de Bariani (2009) de Fluorescência de Raios X (FRX) na fração fina $(<0,063 \mathrm{~mm})$, realizadas também no testemunho KF-02. As análises foram conduzidas em 50 amostras com espaçamento médio de 10 cm no laboratório de Química e ICP-AES do Instituto de Geociências da Universidade de São Paulo. Foram obtidos dados quantitativos dos elementos Titânio (Ti), Cálcio (Ca) e Ferro ( $\mathrm{Fe}$ ) nas amostras de sedimento.

Para as análises, as amostras são homogeneizadas e secas em estufa a $100-110^{\circ} \mathrm{C}$ durante $24 \mathrm{~h}$. Em seguida, adiciona-se fundente composto por uma mistura de tetraborato e metaborato de lítio na razão 1:4, com nova homogeneização e fundição em máquina de fusão por 30 minutos. Por fim, a amostra é resfriada e reduzida a uma geometria padrão (formato de pastilha) e é submetida à análise por fluorescência de raios $X$.

A FRX é um método quali-quantitativo baseado na medida das intensidades (número de raios $\mathrm{X}$ detectados por unidade de tempo) dos raios $\mathrm{X}$ característicos emitidos pelos elementos que constituem a amostra. São utilizadas radiações eletromagnéticas de energia adequada (raios $X$ e raios gama) para induzir transições eletrônicas entre os orbitais mais internos dos átomos. Essas transições podem resultar na emissão de radiações $X$ de energia característica que permitem a identificação da espécie atômica envolvida na transição e a quantificação da sua abundância. Mais especificamente, neste processo a energia da radiação de fluorescência identifica o elemento, enquanto sua intensidade permite que seja medida sua concentração na amostra analisada mediante uma prévia calibragem (Jenkins et al., 1995).

\subsection{Análise estatística}

A comparação apenas visual da oscilação da freqüência das várias espécies ao longo do testemunho pode ser tendenciosa no sentido de dar-se maior importância para aquelas espécies com valores mais expressivos de freqüência (por exemplo, G. ruber), mas que nem sempre são as espécies de 
maior importância para análises das oscilações climáticas e hidrográficas (Toledo, 2000). Dessa forma, faz-se uso das técnicas de estatística para a correta análise dessas variações.

A Análise de Agrupamentos é uma das técnicas de análise multivariada mais difundida e utilizada na literatura de foraminíferos. Ela segrega as entidades (amostras, espécies, medidas) em grupos de maior semelhança e quantifica a relação entre esses grupos. Pode ser aplicada então para explorar as similaridades entre as amostras (modo- Q) ou entre as espécies (modo- $R$ ) (Parker e Arnold, 1999).

A Análise de Componentes Principais (ACP) é uma técnica estatística multivariada que explica a variação dos dados observados em termos de variáveis independentes, chamadas componentes. O processo extrai, idealmente, o mesmo número de dimensões das entidades originais (por exemplo, fatorando uma matriz que contém 10 entidades, 10 componentes principais ou fatores serão obtidos). As componentes então são ranqueadas de acordo com o valor da variância incorporada por elas; cada uma conta com uma parte ou valor decrescente da informação do dado original (Parker e Arnold, 1999). A análise de componentes principais (ACP) foi aplicada aos dados de fauna dos foraminíferos planctônicos a fim de se comparar objetivamente as variações nas freqüências das espécies.

\subsection{Razão Foraminíferos Planctônicos/Bentônicos (FP/FB)}

A paleobatimetria vem sendo de crescente importância na paleoceanografia e em análises de base, tendo sua principal importância na reconstrução da história de movimentos verticais de bacias sedimentares e de curvas de nível do mar (Van der Zwaan et al. 1990). Em 1955, Grimsdale \& Van Morkhoven publicaram um clássico trabalho sobre a aplicação da razão foraminíferos planctônicos/bentônicos na reconstrução de paleoprofundidades. Esses autores encontraram que a proporção de foraminíferos planctônicos em relação à fauna total aumentava sistematicamente em direção a águas mais profundas. 
Berger \& Diester-Haass (1988) publicaram um estudo onde a abundância de foraminíferos bentônicos, relativo à fauna de planctônicos na margem continental noroeste da África é governada pelo suprimento de matéria orgânica no assoalho oceânico, o qual é função da profundidade e proximidade com a costa. Desta forma, a maneira simples com que a razão FP/FB pode ser determinada em sedimentos de mar profundo, torna essa taxa uma importante ferramenta para estudos também de paleoprodutividade.

\section{Resultados e Discussões}

\subsection{Modelo de Idade}

A tabela 1 mostra as profundidades selecionadas para a datação com radiocarbono. Elas foram escolhidas baseadas na análise prévia dos primeiros dados de isótopos de oxigênio obtidos para este testemunho a partir de amostras de 5 a $10 \mathrm{~g}$ de rocha total e na variação da abundância relativa dos foraminíferos planctônicos do Plexo G. menardii, que "sugeriam" possíveis eventos climáticos.

Tabela 1: Amostras selecionadas para datação com radiocarbono e Idades Calendário obtidas

\begin{tabular}{cccccc}
\hline $\begin{array}{c}\text { Prof } \\
(\mathrm{cm})\end{array}$ & $\begin{array}{c}{ }^{14} \text { C idade } \\
\text { (anos) }\end{array}$ & $\begin{array}{c}\text { Desvio Padrão } \\
\text { (anos) }\end{array}$ & $\begin{array}{c}\text { Idade } \\
\text { Reservatório } \\
\text { (anos) }\end{array}$ & $\begin{array}{c}\text { Idade Calendário } \\
\text { (Kyr) }\end{array}$ & $\begin{array}{c}\text { Espécie } \\
\text { analisada }\end{array}$ \\
\hline 2 & 615 & 57 & 271 & 0,404 & G. ruber \\
45 & 850 & 34 & 271 & 0,579 & G. ruber \\
99 & 1080 & 41 & 271 & 0,72 & G. ruber \\
149 & 2910 & 9 & 271 & 2,75 & G. ruber \\
234 & 5230 & 30 & 271 & 5,673 & G. ruber \\
318 & 7750 & 39 & 271 & 8,319 & G. ruber \\
360 & 9660 & 78 & 271 & 10,611 & G. ruber \\
420 & 10550 & 102 & 271 & 12,048 & G. ruber \\
436 & 11150 & 45 & 271 & 12,776 & G. ruber \\
\hline
\end{tabular}


A figura 9 apresenta a correlação entre a curva de isótopos de oxigênio em G. ruber (white) e a curva padrão isotópica de Martinson et al. (1987). A partir desta correlação e das datações de radiocarbono como pontos de controle, foram obtidas as idades das amostras do testemunho.

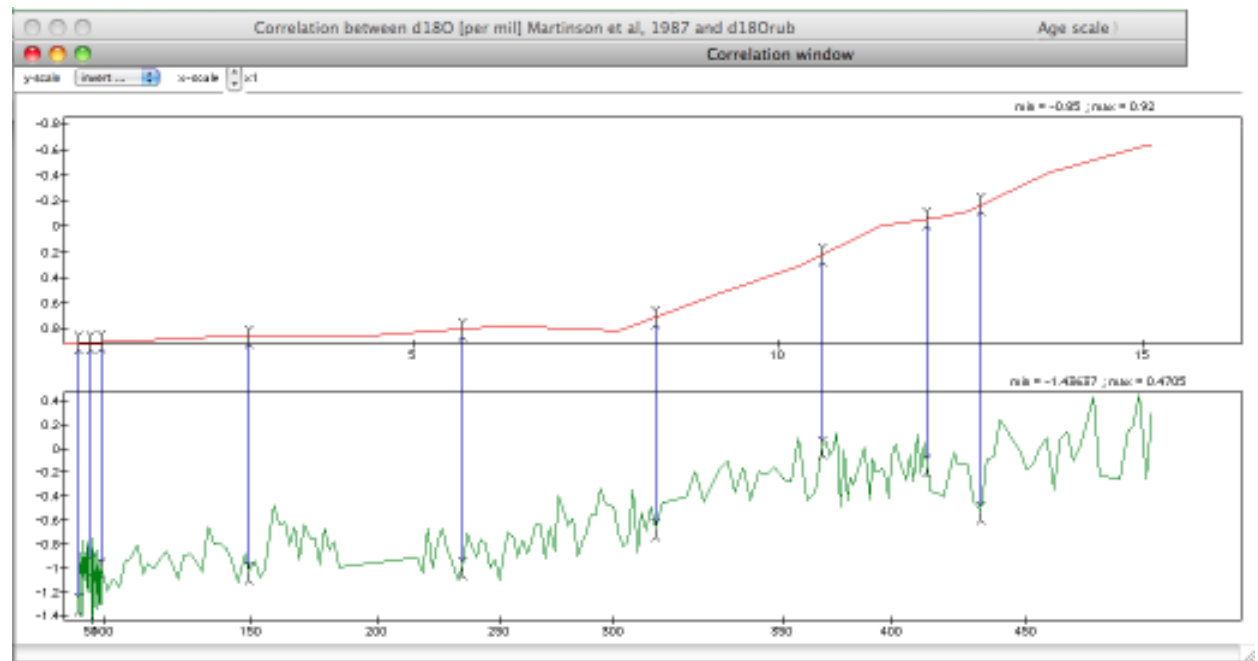

Figura 9: Correlação entre a curva padrão isotópica de Martinson et al., 1987 e a curva de isótopos de oxigênio em G.ruber (white) feita com o programa AnalySeries (Paillard et al., 1996).

A figura 10 apresenta as idades calendário após a correção pelo efeito reservatório de 271 anos. A idade estimada da amostra do topo $(2 \mathrm{~cm})$ foi de aproximadamente 400 anos. É possível que o topo do testemunho tenha sido perdido durante a amostragem realizada com pistão, o que é freqüente durante essa operação. (Damuth, 1977).

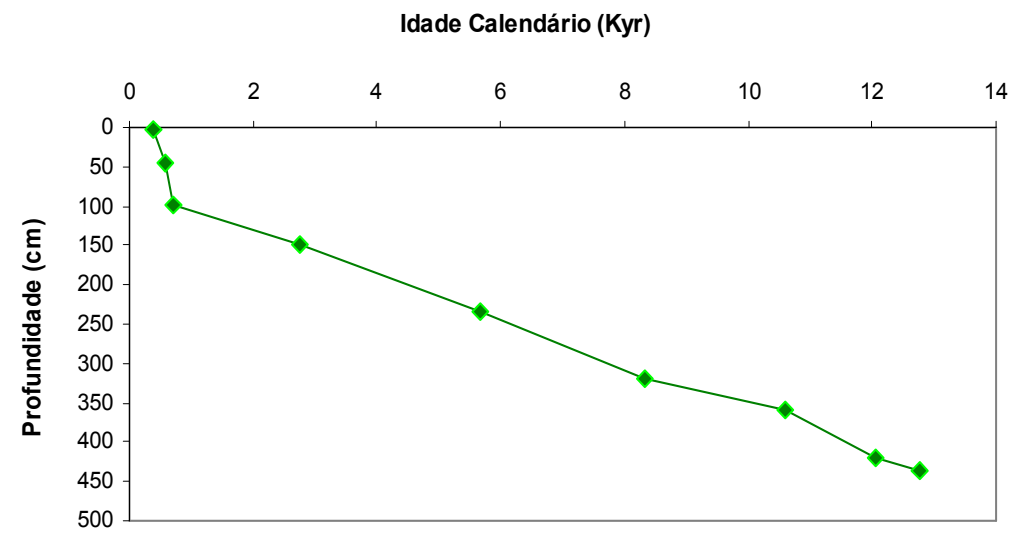

Figura 10: Datações efetuadas no testemunho e sua relação com a profundidade 


\subsection{Foraminíferos Planctônicos}

\subsubsection{Lista das espécies utilizadas}

1 Globorotalia tumida (Brady, 1877)

2 Globorotalia menardii (d'Orbigny, 1865)

3 Globorotalia fimbriata (Brady, 1884)

4 Globorotalia inflata (d'Orbigny, 1839)

5 Neogloboquadrina dutertrei (= Globoquadrina dutertrei) (d'Orbigny, 1839)

6 Globorotalia truncatulinoides (dex) (d'Orbigny, 1839)

7 Globigerinoides ruber (white) (d'Orbigny, 1839)

8 Globigerinoides ruber (pink) (d'Orbigny, 1839)

9 Globigerina bulloides (d'Orbigny, 1826)

10 Globigerinoides sacculifer sem saco (= Globigerinoides trilobus) (Brady, 1877)

11 Globigerinoides sacculifer com saco (Brady, 1877)

12 Globigerinita glutinata (= Globigerina glutinata ) (Egger, 1893)

13 Orbulina universa (d'Orbigny, 1839)

14 Globigerinoides conglobatus (Brady, 1879)

15 Pulleniatina obliquiloculata (Parker e Jones, 1865)

16 Globorotalia crassaformis (Galloway e Wissler, 1927)

As figuras 11 e 12 mostram a variação das abundâncias ao longo do testemunho das principais espécies encontradas neste estudo e de maior importância para inferências sobre as variações paleoceanográficas nos últimos 15.000 anos. Nelas estão destacados os principais intervalos onde foram observadas significativas variações nas abundâncias das assembléias, em aproximadamente 8 e 3 mil anos A.P.

A espécie mais abundante durante todo o intervalo amostrado foi a $G$. ruber (white), apresentado até $61,6 \%$ da abundância total. Em seguida, o morfótipo pink de G. ruber com até 36,7\%, G. bulloides (16,6\%) e G. sacculifer (sem saco), 12,5\%. Outras espécies também apresentaram picos de abundância elevada, porém em intervalos específicos (plexo G. menardii, com 23,9\%, N. dutertrei, com abundância máxima de 15,4\% e G. truncatulinoides dextral, com 12,9\%). 

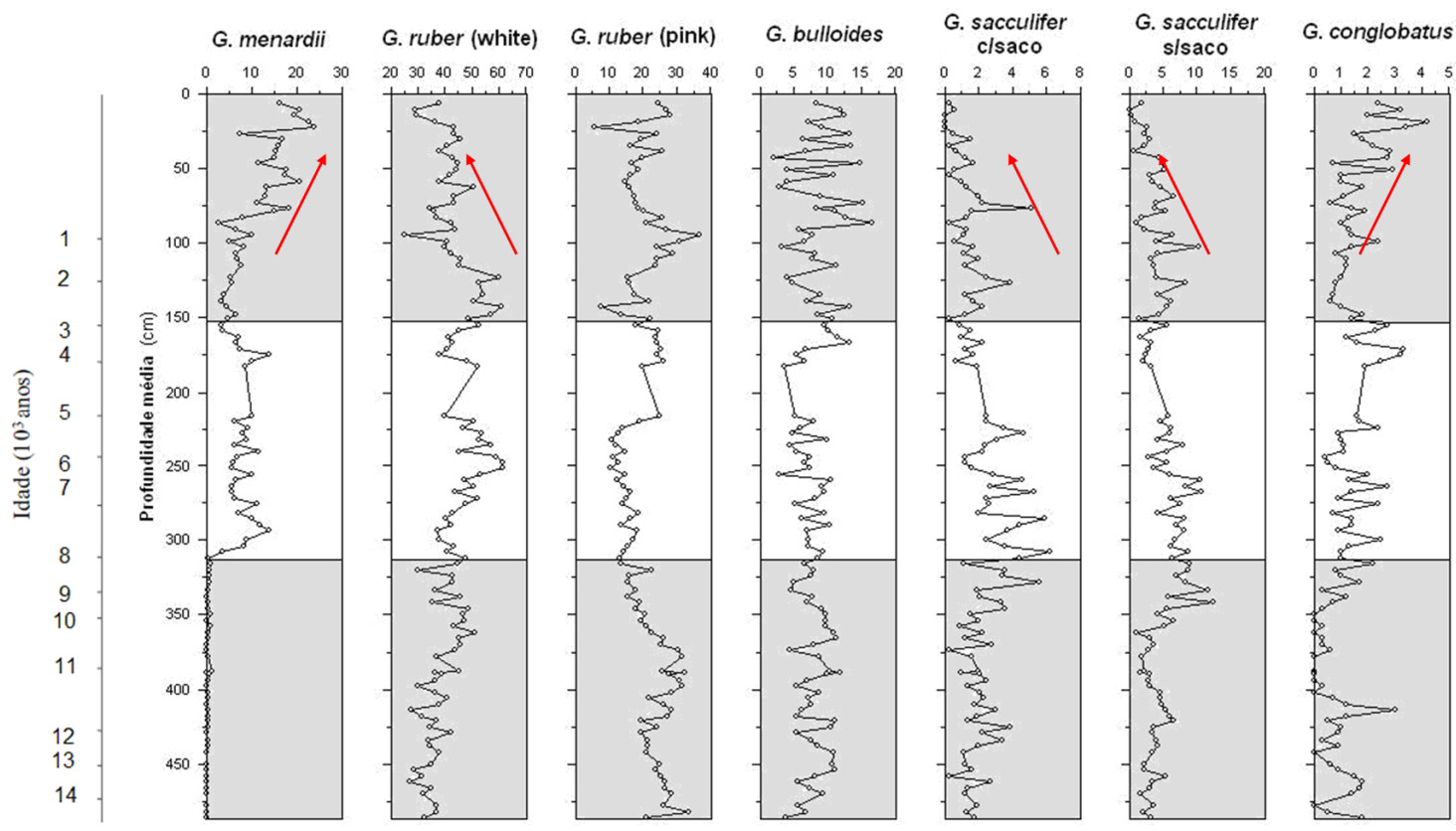

Figura 11- Freqüências relativas das espécies plexo G. menardii, G. ruber (white e pink), G. bulloides, G. sacculifer (com saco e sem saco), G. conglobatus ao longo do testemunho KF2. Áreas sombreadas representam os intervalos onde foram observadas variações significativas na abundância das assembléias (aproximadamente 8 e 3 mil anos A.P.)
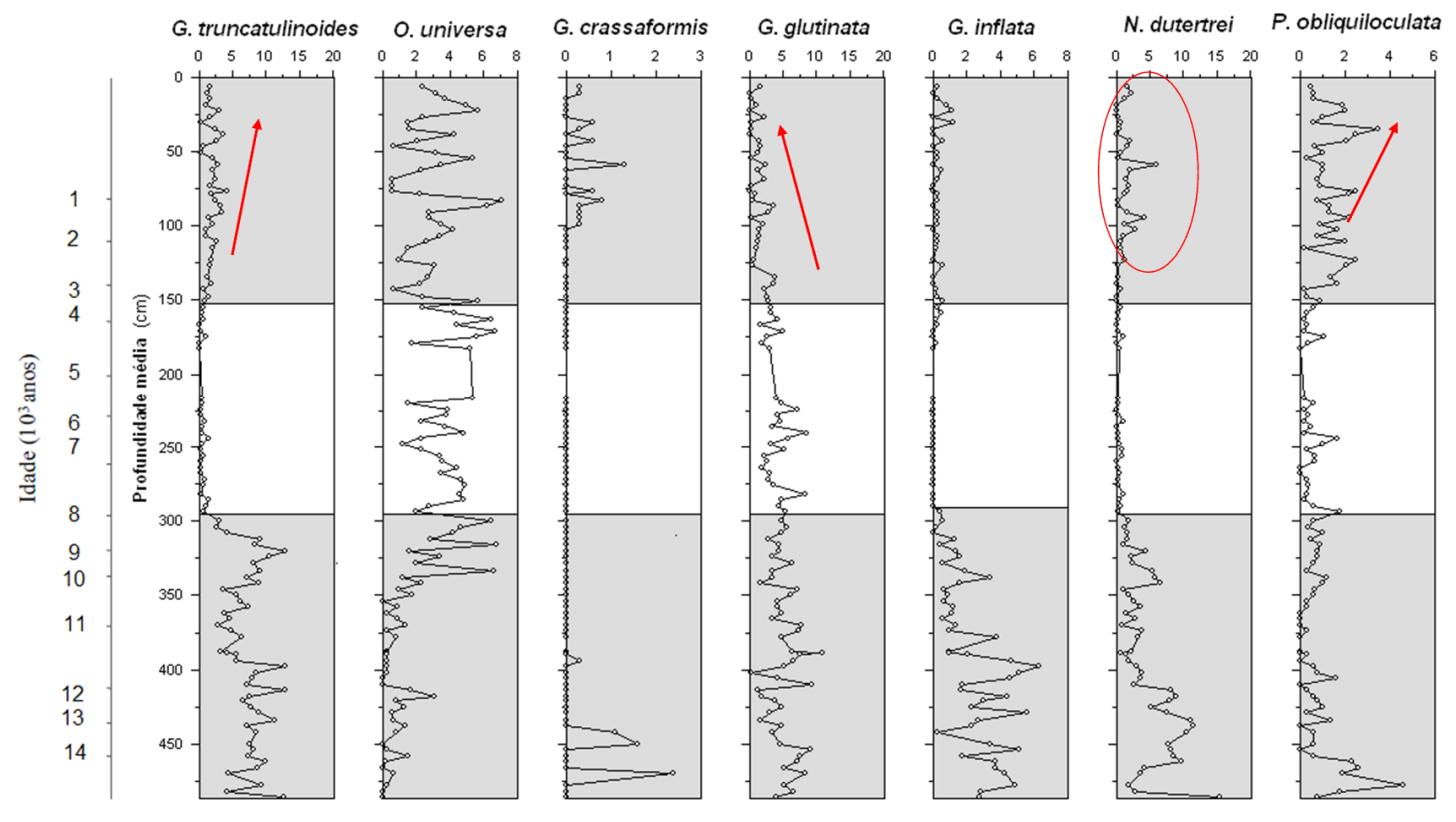

Figura 12- Freqüências relativas das espécies G. truncatulinoides, Orbulina universa, G. crassaformis, G. glutinata, G. inflata N. dutertrei e Pulleniatina obliquiloculata ao longo do testemunho KF2. . Áreas sombreadas representam os intervalos onde foram observadas variações significativas na abundância das assembléias (aproximadamente 8 e 3 mil anos A.P.) 
A seguir, são apresentadas as variações de abundância de cada espécie ao longo do tempo, bem como uma breve descrição sobre suas preferências ecológicas.

A figura 13 apresenta a variação do plexo G. menardii. As espécies que compõem esse grupo ocorrem em massas de águas tropicais e subtropicais, apresentando máxima abundância relativa em ambientes equatoriais e tropicais (Hilbrecht, 1996). Vivem preferencialmente em águas sub-superficiais, abaixo dos 50 metros de profundidade, descendo provavelmente à zona batial no fim de seu ciclo ontogenético (Bé et al., 1966). Essas espécies parecem ser onívoras, com preferência maior ao fitoplâncton (diatomáceas e crisófitas), o qual parte deste pode ser armazenado e utilizado como simbionte facultativo (Hemleben et al., 1989). No presente estudo, até os 8 mil anos A.P., essas espécies, indicadoras de períodos interglaciais no Atlântico, estiveram ausentes no testemunho estudado. Berger \& Wefer (1996) demonstraram que o restabelecimento de uma firme circulação termohalina ao final do último máximo glacial coincidiu com o reaparecimento das espécies do plexo $G$. menardii no Atlântico tropical. Estas espécies se extinguiram durante o período glacial no Atlântico, porém não desapareceram no oceano Índico. Weijer et al. (2002) concluem que este reaparecimento no Atlântico pode somente ser explicado pelo transporte dessas espécies do oceano Índico, possivelmente após o aumento da liberação intermitente de vórtices da retroflexão da corrente das Agulhas. Esses "anéis", como são conhecidos, possuem núcleos de águas quentes e diâmetro médio de 307 km (Lutjeharms \& van Ballegooyen, 1988) e se deslocam através do Oceano Atlântico Sul inicialmente na direção noroeste através da corrente de Benguela. Esses vórtices transferem energia e águas com características próprias de temperatura e salinidade do Oceano Índico para o giro subtropical do Atlântico Sul. Segundo Came et al. (2003) a circulação termohalina no Atlântico Sul atingiu a sua configuração moderna a partir de 9 mil anos A.P., mostrando aumento da temperatura das camadas superficiais e da termoclina. Isto pode ser observado na distribuição de abundância das espécies do plexo G. menardii no registro do testemunho estudado (figura 13), que voltam a aparecer a partir de 8 mil anos A.P. Observa-se também aumento das freqüências relativas a partir de 1000 anos 
A.P., provavelmente indicando uma elevação da termoclina na zona fótica, que favorece essas espécies que vivem em sub-superfície.

Plexo G. menardii

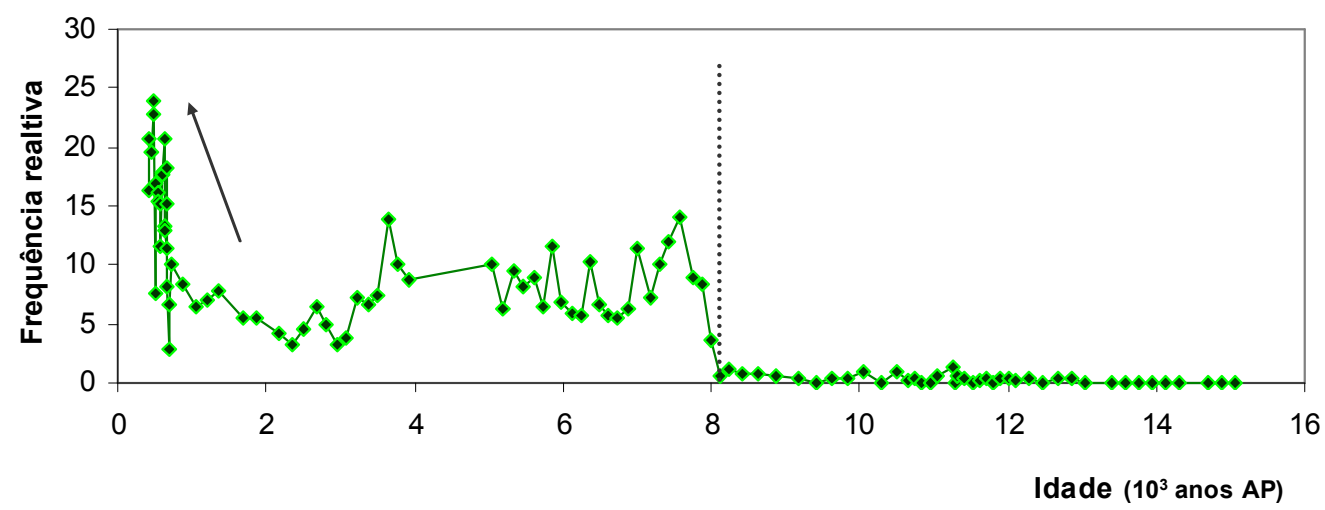

Figura 13: Abundância relativa do Plexo G. menardii

A espécie G. fimbriata (figura 14) é um importante datum da bioestratigrafia do Atlântico, pois ela só ocorre no Holoceno, nos últimos 5 mil anos. Ela apresenta uma abundância muito baixa (média de 0,2\%), contribuindo pouco para a fauna do plexo G. menardii.

\section{Globorotalia fimbriata}

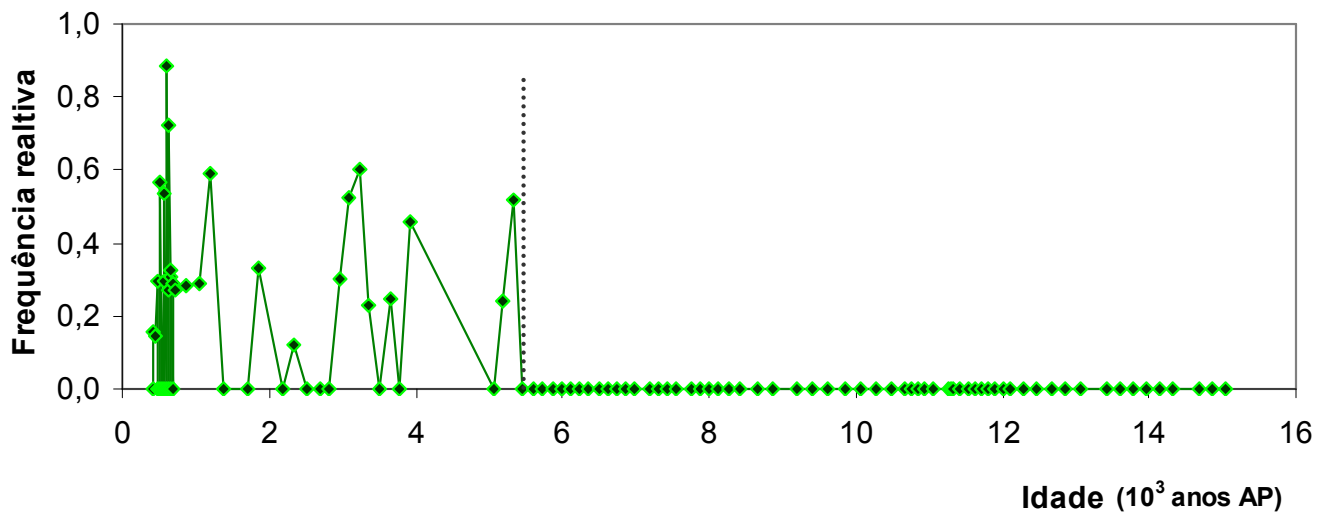

Figura 14: Abundância relativa da espécie G. fimbriata 
As espécies mostradas a seguir, $G$. inflata, $N$. dutertrei e $G$. truncatulinoides (figuras 15, 16 e 17, respectivamente) apresentaram um padrão de abundância praticamente oposto ao do plexo G. menardii, tendo suas freqüências diminuídas drasticamente em $8 \mathrm{mil}$ anos A.P., possivelmente relacionadas ao aumento da temperatura e estratificação da coluna de água. Próximo ao fim do registro essas espécies voltam a aparecer, porém com abundâncias muito baixas.

Globorotalia inflata

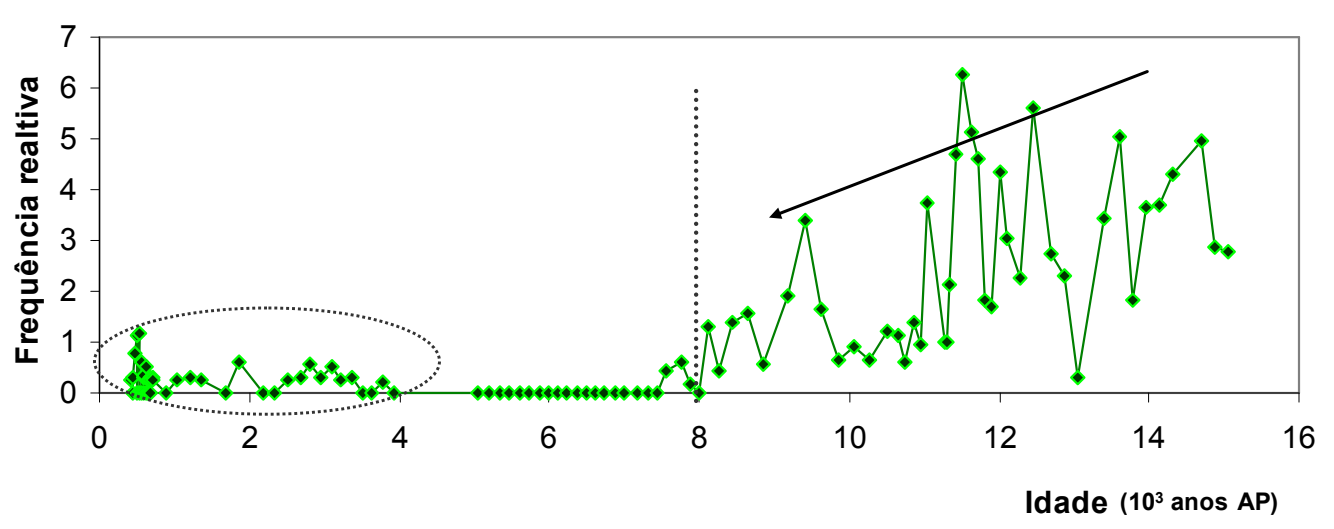

Figura 15: Abundância relativa da espécie G. inflata

A espécie G. inflata (figura 15) é uma excelente indicadora (e única espécie indígena) de zonas transicionais, que separam águas subpolares e subtropicais (Bé \& Tolderlund, 1971). A sua distribuição atual nos oceanos está relacionada a massas de água com pequena variação sazonal da salinidade, apresentando maior preferência a condições de inverno no gradiente de temperatura, densidade superficial e estratificação (Hilbrecht, 1996). No intervalo estudado, esta espécie está presente e em maior abundância até 8 mil anos A.P., indicando provavelmente que sua faixa de distribuição neste período (águas transicionais) estava localizada mais ao norte do que sua posição atual, devido as menores temperaturas. A partir de 8 mil anos A.P. aproximadamente, esta espécie se torna ausente, indicando aumento da temperatura e conseqüente deslocamento de sua faixa de distribuição em direção aos pólos. Após 4 mil anos A.P., G. inflata 
volta a aparecer no registro sedimentar, porém apresentado baixas abundâncias relativas (menores que 1\%).

Neogloboquadrina dutertrei

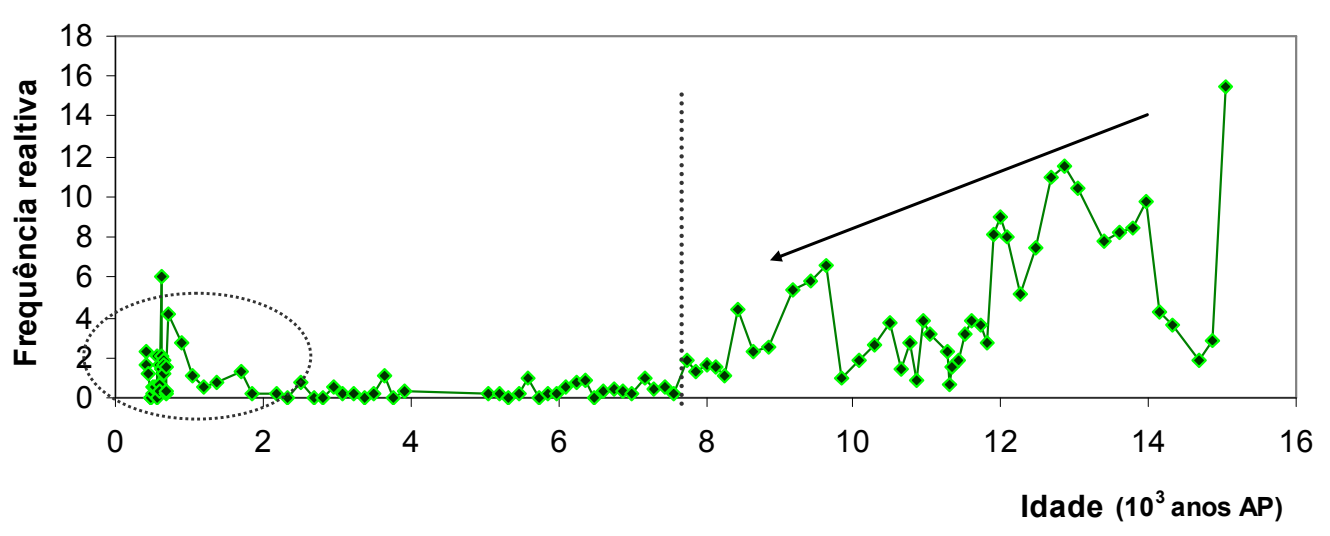

Figura 16: Abundância relativa da espécie N. dutertrei

Picos de abundância da espécie $N$. dutertrei (figura 16) estão relacionados aos principais sistemas de correntes próximos às margens continentais, com condições de termoclina mais rasa e máximo de clorofila entre 25 e 50 metros de profundidade. Sua distribuição geográfica se dá principalmente em águas tropicais a subtropicais, limitada às zonas de transição, sendo rara em águas centrais dos oceanos Atlântico e Índico (Bé \& Tolderlund, 1971; Ravelo et al., 1990; Kemle- Von Mucke \& Hemleben, 1999). Até 8 mil anos A.P. esta espécie apresentou abundância relativamente alta, em torno de $5 \%$. A partir deste limite, ela se torna praticamente ausente no registro sedimentar, indicando condições ambientais desfavoráveis a sua proliferação, como aumento da temperatura e termoclina mais profunda. A partir de 2 mil anos A.P., observa-se um ligeiro aumento de sua abundância, podendo estar relacionado a condições menos estratificadas da coluna de água, possivelmente menor temperatura e termoclina mais próxima a superfície, favorecendo aumento da produtividade local.

A espécie G. truncatulinoides (dextral) (figura 17) é predominantemente subtropical, habitando massas de água centrais dos oceanos. Ela apresenta ciclo de vida anual e enquanto desce na coluna de água a maiores profundidades, ao contrário de outras espécies, continua a se desenvolver, adicionando mais câmaras à sua estrutura. Além disso, forma uma parede de 
calcita quando atinge a isoterma de $10^{\circ} \mathrm{C}$, o que corresponde a aproximadamente 1000 metros de profundidade (Hemleben et al., 1989).

A sua maior abundância parece estar associada a variações na profundidade da termoclina e intensidade de mistura vertical (Ravelo et al., 1990; Lohmann, 1992). Bé (1977) e Mulitza et al. (1997) observaram que as máximas abundâncias estão localizadas nos subtrópicos, onde a mistura vertical é intensa. Por outro lado, baixas abundâncias foram obtidas em coletas abaixo da camada de mistura com redes de plâncton em regiões tropicais, onde se observa grande estratificação da coluna de água (Ravelo et al., 1990). O ciclo de reprodução dessa espécie está sincronizado aos processos sazonais de mistura vertical e de ressurgência, sendo que o retorno das formas juvenis às águas superficiais é facilitado pela menor estratificação da coluna de água. Dessa forma, podemos inferir que a drástica redução da abundância relativa dessa espécie no presente estudo a partir de 8 mil anos A.P. está relacionada a um aumento da estratificação da coluna de água, como conseqüência do aumento da temperatura das águas superficiais. Ao contrário, as altas freqüências relativas entre 15 e 8 mil anos A.P. (média de 7,5\%) indicam condições mais favoráveis ao desenvolvimento desta espécie, ou seja, mistura vertical profunda e uma coluna de água mais homogênea, com gradientes menores de temperatura entre a superfície e as camadas mais profundas. Próximo ao fim do registro observa-se um pequeno aumento da abundância relativa, sugerindo condições menos estáveis da coluna de água.

Globorotalia truncatulinoides (dextral)

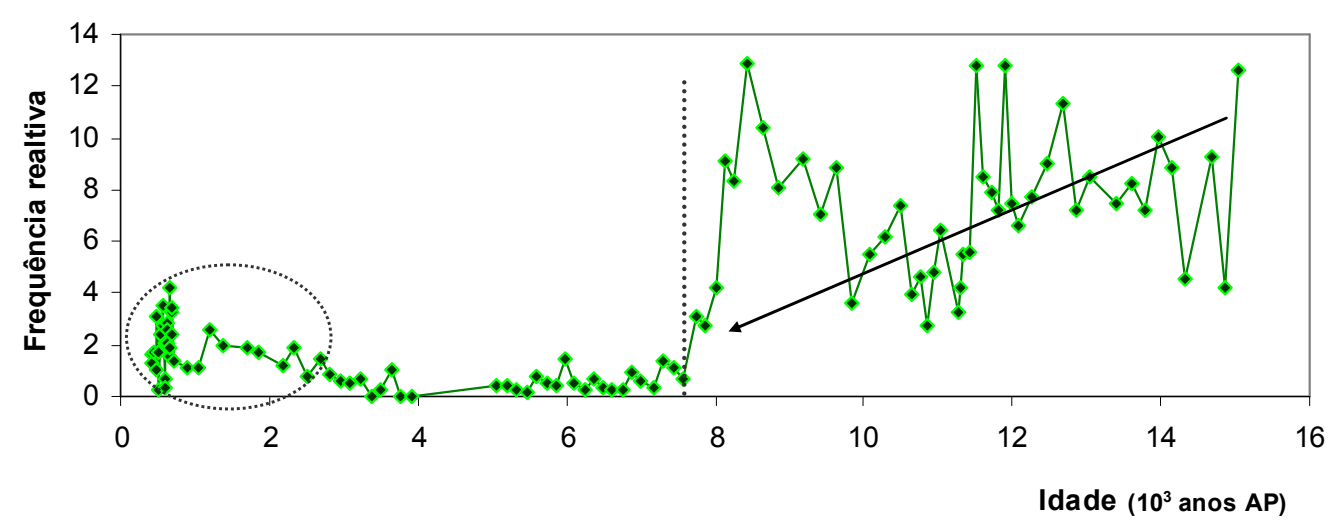

Figura 17: Abundância relativa da espécie G. truncatulinoides (dextral) 
G. ruber (white, figura 18 e pink, figura 19) é a espécie de água quente mais bem-sucedida em termos de distribuição e abundância, sendo a espécie mais prolífica em águas subtropicais e a segunda mais abundante, depois de G. sacculifer em águas tropicais. Essa espécie não ocorre em águas com temperaturas inferiores a $14^{\circ} \mathrm{C}$ e sua população diminui drasticamente quando transportada por correntes a ambientes transicionais. É a espécie que vive mais próxima à superfície, sendo pouco comum abaixo dos 50 metros de profundidade (Bé \& Tolderlund, 1971).

Bé (1977), Thunell \& Reynolds (1984), Guptha et al. (1994), Andreasen \& Ravelo (1997) e Martinez et al. (1998) associaram esse táxon, juntamente com G. sacculifer, a ambientes de águas superficiais quentes, com camada de mistura profunda, marcada por condições oligotróficas.

A espécie G. ruber apresenta-se em 2 morfotipos: pigmentada (pink) e sem pigmento (white). A primeira se extinguiu durante o início do Pleistoceno nos oceanos Índico e Pacífico, mas persistiu no Atlântico e no Mar Mediterrâneo (Thompson et al., 1979). Sua distribuição está relacionada a ambientes mais quentes e próximos dos trópicos (Hemleben, 1989).

No presente estudo G. ruber white foi mais abundante que a pink ao longo de todo o testemunho, exceto por volta de 700 anos A.P, quando observamos uma queda brusca do morfotipo white e um pico do morfotipo pigmentado ( $25 \%$ e $36 \%$, respectivamente).

Globigerinoides ruber (white)

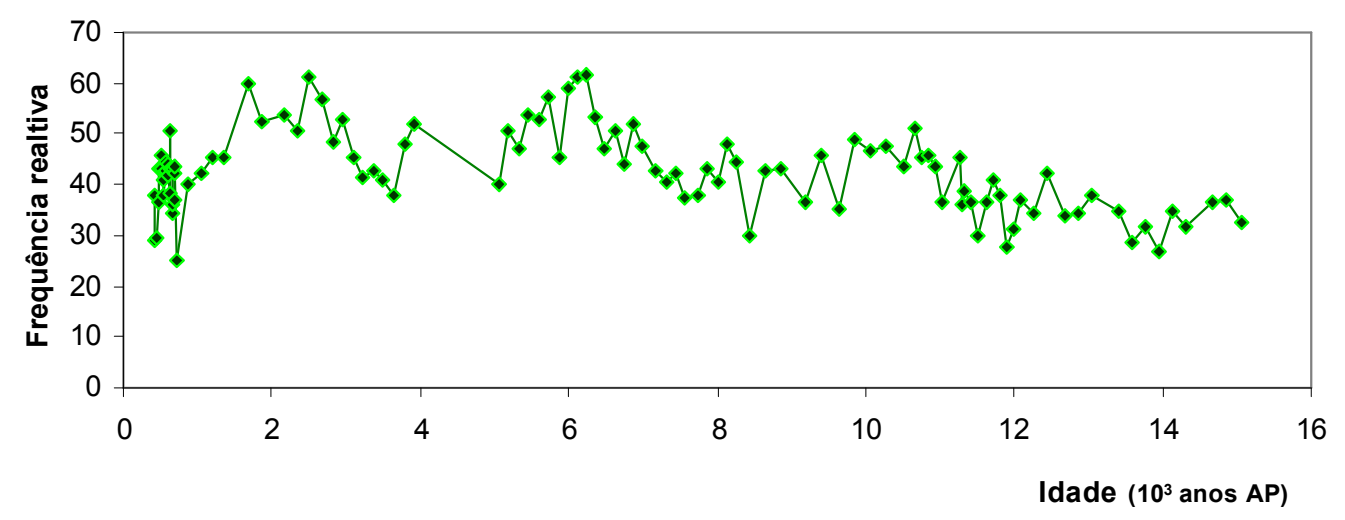

Figura 18: Abundância relativa da espécie G. ruber (white) 
Globigerinoides ruber (pink)

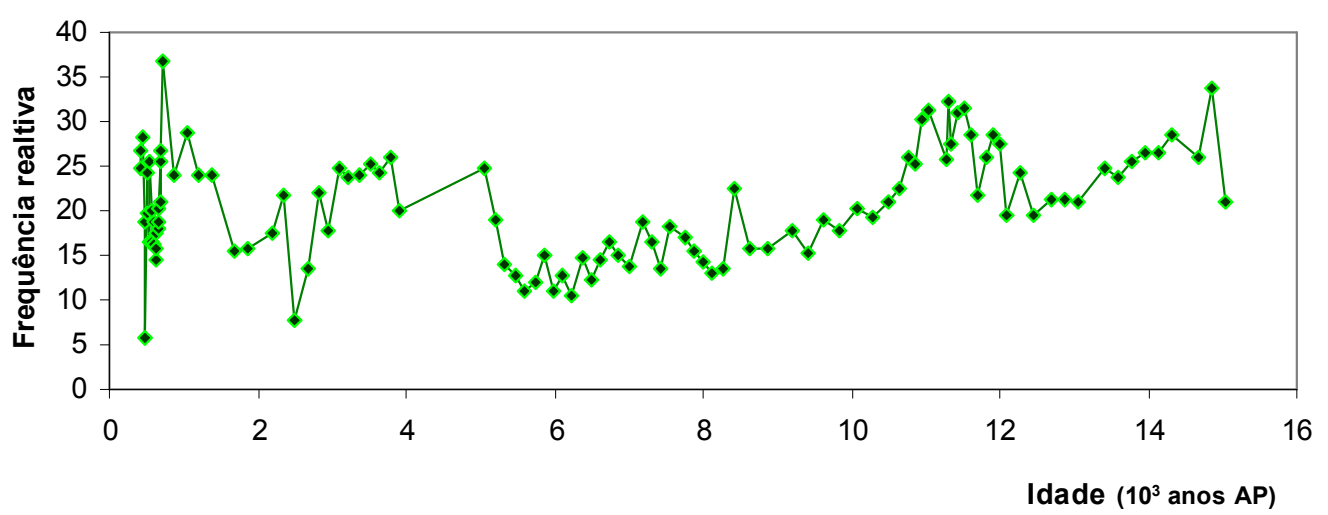

Figura 19: Abundância relativa da espécie G. ruber (pink)

Observando as curvas de freqüência relativa dessas espécies ao longo do testemunho (figuras 18 e 19) nota-se de maneira geral que as abundâncias relativas apresentaram um padrão de distribuição oposto, ou seja, quando há aumento do morfotipo pink, observa-se diminuição da freqüência relativa do morfotipo white e vice-versa. Deuser \& Ross (1989) e Hilbrecht (1996) observaram que esses dois morfotipos apresentam preferências ecológicas distintas e que o morfotipo pigmentado ocupa um nicho parcialmente desocupado pela white. Isso poderia explicar o comportamento praticamente inverso de abundância observado no presente estudo.

A espécie G. bulloides (figura 20) foi definida por Vincent \& Berger (1981) e Oberhansli et al. (1992) como um táxon oportunista e marcador de condições de alta fertilidade, tendo sua distribuição geográfica associada a regiões de ressurgência e áreas costeiras. Sua ocorrência é típica de ambientes transicional a polar, vivendo na coluna d'água acima dos 400 metros de profundidade, mas principalmente acima e dentro da termoclina. Ao contrário da maioria das espécies que contém espinhos em suas testas, essa espécie não apresenta algas simbiontes em sua estrutura, se alimentando principalmente do zooplâncton (Hemleben et al., 1989). 
Globigerinoides bulloides

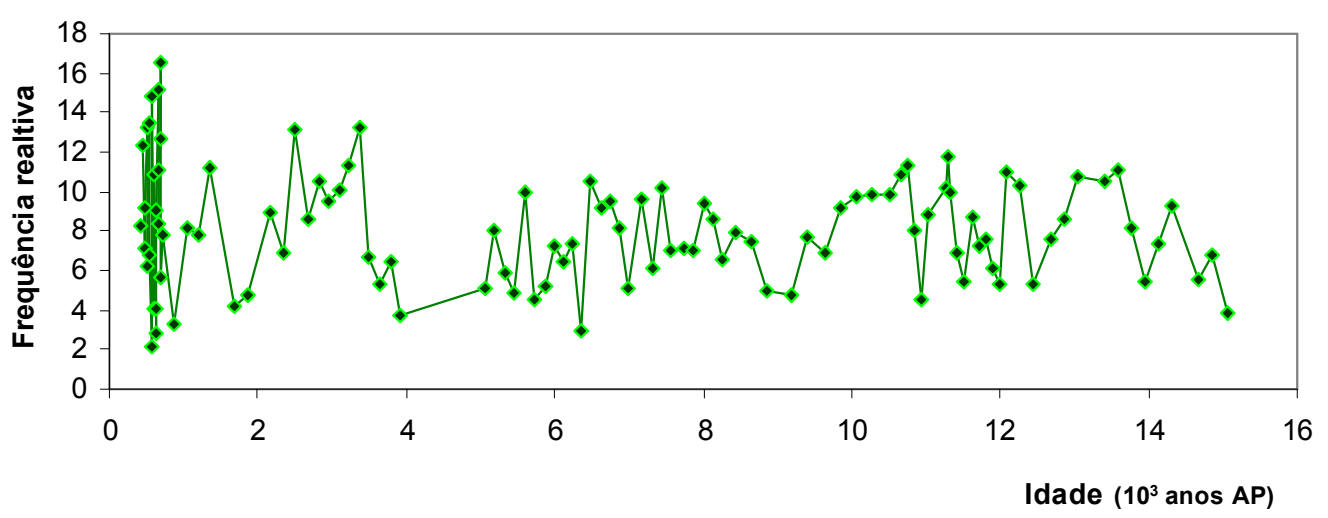

Figura 20: Abundância relativa da espécie G. bulloides

No presente estudo a espécie G. bulloides se apresentou como um componente importante da fauna, com uma média de abundância em torno de $8 \%$ e um pico em 700 anos A.P. de 16\%. Sua distribuição ao longo do tempo foi aproximadamente constante, não apresentando nenhuma tendência clara. Sorano (2006), estudando os foraminíferos planctônicos da margem continental sudeste brasileira, encontrou abundâncias expressivas dessa espécie entre 40 e 60 metros de profundidade e temperatura da água entre $22^{\circ}$ e $26^{\circ} \mathrm{C}$, concluindo que neste local ela não se apresenta como uma espécie típica de águas frias.

A espécie G. sacculifer (figuras 21 e 22) é tipicamente encontrada em altas abundâncias (mais de 20\%) em águas tropicais e subtropicais. Ela vive na camada fótica, apresenta simbiontes dinoflagelados e sua dieta é baseada principalmente em copépodes calanoides. Apresenta certa preferência por ambientes oligotróficos, bem oxigenados e com baixa salinidade. A sua última câmara apresenta variação na morfologia, podendo se desenvolver com formato de "saco" (Hemleben et al., 1989; Oberhansli et al., 1992; Kemle-von Mücke \& Hemleben, 1999). Estes dois morfotipos, porém não possuem diferenças ecológicas (Hemleben et al., 1987; Hilbrecht, 1996) e no intervalo amostrado tiveram padrões similares de variação de suas abundâncias relativas. 
Globigerinoides sacculifer (com saco)

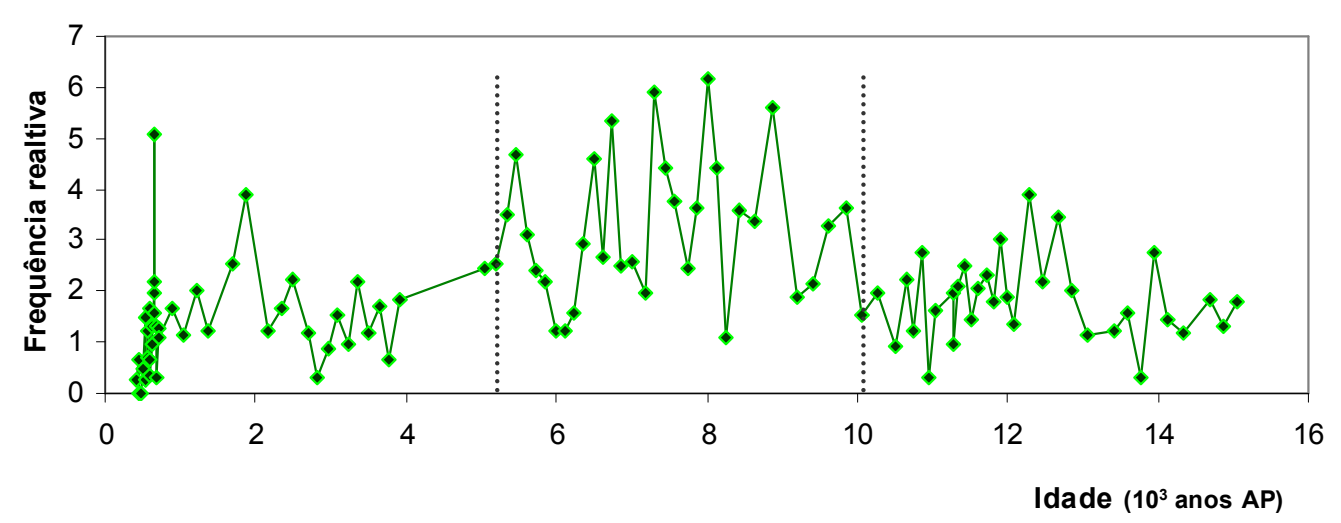

Figura 21: Abundância relativa da espécie G. sacculifer (com saco)

Globigerinoides sacculifer (sem saco)

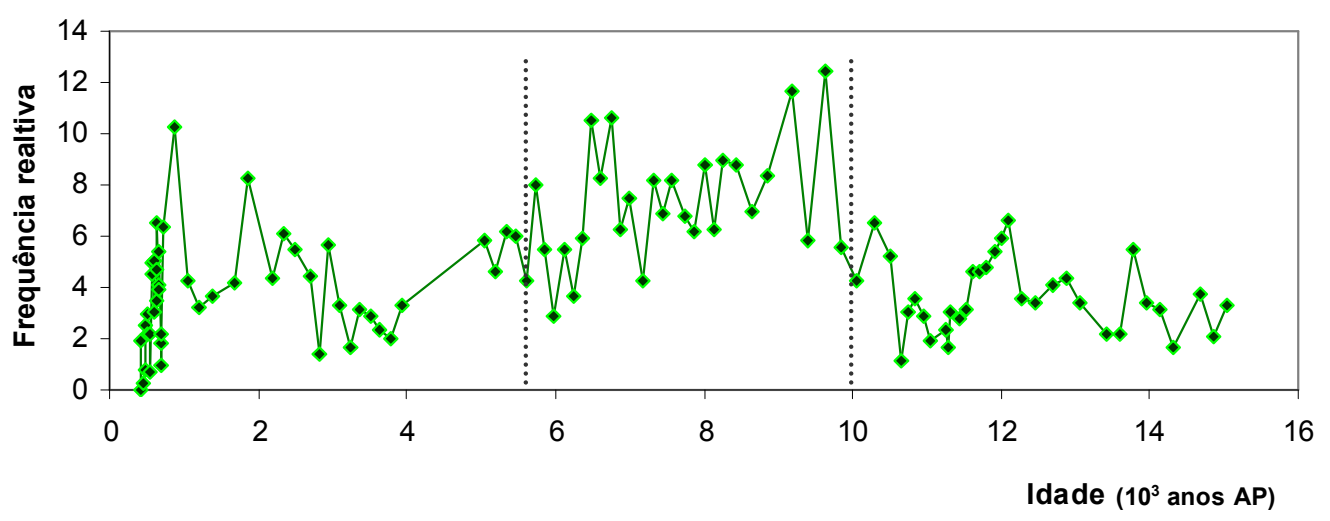

Figura 22: Abundância relativa da espécie G. sacculifer (sem saco)

Esta espécie constituiu um táxon importante da fauna, com médias de abundância em torno de $6,7 \%$. No presente estudo foram observados 3 intervalos principais de variações da abundância relativa: entre 15 e 10 mil anos A.P e a partir 6 mil anos A.P. até o final do registro, onde são evidenciadas, de uma maneira geral as menores freqüências relativas desta espécie; e aproximadamente entre 10 e 6 mil anos A.P., onde estão registradas as maiores abundâncias. No primeiro caso, poderíamos inferir condições de maior produção primária e menor estratificação da coluna de água, características essas do ambiente marinho que desfavorecem essa espécie. Contrariamente, entre 10 e 6 mil anos A.P. provavelmente as características eram de temperaturas superficiais marinhas mais altas, ambiente mais 
oligotrófico e coluna de água mais estratificada, condições ideais para a proliferação dessa espécie.

A espécie G. glutinata (figura 23) apresenta uma das maiores variedades de distribuição geográfica: está presente desde águas sub-árticas, passando por águas tropicais até o ambiente antártico. Porém, raramente é a espécie dominante e está presente em altas freqüências (entre 5 e 10\%) em águas centrais e transicionais do Atlântico sul. Observando as áreas de maior abundância e ocorrências mais comuns, Bé \& Tolderlund, (1971) classificaram esta espécie como subtropical, com distribuição cosmopolita. Hilbrecht (1996) e Kemle-von Mücke \& Hemleben (1999) encontraram as maiores abundâncias desta espécie próximas a ambientes de maior produtividade e associadas às zonas marginais de ressurgência no Atlântico norte, costa oeste da África e Oceano Índico. Toledo (2000) e Feldberg \& Mix (2002), porém classificaram esta espécie, juntamente com G. ruber e G. sacculifer como representantes da camada de mistura, relacionadas a águas mais quentes e oligotróficas das regiões subtropicais do Atlântico e Pacífico, respectivamente.

Globigerinita glutinata

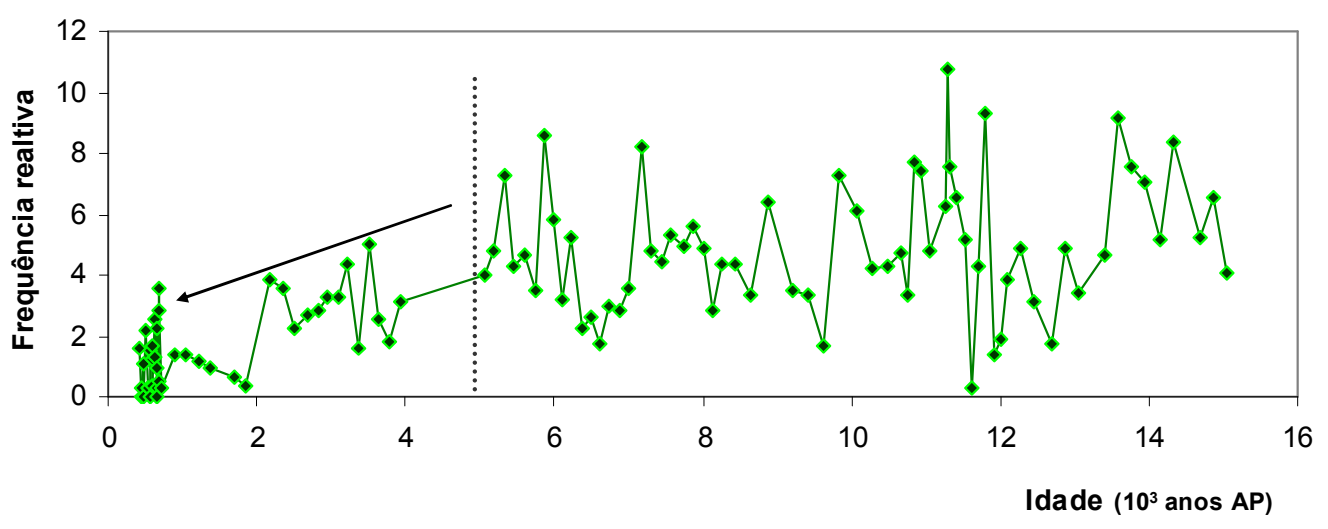

Figura 23: Abundância relativa da espécie G. glutinata

No presente estudo, esta espécie apresentou abundância média de $3,6 \%$ e, assim como G. sacculifer (figuras 21 e 22), diminuição de sua freqüência após 5 mil anos A.P. No restante do registro, nenhuma tendência clara foi observada. É possível que G. glutinata, por apresentar maior tolerância às variações de temperatura não tenha sido tão afetada pelas variações da 
mesma como outras espécies. A sua diminuição após 5 mil anos A.P. poderia estar associada à diminuição da espessura da camada de mistura, como conseqüência da instabilidade gerada por aumento da intensidade do regime de ventos ou aumento da densidade superficial.

Assim como a espécie G. glutinata, Orbulina universa (figura 24) também apresenta ampla distribuição geográfica (Hilbrecht, 1996), porém no oceano Atlântico parece estar restrita a ambientes de águas mais quentes e regiões de ressurgência próximo ao sistema de correntes de Angola e Benguela. Na porção oeste do Atlântico Sul, poucos espécimes foram observados em águas frias (Boltovskoy, 1962). No testemunho analisado, esta espécie obteve média de abundância de 2,5\% e um pico de 7\% em 6700 anos A.P. Observa-se de uma maneira geral, que sua freqüência aumentou ao longo do tempo, principalmente em torno de 10 mil anos A.P., possivelmente em resposta ao aumento gradual da temperatura.

\section{Orbulina universa}

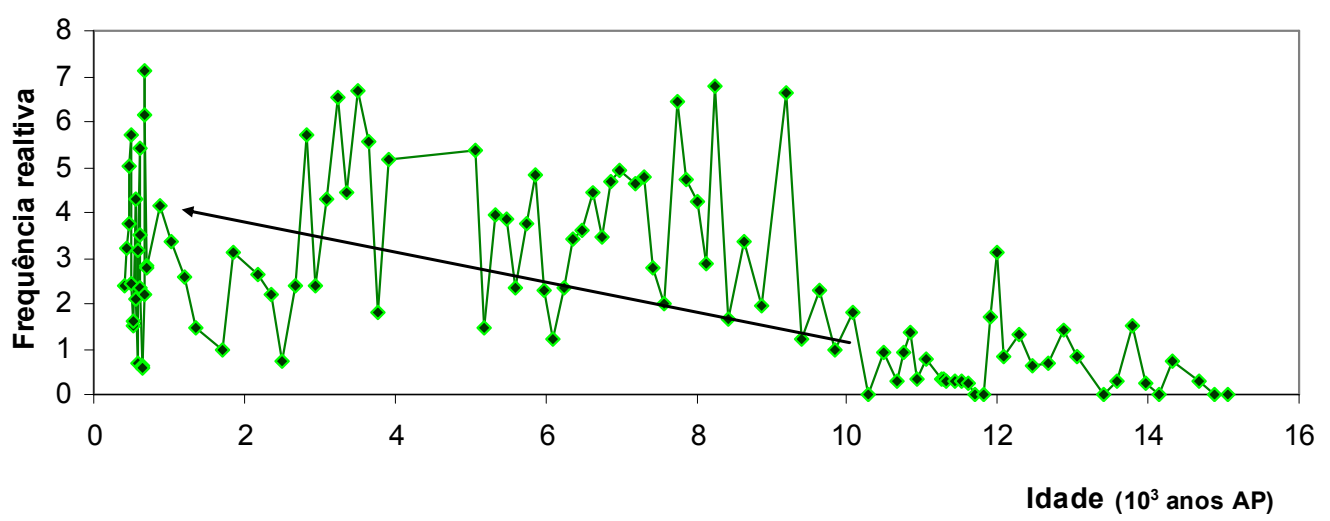

Figura 24: Abundância relativa da espécie Orbulina universa

A espécie G. conglobatus (figura 25) é tipicamente subtropical, sendo encontrada mais freqüentemente nas massas de água centrais dos oceanos Atlântico e Índico. Ela vive na zona fótica e possui o mesmo tipo de simbionte dinoflagelado encontrado nas espécies G. ruber, G. sacculifer e O. universa, porém pode descer a maiores profundidades na coluna de água antes da gametogênese, já que é a única espécie do gênero Globigerinoides a formar uma parede de calcita (Hemleben et al., 1989). Hilbrecht (1996) sugere ampla 
tolerância desta espécie aos parâmetros físicos analisados (temperatura, salinidade, densidade) e não apresenta preferência por uma estrutura vertical distinta da água ou estratificação durante sua migração vertical. No presente estudo, teve baixas freqüências (em torno de 1,5\%), com uma leve tendência de aumento ao longo do tempo.

Globigerinoides conglobatus

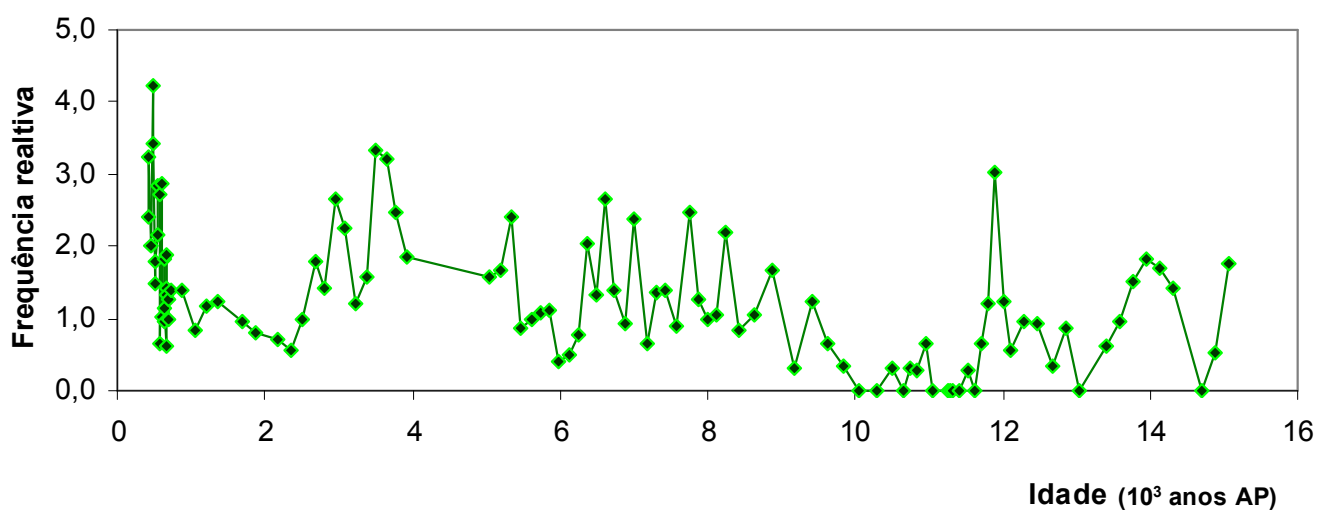

Figura 25: Abundância relativa da espécie G. conglobatus

As espécies que compõem o plexo Pulleniatina (figura 26) apresentam distribuição em ambientes tropical-subtropicais, provavelmente restritas a ambientes de temperaturas mais elevadas e com preferência a maiores profundidades na coluna de água. Jones (1967), estudando a distribuição dos foraminíferos planctônicos ao longo da Corrente Equatorial, concluiu que estas espécies são excelentes indicadoras dessa corrente, com preferências extremamente limitadas de temperatura, profundidade e salinidade. Nesses locais, apresentaram abundância relativa de $4 \%$. Na porção sul do oceano Atlântico elas são extremamente raras (<0,1\%). Ravelo et al., (1990) e Martinez et al., (1998) associaram as espécies desse a gênero a ambientes de águas mais quentes, com uma termoclina sub-superficial, onde a concentração de clorofila e a produtividade primária são máximas.

As espécies do plexo Pulleniatina apresentaram a menor abundância relativa entre todas as espécies $(0,9 \%)$ e não mostrou nenhum padrão claro de tendência ao longo do testemunho. Foi observado um pico de 4,6\% em aproximadamente 14,6 mil anos A.P. e maiores abundâncias próximas ao topo 
do testemunho. Esses dois intervalos poderiam ser associados a condições de termoclina mais rasa e maior produtividade próximo à superfície, que favoreceria a proliferação dessas espécies.

Juntamente com as espécies G. menardii menardii e G. menardii tumida, as espécies que compõem o gênero Pulleniatina são consideradas umas das espécies de foraminíferos planctônicos mais resistentes à dissolução (Berger, 1968). Dessa forma, poderíamos especular que os dois períodos de maior abundância desse gênero são conseqüência de uma dissolução seletiva. Entretanto, essa possibilidade pode ser descartada (ver discussão no item 6.4), pois aparentemente, a dissolução seletiva teve um papel insignificante na composição das espécies desse testemunho.

Plexo Pulleniatina

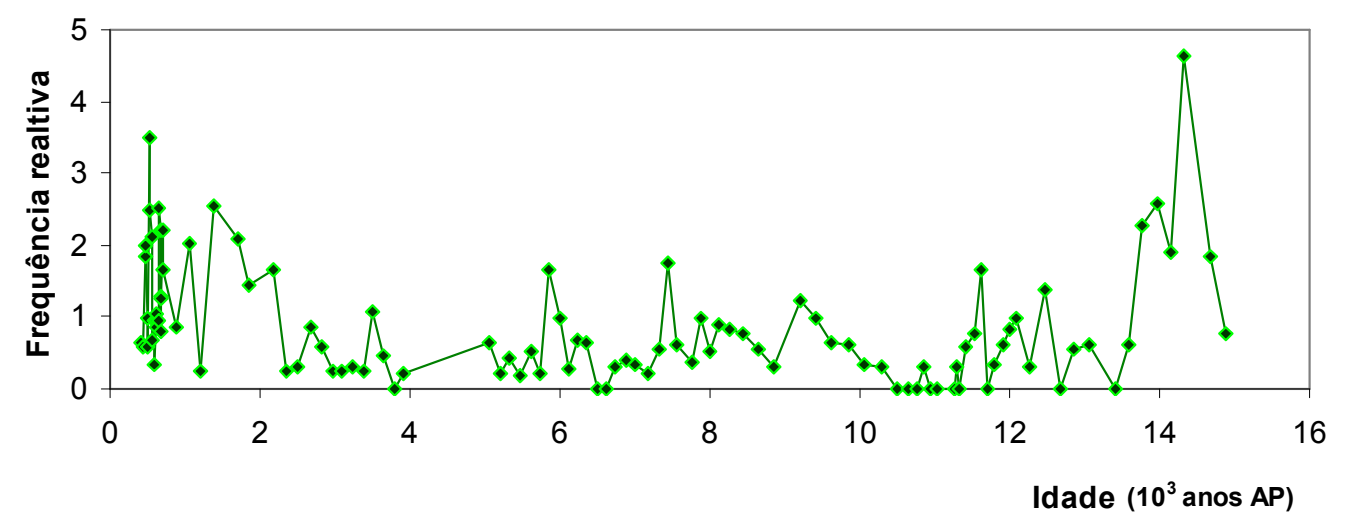

Figura 26: Abundância relativa da espécie Pulleniatina obliquiloculata

\subsection{Foraminíferos bentônicos}

A freqüência relativa de foraminíferos bentônicos (razão $P / B$ ) (figura 27) foi calculada dividindo-se o número de exemplares bentônicos pelo número total de foraminíferos (planctônicos + bentônicos), para cada amostra. 
Foraminíferos bentônicos

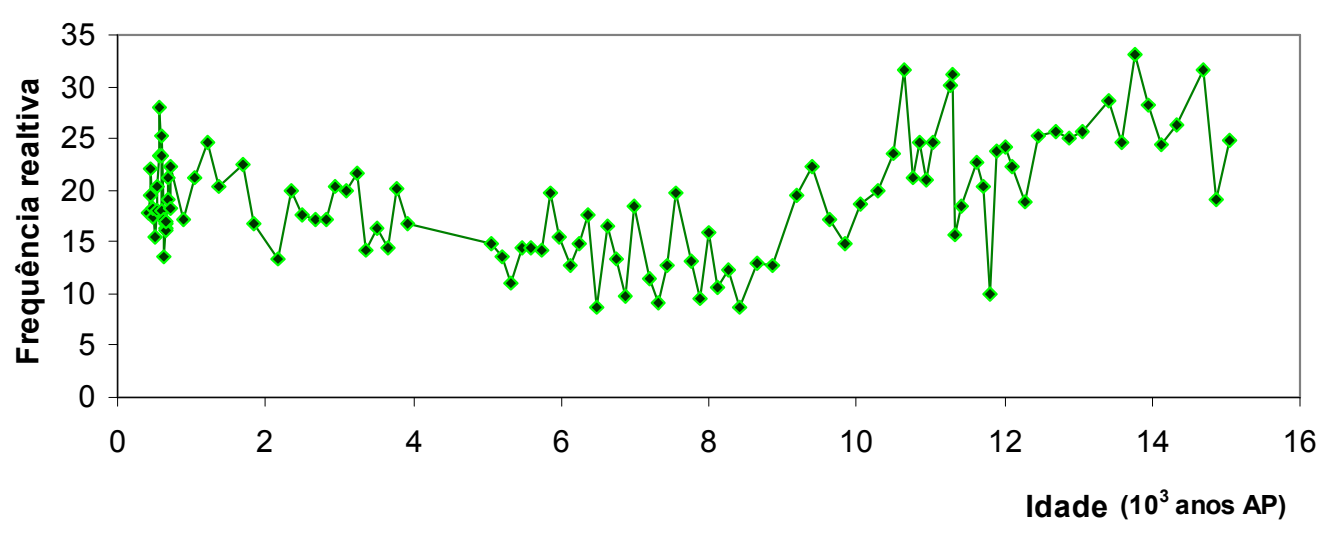

Figura 27: Abundância relativa de foraminíferos bentônicos

O aumento da biomassa da comunidade bentônica pode ser considerado uma resposta ao aumento do fluxo de matéria orgânica vindo da zona eufótica. A profundidade, refletida através das variações de pressão, temperatura, é considerada um fator secundário (Lutze \& Coulbourn, 1983/84). Os organismos "menores" (bactérias e protozoários) são ótimos indicadores de produtividade, pois respondem ao aumento de fluxo de matéria orgânica tanto em áreas oceânicas oligotróficas como em ambientes de margens continentais, considerados mais eutróficos (Gooday, 2002). Por este motivo, é possível considerar a abundância relativa de foraminíferos bentônicos como indicadora de paleoprodutividade.

Os foraminíferos planctônicos são organismos de oceano aberto e estão ausentes ou encontram-se pouco representados em águas costeiras e de plataforma. De um modo geral, a relação entre planctônicos e bentônicos também é reflexo do grau de influência do habitat oceânico versus marinho no momento da deposição (Hemleben et al., 1989). Por este motivo, a relação também é utilizada como indicador de paleoprofundidade.

A curva da abundância relativa dos foraminíferos bentônicos mostra que os maiores valores estão representados antes de 8 mil anos A.P., com valor máximo entre 13 e 14 mil anos A.P. Em seguida, observa-se um período com os menores valores (entre 8 e 5 mil anos A.P.), para posteriormente haver um aumento na abundância relativa até o recente. Este comportamento sugere 
que a produtividade foi maior durante a deglaciação e início do Holoceno e nos últimos 5 mil anos A.P.

\subsection{Fragmentação}

A dissolução do carbonato no sedimento altera a composição original das assembléias de foraminíferos pela remoção seletiva das espécies mais suscetíveis a este processo. Isso influencia parcialmente as interpretações paleoambientais baseadas nas variações das abundâncias relativas das espécies (Morey et al., 2005).

Analisando a relação entre o grau de dissolução de assembléias atuais de foraminíferos e a profundidade, notou-se a presença de uma zona onde a dissolução aumentava significativamente. Esta zona é conhecida como lisoclina (Berger, 1968). Abaixo deste limite, os sedimentos carbonáticos sofrem expressiva corrosão com a profundidade. A posição atual da lisoclina (referente aos foraminíferos) no Atlântico Sul varia entre 4 e $4.5 \mathrm{~km}$ e se encontra próximo à isoterma de temperatura potencial de $2^{\circ} \mathrm{C}$ (Melguen \& Thiede, 1974). Sedimentos carbonáticos acumulados em profundidades muito mais rasas do que a lisoclina também estão sujeitos à dissolução (Berger, 1968; Swanson \& van der Lingen, 1997; de Villiers, 2005).

Diversos autores têm sugerido que o Índice de Fragmentação (IF) é um indicador confiável do grau de dissolução de uma assembléia de foraminíferos (e.g. Thunell, 1976; Le \& Shackleton, 1992; Le et al., 1995).

A curva da abundância de fragmentos (figura 28) (Thunell, 1976; Le \& Thunell, 1996) foi obtida através da equação:

$$
\text { IF }=100 * \mathrm{~F} /(\mathrm{F}+\mathrm{P})
$$

Onde IF é o índice de fragmentação; F é o número de fragmentos de foraminíferos planctônicos na amostra; e $P$ é o número total de foraminíferos planctônicos bem preservados na amostra. 


\section{Fragmentos}

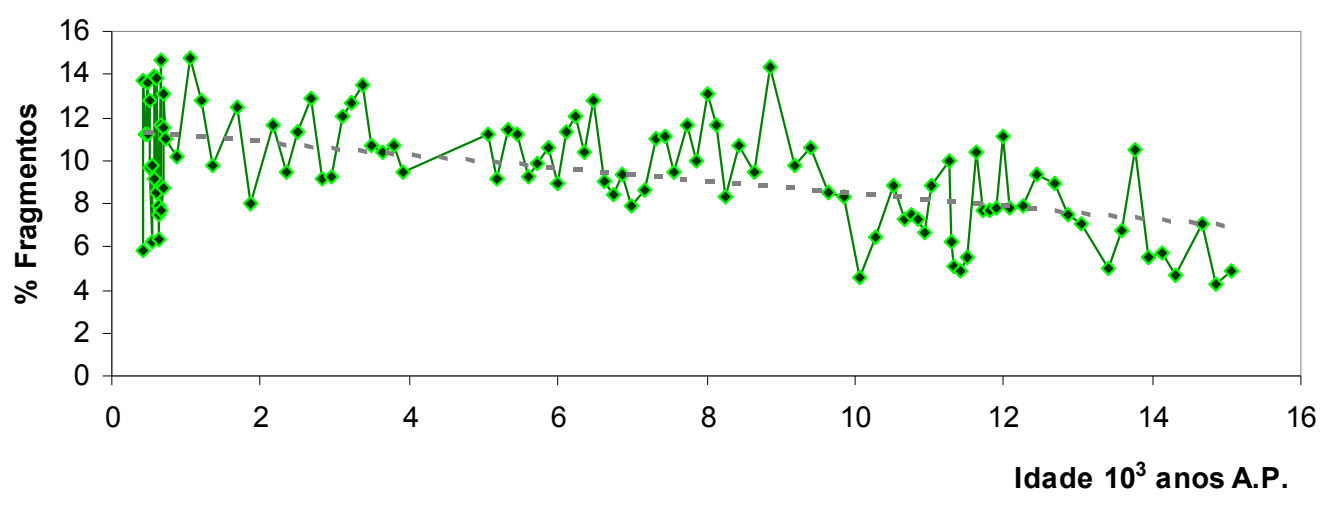

Figura 28: Abundância relativa de fragmentos

A linha de tendência mostra um aumento da abundância de fragmentos em direção ao recente. A média contabilizada para o testemunho foi de $9,5 \%$, com picos no final do registro de $15 \%$.

A diminuição da preservação do carbonato (maior dissolução) pode ser o resultado do aumento da produtividade superficial, que gera maior fluxo de matéria orgânica para o sedimento. Isso levaria a um aumento do $\mathrm{CO}_{2} \mathrm{com}$ a oxidação do carbono orgânico, resultando em maior acidificação do meio e conseqüente dissolução (Emerson \& Bender, 1981). Assim, sugere-se aumento da produtividade ao longo do Holoceno.

Segundo o estudo de dissolução de foraminíferos planctônicos de Berger (1968), G. ruber e G. sacculifer são as espécies mais frágeis e suscetíveis à dissolução. Para verificar se no testemunho KF-02 essas espécies foram atingidas pela dissolução seletiva, efetuou-se um teste simples de correlação entre essas variáveis (figura 29). Os baixos coeficientes de correlação obtidos para as espécies G. ruber e G. sacculifer $\left(r^{2}=0,001\right.$ e 0,1, respectivamente) mostram a baixa influência do Índice de fragmentação sobre a variação de abundância dessas espécies. Aparentemente, a dissolução seletiva tem um papel insignificante na composição das espécies desse testemunho. Conclui-se então que as variações das assembléias refletem primariamente as mudanças das condições das águas superficiais durante o intervalo estudado. 

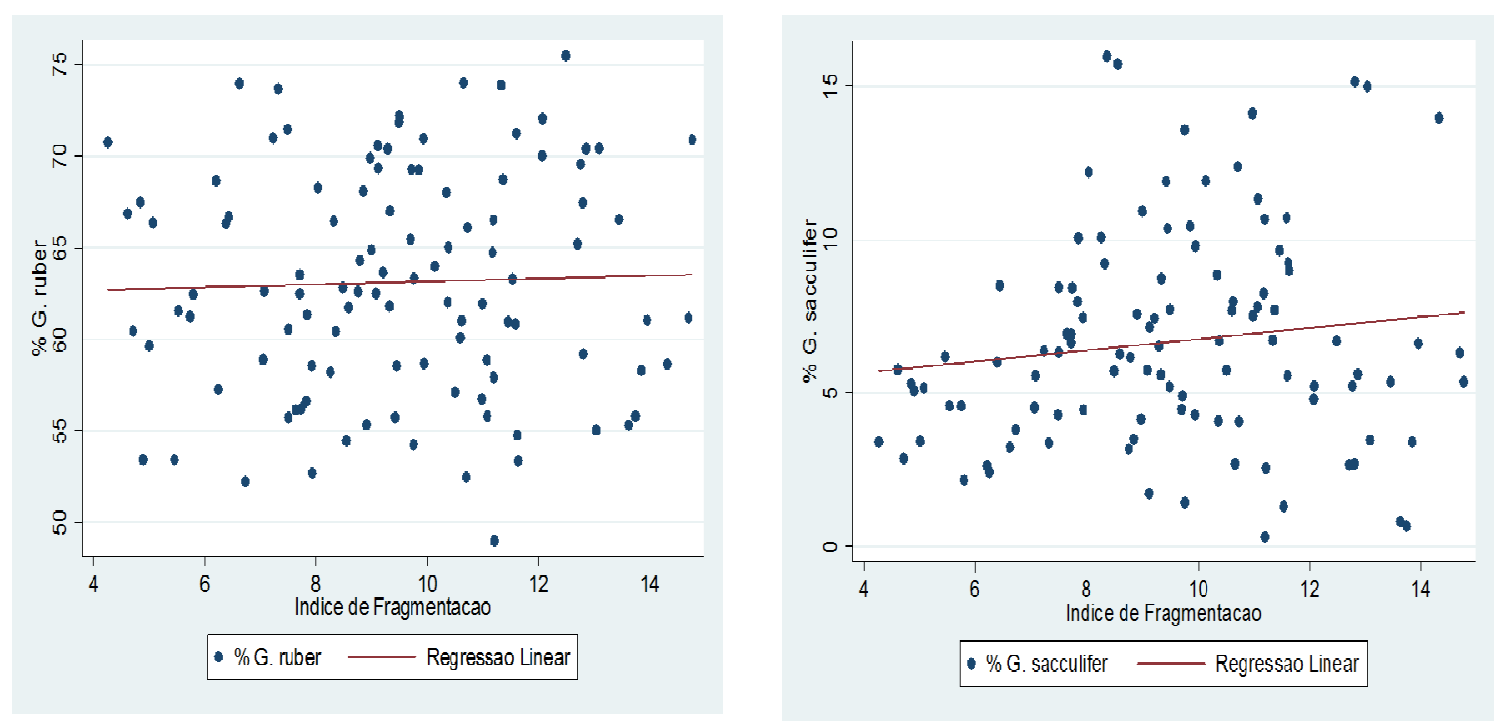

Figura 29: Gráfico de dispersão com regressão linear da abundância relativa de G. ruber (white+pink) e G. sacculifer (com saco e sem saco) e índice de fragmentação.

\subsection{Biozoneamento}

O biozoneamento apresentado neste estudo (figura 30 ) segue o esquema básico proposto por Ericson \& Wollin (1968), complementado pelos biozoneamentos sugeridos por Vicalvi (1997) e Kowsmann \& Vicalvi (2003).

Com base nas variações de freqüência do plexo G. menardii, e o desaparecimento/reaparecimento do plexo Pulleniatina, Vicalvi (1997) subdividiu a zona $Y$ (Pleistoceno) e $Z$ (Holoceno) de Ericson \& Wollin (1968) em 4 subzonas ( $Y 2$, $\mathrm{Y} 1, \mathrm{Z} 2$ e Z1).

Kowsmann \& Vicalvi, (2003) subdividiram a Subzona Y1 em duas, Y1B e Y1A, baseado no último aparecimento do plexo Pulleniatina em torno de 15 mil anos A.P. (Bé et al., 1976).

Segundo Vicalvi (1997), a abundância relativa no início do Holoceno (Z2) seria menor que na subzona Z1, refletindo o progressivo aquecimento do Atlântico após o Máximo Glacial. Para o presente trabalho, foi observado um aumento desse plexo em direção ao topo do testemunho e o limite dessas subzonas foi marcado à profundidade de $70 \mathrm{~cm}$. A subzona Z2 está caracterizada com porcentagens média do plexo G. menardii de $7,5 \%$, enquanto a zubzona Z1 apresenta maior média da abundância relativa (16,4\%). 
$\%$ Plexo G. menardii

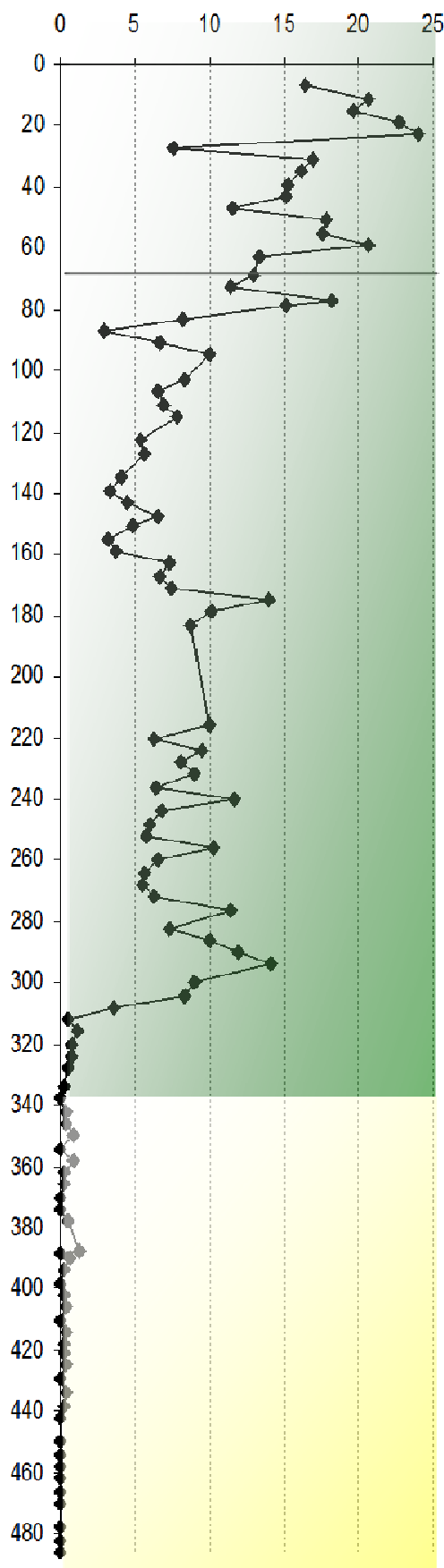

$\%$ Pulleniatina obliquiloculata

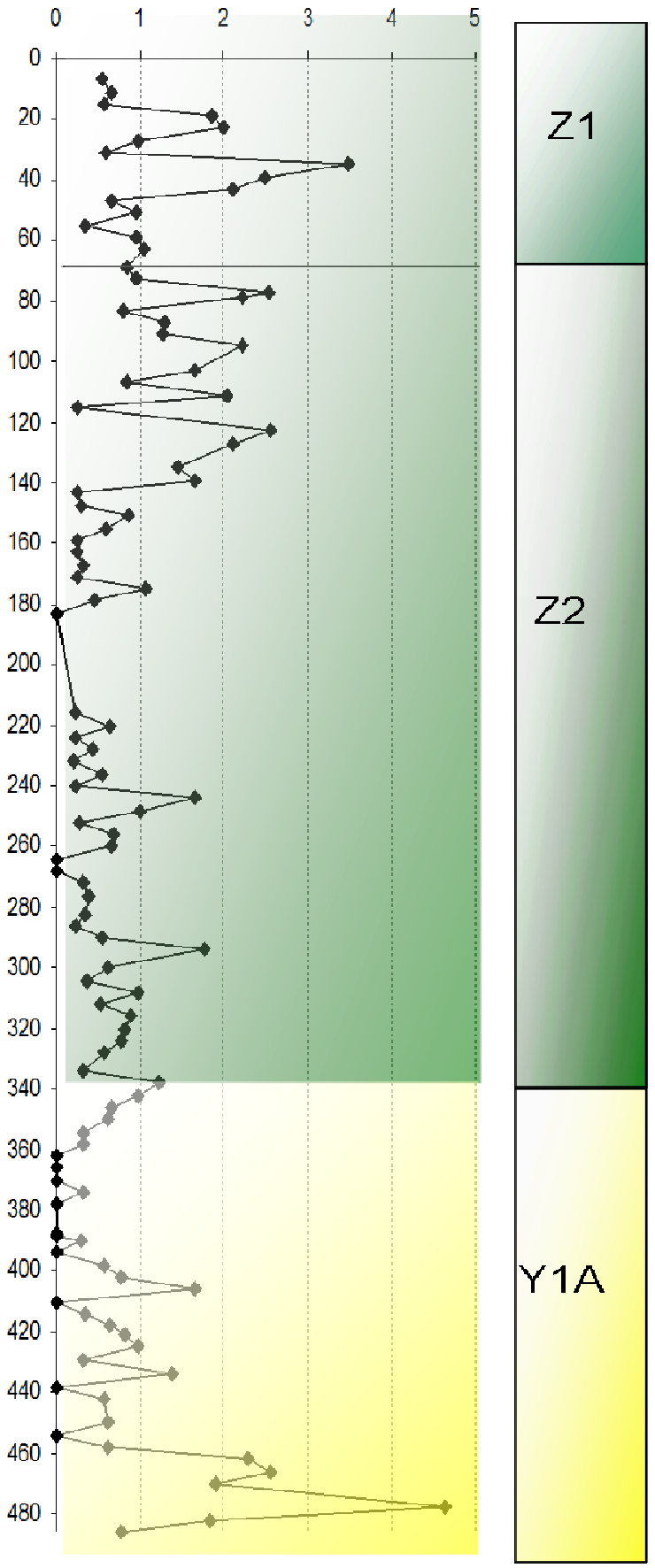

Figura 30: Biozoneamento proposto por Ericson \& Wollin (1968), com base na curva de abundância relativa do plexo Globorotalia menardii e no plexo Pulleniatina. 


\subsection{Isótopos de oxigênio}

Na figura 31, apresentam-se os resultados da análise isotópica realizadas nas testas da espécie Globigerinoides ruber (white) ao longo de todo o testemunho.

$$
\delta^{18} \mathrm{O}(\% \text { PDB) }
$$

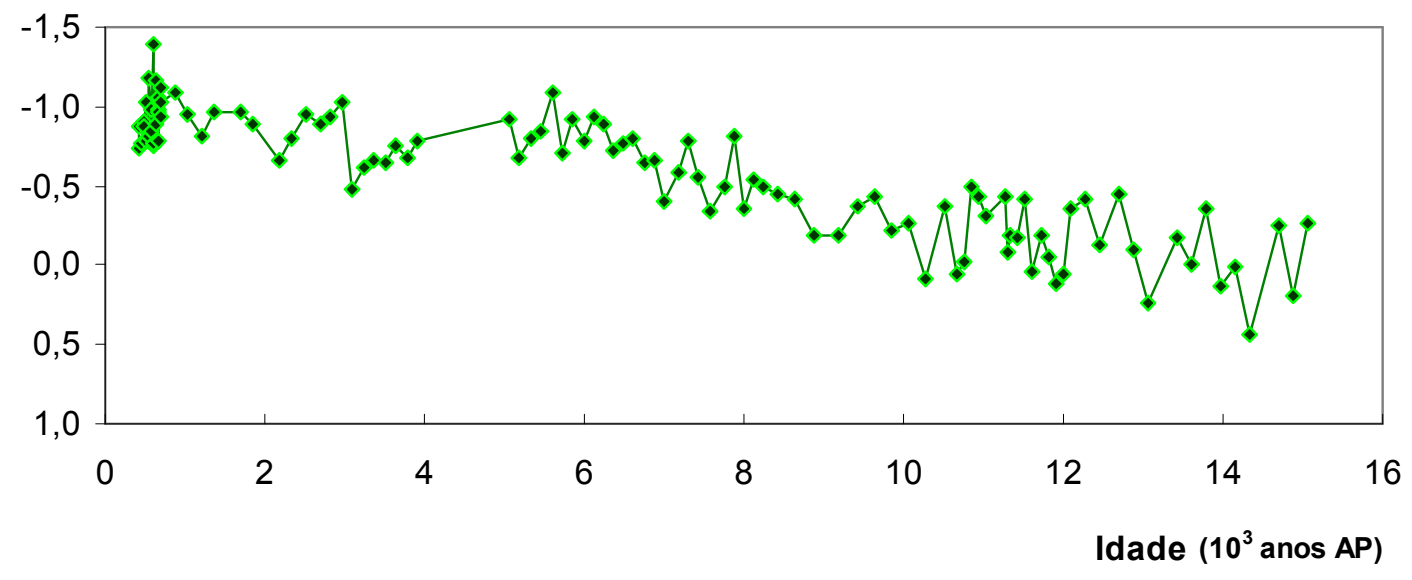

Figura 31: Resultados da análise da composição isotópica das testas da espécie Globigerinoides ruber (white). A escala de $\delta^{18} \mathrm{O}$ está invertida, de acordo com o convencionado em estudos paleoceanográficos

O sinal isotópico constitui fundamentalmente uma combinação dos efeitos de variações isotópicas da água do mar e da temperatura superficial.

Observando a curva, nota-se progressiva diminuição dos valores de $\delta^{18} \mathrm{O}$ em direção ao período recente, indicando um aquecimento das águas superficiais. Nota-se um ponto de valor mínimo do $\delta^{18} \mathrm{O}$ em aproximadamente 594 anos A.P. (A.D. 1350).

\subsection{Análises Multivariadas}

\subsubsection{Análise de Agrupamentos}

A Análise de Agrupamentos foi utilizada para explorar e quantificar as similidaridades entre as espécies de foraminíferos planctônicos encontradas ao longo do testemunho. Para a análise em modo- $\mathrm{R}$ aplicou-se o Método de 
Ward, que utiliza a análise das variâncias para determinar as distâncias entre os agrupamentos, como método de agregação. Complementarmente às medidas de distância, a medida de similaridade (coeficiente de Pearson) também foi utilizada na construção do dendograma. A escolha por esse método e coeficiente de similaridade se deve ao fato da sua vasta utilização na literatura (eg, Rohlinhg et al, 1993; Triantaphyllou, 2009) e por ter apresentado também os melhores resultados, ou seja, agrupamentos melhores definidos na fase de teste.

A análise revelou 2 grupos principais, $A$ (subgrupo $A 1$ e $A 2$ ) e $B$ (subgrupos B1 e B2) (figura 32). No grupo A tem- se as espécies G. menardi, G. conglobatus, Orbulina universa, Pulleniatina obliquiloculata, G. bulloides, G. ruber (white), G. sacculifer (com saco), G. sacculifer (sem saco). O grupo B está representado pelas espécies G. ruber (pink), G. glutinata, G. truncatulinoides, N. dutertrei, e G. inflata.

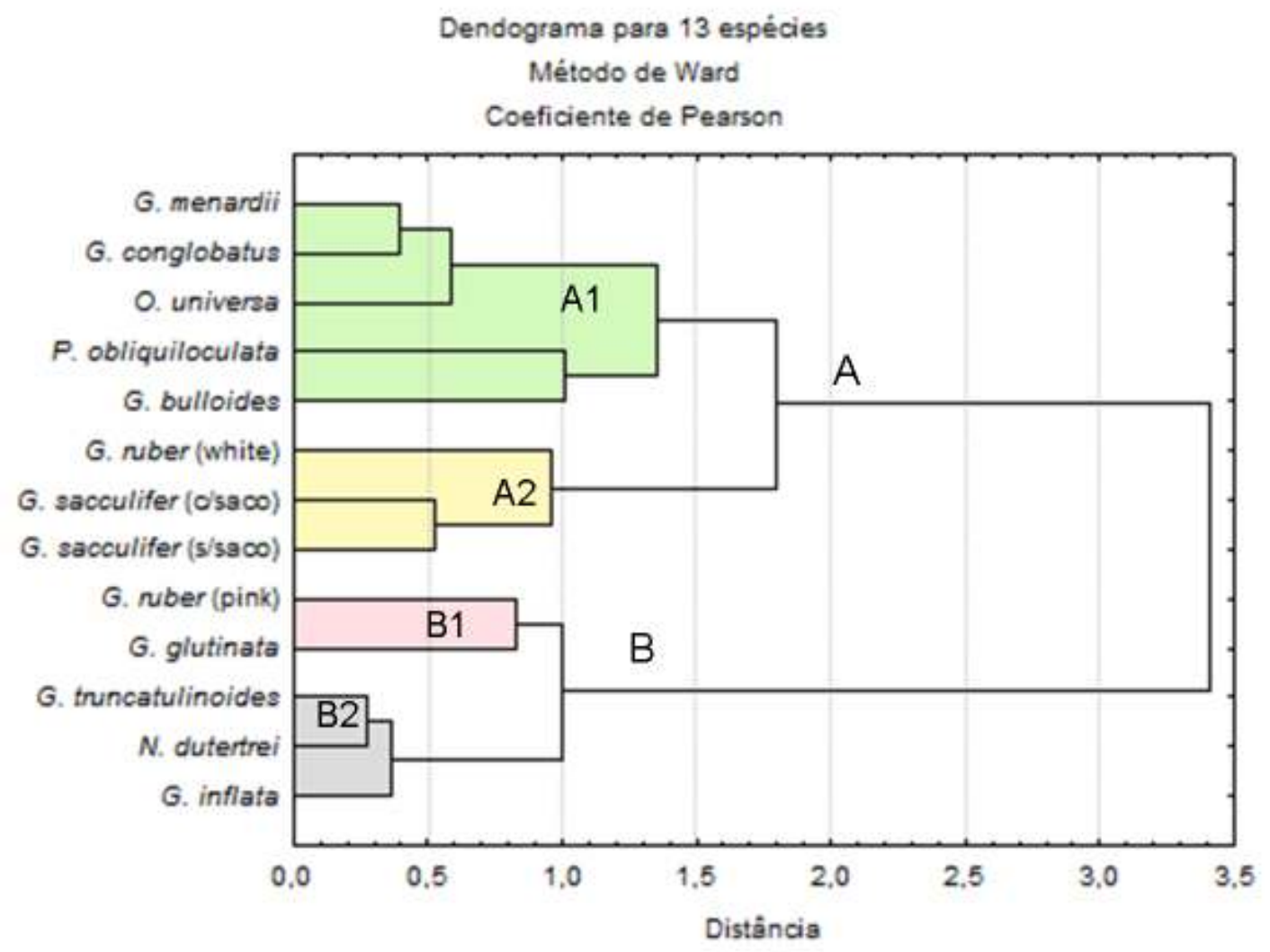

Figura 32: Dendograma da análise de agrupamentos modo- R, pelo método de Ward do KF- 02, com os 3 principais grupos identificados 
O subgrupo A1 (plexo G. menardi, G. conglobatus, Orbulina universa, Pulleniatina obliquiloculata e $G$. bulloides) apresenta as espécies que habitam águas tropicais e subtropicais e apresentam maior preferência a ambientes mais quentes e habitam camadas mais profundas da coluna de água, conforme apresentado no item 6.2.

O subgrupo A2 (G. ruber white, G. sacculifer com saco e sem saco) também agrupou espécies típicas de ambientes mais quentes, porém que estão associadas à porção mais superficial da camada de mistura.

O subgrupo B1 (G. ruber pink e G. glutinata) agrupou espécies que mostraram uma leve diminuição de sua abundância em direção ao topo do testemunho.

O subgrupo B2 (G. truncatulinoides, N. dutertrei, e G. inflata) é formado pela assembléia de foraminíferos planctônicos com preferências a menores temperaturas e cuja distribuição geográfica está mais restrita a regiões temperadas e até subpolares. Todas essas espécies apresentaram diminuição de sua abundância em direção ao recente.

\subsubsection{Análise de Componentes Principais}

A Análise de Componentes Principais foi aplicada aos dados de abundância das associações de foraminíferos com o objetivo de se obter a curva paleoclimática para o testemunho analisado. A curva paleoclimática é um indicativo da temperatura superficial marinha (TSS) e é baseada na assembléia de foraminíferos planctônicos representantes de águas mais quentes e frias, respectivamente. Os diversos estudos que utilizam esse índice de temperatura costumam recorrer à literatura para a escolha das espécies a serem utilizadas (Rögl \& Bolli, 1973; Thunell et al., 1977; Capotondi \& Vigliotti, 1999). Esses autores dispõem de uma vasta coleção de estudos locais sobre a ecologia de foraminíferos planctônicos. Para a região específica do presente trabalho, porém, poucos são os estudos disponíveis. Dessa forma, se fez uso da ACP

para a escolha das espécies mais apropriadas, evitando qualquer manipulação subjetiva dos dados. 
A Análise de Componentes Principais gerou 4 componentes (tabela 2), considerando apenas os autovalores maiores que 1,0. Esses 4 componentes são suficientes para explicar $68,4 \%$ da variância total dos dados.

Tabela 2: Autovalores e porcentagens das variâncias explicadas por cada uma das componentes separadamente e a porcentagem cumulativa

\begin{tabular}{|c|c|c|c|}
\hline CP & Autovalor & $\begin{array}{c}\text { Variância } \\
(\%)\end{array}$ & $\begin{array}{c}\text { Variância } \\
\text { Total } \\
\text { Acumulada } \\
(\%)\end{array}$ \\
\hline 1 & 4,092813 & 31,48317 & 31,4832 \\
2 & 2,260996 & 17,39228 & 48,8755 \\
3 & 1,362182 & 10,47832 & 59,3538 \\
4 & 1,170983 & 9,00756 & 68,3613 \\
\hline
\end{tabular}

A matriz de escores (tabela 3) e o histograma gerado a partir desses valores (figura 33) revelam quanto cada espécie contribuiu proporcionalmente em cada um dos componentes principais. Pode-se observar que as espécies G. menardii, O. universa (com cargas positivas), G. truncatulinoides, G. inflata e $N$. dutertrei (com cargas negativas) apresentam as maiores contribuições ao Componente Principal (CP)1. Dessa forma, esse componente pode ser relacionado claramente com a temperatura das águas superficiais marinhas.

Já o CP 2 é dominado pelas espécies $G$. sacculifer (com saco e sem saco) e G. ruber. Essas espécies são encontradas em maior abundância na porção mais superior da camada de mistura onde há uma zona eufótica bem estratificada, relativamente oligotrófica e presença de uma termoclina mais profunda (Rohling et al, 1993, Watkins et al., 1996). Ravelo et al. (1990) e Toledo (2000) encontraram esse mesmo grupo de espécies e mais G. glutinata (que no presente estudo mostrou também um valor relativamente alto de escore, 0,4$)$ classificando as assembléias de foraminíferos planctônicos por análise fatorial nas regiões tropical e subtropical, respectivamente. Dessa forma, O CP 2 pode ser interpretado como "camada de mistura". Os valores 
maiores indicam maior estabilidade da coluna de água, mostrando maior estratificação da mesma, com uma termoclina profunda.

Os outros componentes principais gerados não foram utilizados neste estudo por apresentarem valores de variância bem mais baixos que os dois primeiros, sendo estes considerados suficientes para explicar as variações das associações de foraminíferos planctônicos.

A figura 34 mostra a projeção das 2 primeiras componentes principais e as espécies de foraminíferos planctônicos associadas. A componente 1, representando a variação de temperatura $(31,48 \%$ de variância) está positivamente associada ao plexo G. menardii $(0,76)$ e Orbulina universa $(0,66)$, principalmente. Aos valores negativos da componente 1, observamos associadas as espécies $G$. truncatulinoides $(-0,83), G$. inflata $(-0,83)$ e $N$. dutertrei $(-0,75)$. A componente 2 , associada à camada de mistura $(17.39 \%$ de variância) tem associada positivamente as espécies G. sacculifer (com saco, 0,69 e sem saco, 0,67) e G. ruber (white). As espécies G. conglobatus e pertencentes aos plexos G. menardii e Pulleniatina vivem em camadas mais profundas da coluna de água (próximas ou na termoclina), sendo associadas negativamente a essa componente. As outras espécies mostraram valores menos expressivos com relação às componentes.

Tabela 3: Resultado da análise de Componentes Principais modo- $\mathrm{R}$

\begin{tabular}{|l|c|c|}
\hline Espécies & Comp. 1 & Comp. 2 \\
\hline Plexo G. menardii & 0,761836 & $-0,42354$ \\
G. ruber (white) & 0,53659 & 0,5136 \\
G. ruber (pink) & $-0,55512$ & $-0,54285$ \\
G. sacculifer (c/saco) & $-0,00063$ & 0,692224 \\
G. sacculifer (s/saco) & 0,095219 & 0,670078 \\
G. conglobatus & 0,543058 & $-0,43018$ \\
G. truncatulinoides & $-0,8333$ & 0,034941 \\
O. universa & 0,666576 & 0,017371 \\
G. glutinata & $-0,47196$ & 0,406005 \\
G. inflata & $-0,82951$ & $-0,11075$ \\
N. dutertrei & $-0,7501$ & $-0,05283$ \\
P. obliquiloculata & 0,011494 & $-0,4336$ \\
G. bulloides & 0,006905 & $-0,2012$ \\
\hline
\end{tabular}



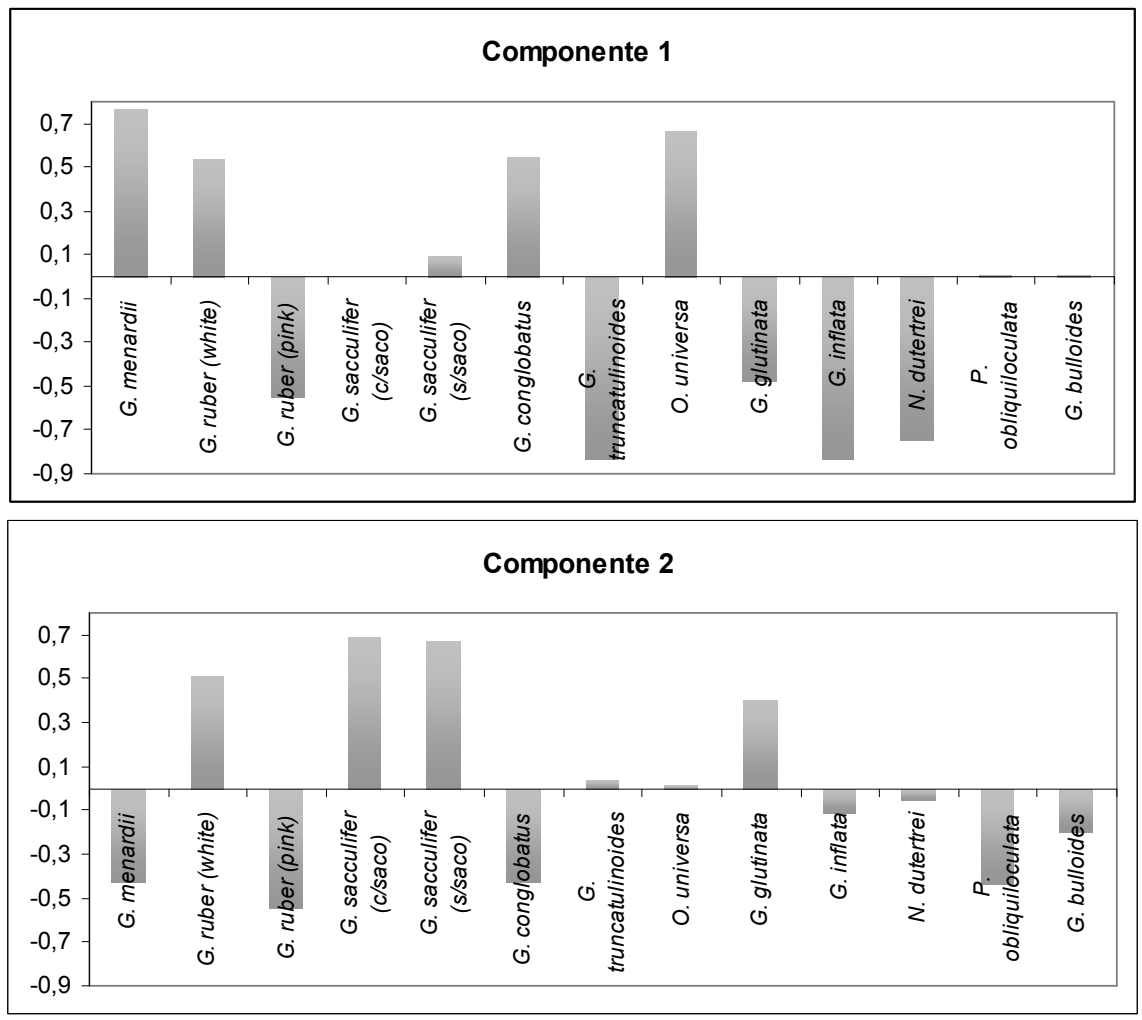

Figura 33: Histograma demonstrando a contribuição das espécies de foraminíferos planctônicos para as componentes principais 1 e 2 .

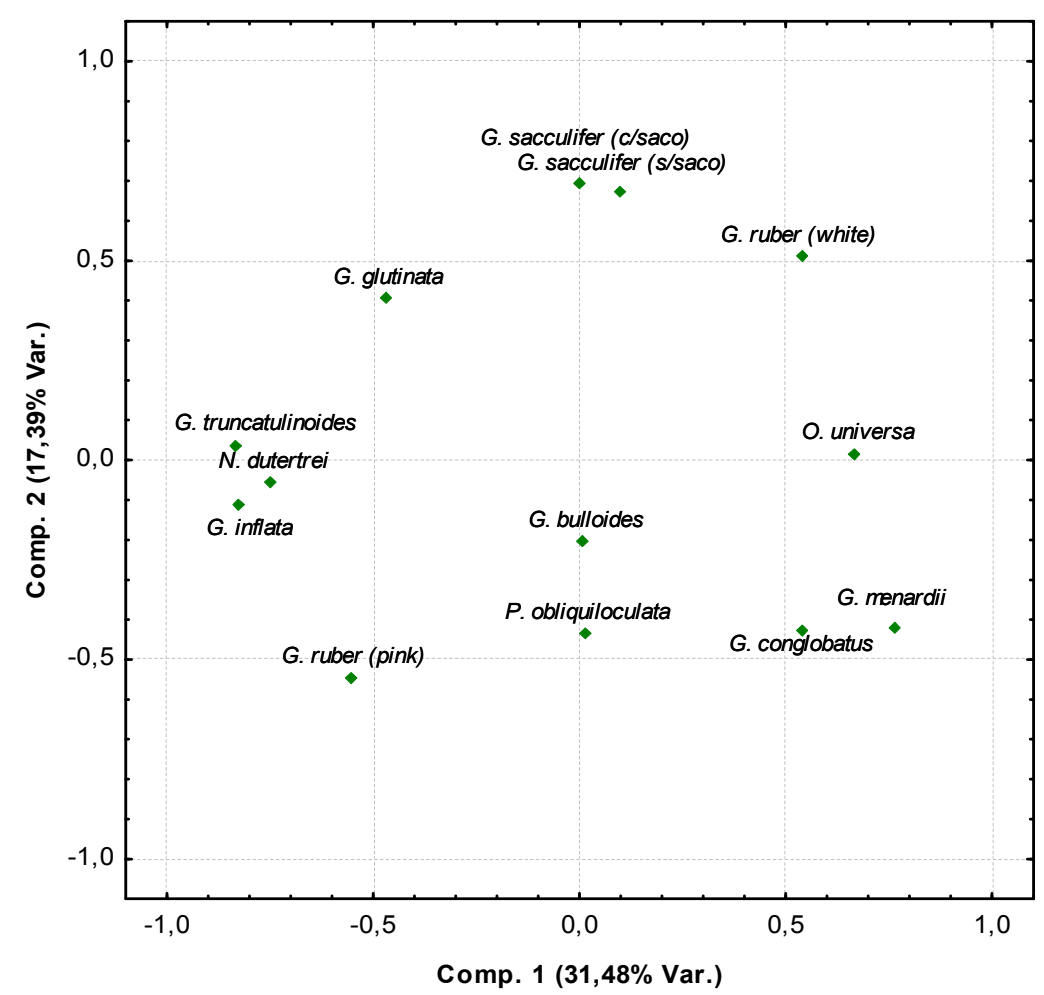

Figura 34: Projeção das componentes principais 1 e 2, correlacionando as espécies de foraminíferos planctônicos. 
A figura 35 mostra a variação das cargas fatoriais das componentes principais 1 (temperatura) e 2 (camada de mistura).

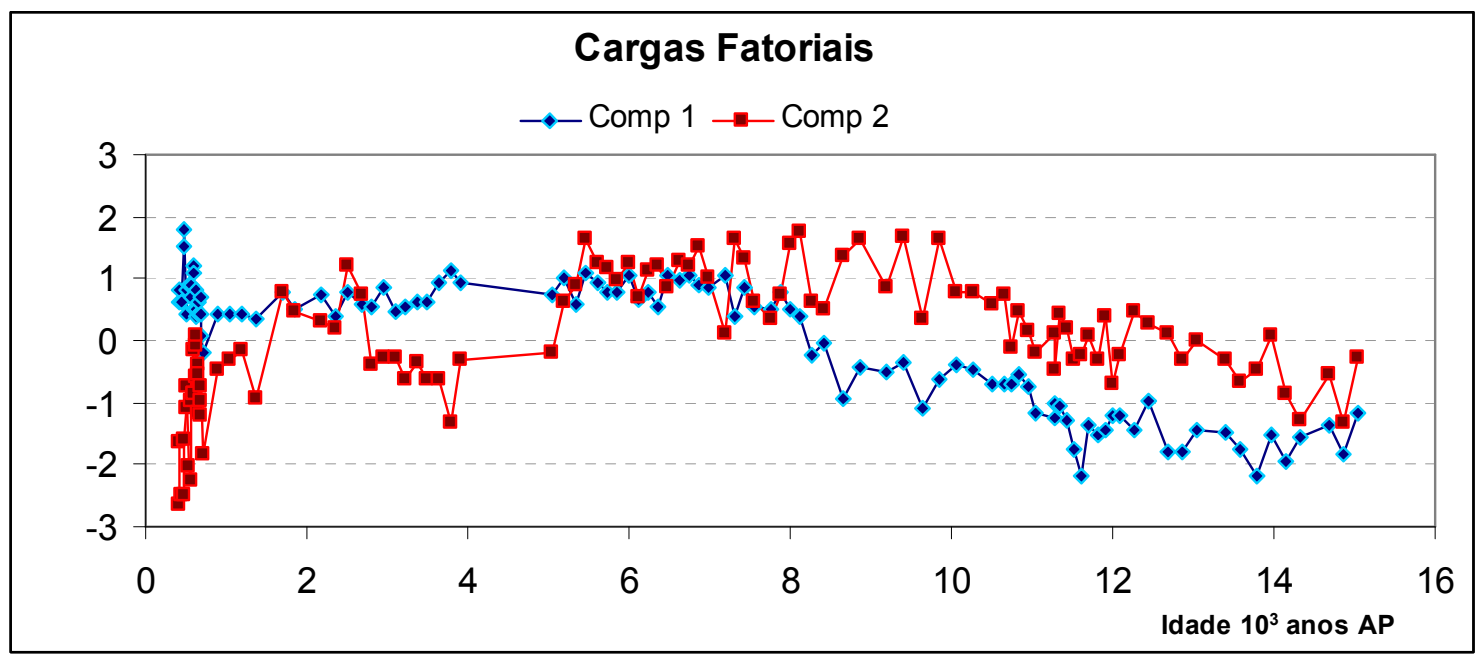

Figura 35: variação das cargas fatoriais das componentes principais 1 e 2 ao longo do tempo

As cargas fatoriais da componente principal 1 (figura 35) mostram valores negativos, indicando menores temperaturas até aproximadamente 8 mil anos A.P. Após essa idade, segue-se um período com valores aproximadamente constantes até o recente. $\mathrm{O}$ valor máximo da componente 1 $(1,7)$ no testemunho é atingido ao fim do registro, em aproximadamente 489 anos A.P.

Já as cargas fatoriais da componente principal 2 apresentaram valores mais variados ao longo do tempo. De 15 a 11 mil anos A.P. observa-se valores relativamente mais baixos $A$ partir dos 11 mil anos A.P aproximadamente, os valores se tornam essencialmente positivos, atingindo valores máximos e apresentando uma certa constância dos valores até 5 mil anos A.P. A partir desse momento os valores decrescem gradualmente. Em 2,3 mil anos A.P. os valores voltam a crescer, tornando-se positivos até 1,9 mil anos A.P., quando nova queda é observada, atingindo os valores mais baixos durante o Holoceno superior. Os baixos valores antes de 11 mil anos A.P. e a queda dos valores a partir de 5 mil anos A.P. poderiam estar relacionados com o maior aporte de nutrientes do continente ou com a quebra da estratificação da coluna de água e possível advecção de nutrientes para as zonas mais superficiais, o que desfavoreceria espécies como G. ruber e G. sacculifer, as principais 
representantes da CP 2. A importância da fotossíntese dos simbiontes para o crescimento e sobrevivência da espécie G. sacculifer tem sido demonstrada em experimentos laboratoriais de cultura (Caron et al., 1981). Esses simbiontes requerem luz, a qual poderia ser reduzida a níveis limitados na coluna de água pela turbidez causada por alta concentração de fitoplâncton em regiões mais produtivas (Watkins et al., 1996).

A curva paleoclimática (figura 36) foi obtida através da fórmula (w$\mathrm{c}) /(\mathrm{w}+\mathrm{c}) \times 100$ (Triantaphyllou, 2009), onde $w$ (warm) representa as espécies indicadoras de águas mais quentes e $c(c o l d)$, as representantes de águas mais frias. Assim, após a aplicação da Análise de Componentes Principais, que definiu através do CP 1 (temperatura) dois grupos principais de espécies, com cargas positivas e negativa, temos:

O. universa + plexo G. menardii $-G$. truncatulinoides $-G$. inflata $-N$. dutertrei O. universa + plexo G. menardii + G. truncatulinoides + G. inflata $+N$. dutertrei

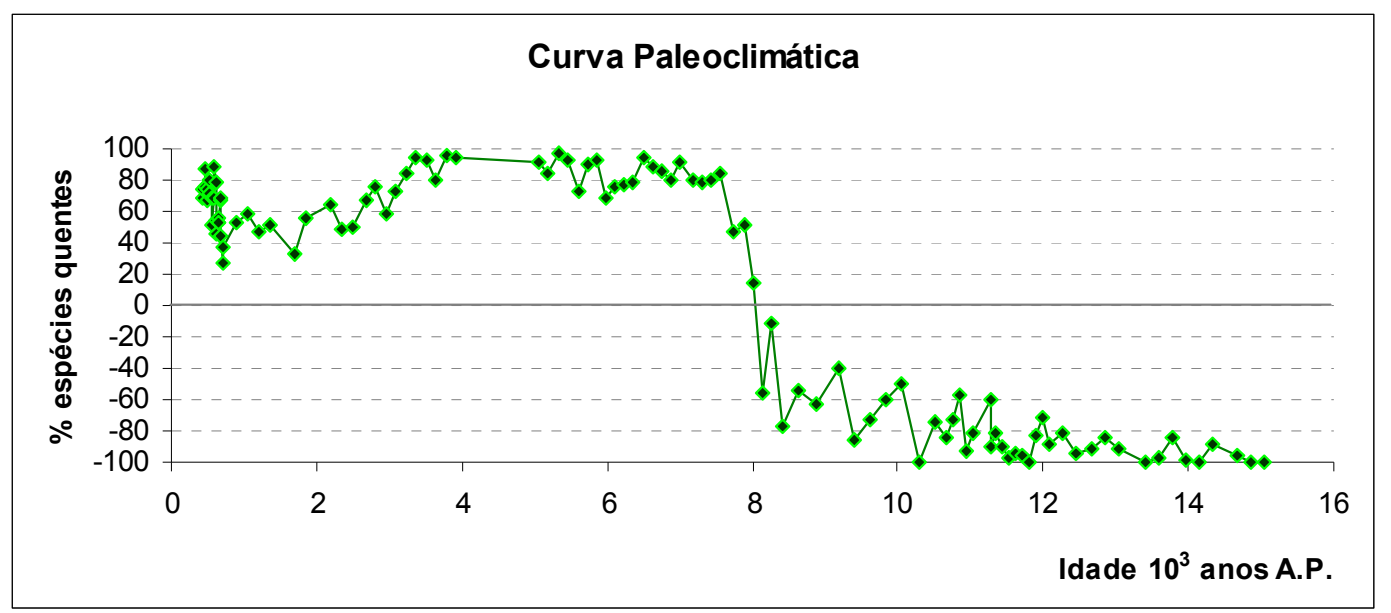

Figura 36: Curva paleoclimática obtida após aplicação do método de componentes principais nas assembléias de foraminíferos planctônicos do testemunho KF 02

A curva paleoclimática, que é considerada um índice de temperatura também, apresenta valores progressivamente crescentes e a partir de 8 mil anos A.P. observamos o domínio das assembléias tipicamente mais tropicais, provavelmente refletindo o restabelecimento das condições atuais mais quentes.

As causas para as variações observadas ao longo dos últimos 15 mil anos neste testemunho estão possivelmente relacionadas às variações da 
circulação termohalina e atmosférica e à variação regional do aporte continental do Rio da Prata e de sistemas lagunares menores.

Diversos estudos (e.g. Broecker, 1994; Ruhlemann et al., 1999; Vidal et al., 1999) demonstram que a circulação termohalina do Atlântico é sensível ao aporte de grandes quantidades de água de degelo em locais de formação de água profunda. O evento conhecido como Younger Dryas (11,5 a 13 mil anos A.P.) possivelmente teve origem pelo influxo de água doce proveniente da "Laurentide ice sheet" (uma maciça placa de gelo, com milhares de quilômetros quadrados que cobria a maior parte da América do Norte), o que diminuiu a densidade das águas superficiais, reduzindo a formação da Água Profunda do Atlântico Norte (NADW). Dessa forma, a circulação termohalina foi diminuída assim como a exportação de calor através do equador para o hemisfério norte. Acredita-se que como conseqüência dessa diminuição, ocorra o aquecimento das águas superficiais em latitudes mais baixas (Ruhlemann et al 2004). Estudos de modelagem, porém indicam que um maior aumento da temperatura da água seria melhor observado em profundidades intermediárias do que nas camadas mais superficiais do oceano (Dahl et al., 2005). Isso explicaria a ausência desse evento nos registros de fauna e isotópico (figura 39) do presente estudo.

Uma forçante astronômica também é proposta para explicar os registros de resfriamento em altas latitudes no hemisfério norte e aquecimento em altas latitudes no Sul: variação sazonal da insolação. Enquanto no norte a insolação de verão seria máxima, no hemisfério sul ela estaria próxima do seu mínimo (Ledru et al., 2002). Dentre os efeitos atmosféricos causados por esse resfriamento no hemisfério norte podemos citar a redução da intensidade dos sistemas de monções (e redução de umidade) e gradientes mais acentuados de temperatura entre o equador e o hemisfério norte, aumentando a intensidade dos ventos (Broecker et al., 1985; Fawcett et al., 1997), bem como a freqüência de advecção de ventos frios de origem ártica. Estes seriam responsáveis pela manutenção de uma ZCIT mais ao sul do equador e estendendo a influência ártica a regiões tropicais da América do Sul (Ledru et al., 2002), (figura 37). Uma posição mais meridional da ZCIT estaria associada a um fortalecimento tanto dos alísios de NE como da Corrente do Brasil o que está de acordo com a manutenção de valores elevados das temperaturas 
superficiais marinhas resultantes de uma redução do fluxo de calor através do equador.
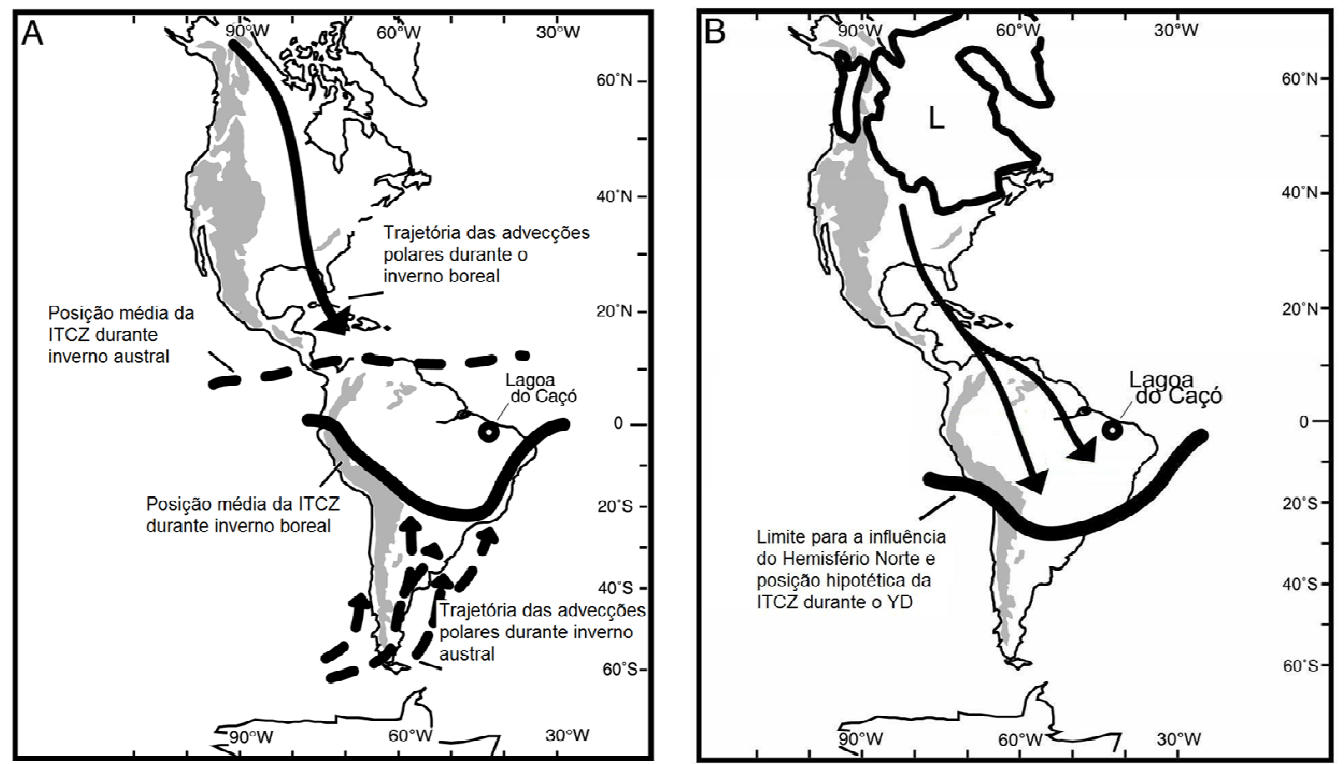

Figura 37: Mecanismo atmosférico inferido por Ledru et al., 2002 a partir de estudos palinológicos na Lagoa do Caiçó $(A)$ para explicar maior influência de advecções polares árticas em regiões tropicais da América do Sul (B) durante o Younger Dryas (YD). L representa Laurentide Ice Sheet durante YD.

Um aquecimento na porção oeste do Atlântico Sul seria responsável por uma intensificação na atividade da ZCAS e de pluviosidade sobre o sudeste da América do Sul, aumentando a descarga do principal sistema de drenagem da região, a Bacia do Prata (Robertson \& Mechoso, 2000; Chiessi et al., 2009).

Observando os dados das razões de $\mathrm{Fe} / \mathrm{Ca}$ e $\mathrm{Ti} / \mathrm{Ca}$ (figura 38) realizados neste testemunho na fração fina por Bariani (2009), notam-se altos valores para esse período, confirmando maior aporte terrígeno para a região. A conseqüente fertilização das águas superficiais e a resposta biológica para esse aporte continental podem ser observados através dos valores relativamente baixos da CP 2 até 11 mil anos A.P. (figura 39), indicando aumento da produtividade e desfavorecimento das espécies com preferência a ambientes mais oligotróficos, como G. ruber e G. sacculifer. O aumento da produtividade poderia estar relacionado também ao processo de ressurgência de borda de plataforma (Mesquita et al., 1993). Conforme sumarizado por Gaeta \& Brandini (2006) o enfraquecimento dos ventos de nordeste e da 
velocidade do fluxo da Corrente do Brasil (CB) no inverno intensificam o meandramento da $\mathrm{CB}$, trazendo ACAS para regiões externas da Plataforma da Bacia de Santos (Campos et al 1995). Odebrecht \& Castelo (2001) destacam a importância desses núcleos de águas frias e água continuamente renovada na teia alimentar do atum ao longo do talude continental.

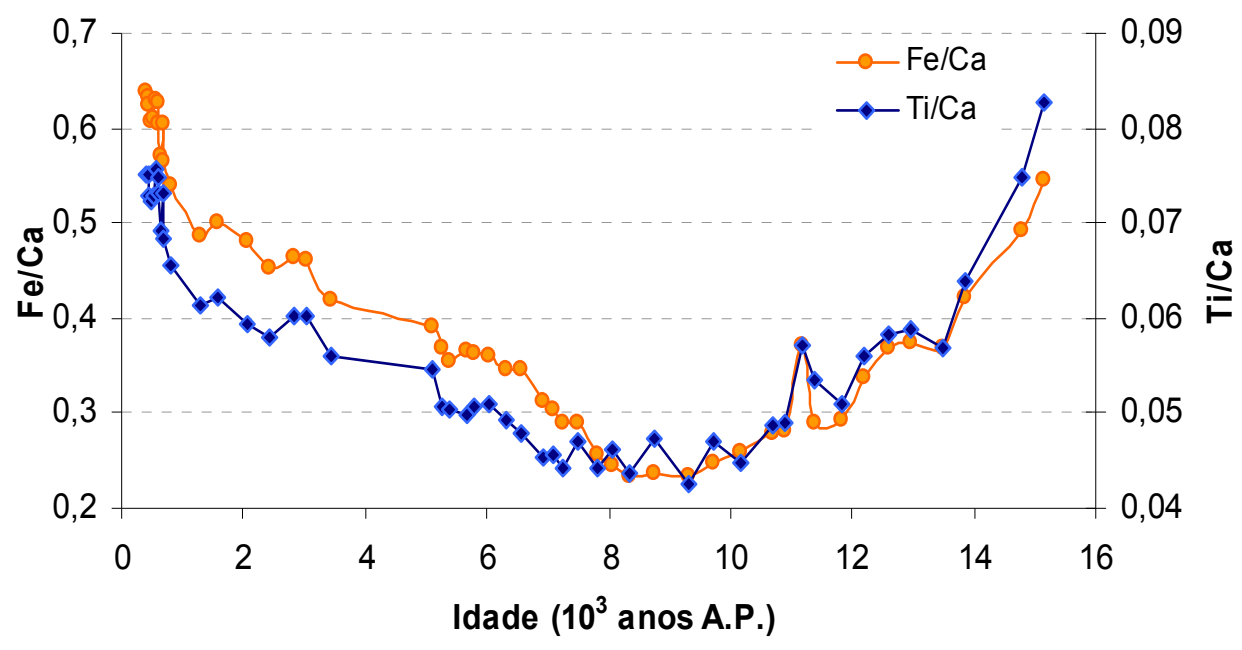

Figura 38: Variações dos teores de Fe/Ca e Ti/Ca para o testemunho KF-02, realizados por Bariani (2009)

A partir de 9 mil anos A.P. a circulação termohalina no Atlântico Sul atingiu a sua configuração moderna, mostrando aumento da temperatura das camadas superficiais e da termoclina (Came et al., 2003). Os registros palinológicos também demonstram lenta recomposição da floresta tropical da América do Sul a partir de 15 mil anos A.P, alcançando o seu ótimo próximo a 9,5 mil anos A.P. (Turcq et al., 1996). Isso se reflete na diminuição ou mesmo desaparecimento de espécies relacionadas a águas mais frias, como $G$. inflata e G. truncatulinoides (figuras 11 e 12) e aumento dos valores da curva paleoclimática e do $\delta^{18} \mathrm{O}$ (figura 34), indicando um aquecimento das águas superficiais. Ledru et al. (1996) descreveu a ocorrência de um período mais seco e quente entre 7 e 4 mil anos A.P. no sudeste do Brasil, seguido por um subseqüente aumento da umidade, como conseqüência das oscilações do posicionamento da ITCZ. Neste período são observados os valores mais altos da curva paleoclimática (próximos a 100\%). 
Cruz et al. (2009) e Baker et al. (2001) também sugeriram condições mais secas durante o Holoceno médio no sudeste/sul do Brasil e no Altiplano da Bolívia e Peru, respectivamente, sendo relacionadas ao mínimo de insolação de verão no hemisfério sul. Para o mesmo período, Melo \& Marengo (2008) também sugeriram um clima mais seco nas regiões sul, sudeste e centro oeste do Brasil devido a um menor transporte de umidade da região Amazônica. Os dados de $\mathrm{Fe} / \mathrm{Ca}$ e Ti/Ca (figura 38) e a CP 2 (figura 39) confirmam esse cenário de clima mais seco entre 11 e 5 mil anos A.P., onde são apresentadas os menores valores referentes ao aporte continental e os maiores valores da componente "camada de mistura", indicando favorecimento das espécies oligotróficas.

Estudos palinológicos mostram que a partir de 3 mil anos A.P., aproximadamente o clima na região sudeste do Brasil se torna mais úmido, com a expansão da floresta de Araucárias (Behling, 1997, 2002; Behling et al., 2001). Novamente pelos dados da razão de $\mathrm{Fe} / \mathrm{Ca}$ e Ti/Ca (figura 38), observamos aumento do aporte terrígeno como consequêencia do aumento de pluviosidade sobre a região continental adjacente. A CP 2 (figura 39) tem seus valores diminuídos um pouco mais tarde, após os 2 mil anos A.P. e atingindo seus valores mínimos ao final do registro, como resposta ao possível aumento da produtividade.

A curva de abundância relativa de foraminíferos bentônicos (figura 27), indicadora também de fluxo de matéria orgânica para o sedimento, apresentou um padrão de distribuição de seus valores bem semelhante aos resultados encontrados para a CP 2 e para o aporte de terrígenos, confirmando ser a princípio um bom indicador de produtividade. $\mathrm{O}$ Índice de Fragmentação (figura 28) não mostrou queda de seus valores durante o período mais seco (9 e 5 mil anos A.P.) e de menor produtividade, conforme sugerido pelos outros parâmetros, mas apresentou valores crescentes em direção ao recente.

A curva do $\delta{ }^{18} \mathrm{O}$ a partir de 3 mil anos A.P. apresenta uma queda brusca $(-1 \%$ o dos seus valores (figura 39$)$. Isso poderia ser devido ao aumento da temperatura ou à mudança da composição isotópica da água do mar. Como não foi observada nenhuma variação brusca na curva paleoclimática no mesmo período e, portanto na temperatura, sugere- se que a diminuição dos valores de 
$\delta{ }^{18} \mathrm{O}$ tenha sido devido ao aumento da quantidade de isótopos leves no sistema oceânico, provenientes do aumento da pluviosidade.

Próximo ao final do registro (1000 anos A.P.) notam-se valores crescentes da curva paleoclimática e do $\delta{ }^{18} \mathrm{O}$, com pico de máximo em 600 anos A.P. ( $90 \%$ e $-1,4 \%$, respectivamente). 


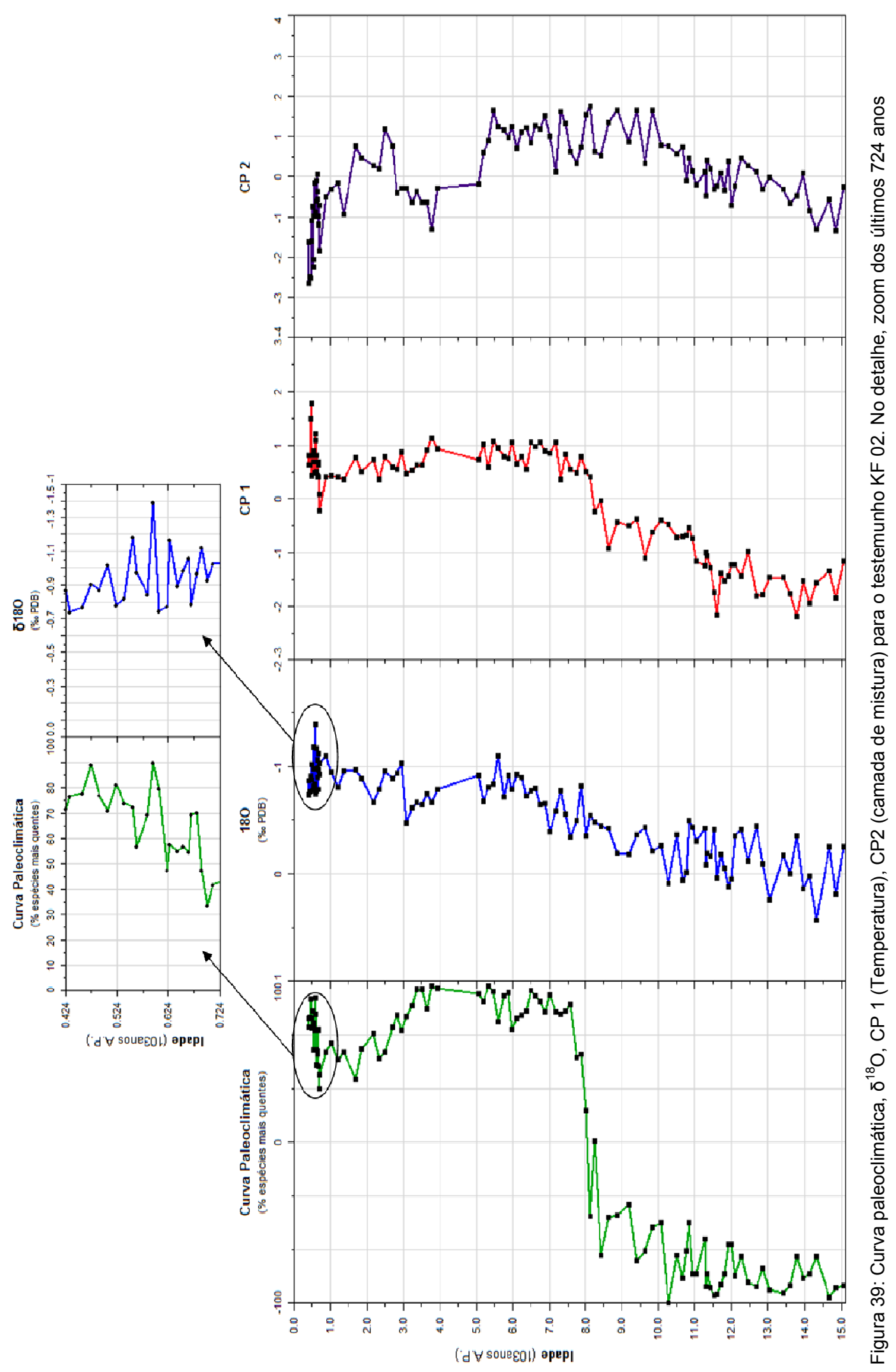




\section{Conclusões}

A análise da fauna de foraminíferos planctônicos, juntamente com os dados de isótopos de oxigênio e das razões de $\mathrm{Fe} / \mathrm{Ca}$ e Ti/Ca contribuíram para a compreensão do cenário paleoceanográfico do oeste do Atlântico Sul nos últimos 15 mil anos.

No início do registro (15 mil anos A.P.) até aproximadamente 8 mil anos A.P. tem-se o predomínio da fauna fria, inferida pela componente principal 1 (CP1) e pela curva paleoclimática e valores mais altos de $\delta{ }^{18} \mathrm{O}$, indicando menores temperaturas. A componente principal 2 (CP2), relacionada à camada de mistura e as razões de $\mathrm{Fe} / \mathrm{Ca}$ e $\mathrm{Ti} / \mathrm{Ca}$ indicam que esse período era de maior produtividade, em função possivelmente do maior aporte de terrígenos para o ambiente oceânico.

A partir de 8 mil anos A.P. a circulação termohalina atinge a sua configuração atual e tem-se o retorno às condições mais quentes, evidenciadas pelo aumento dos valores da curva paleoclimática (indicando aumento da fauna de foraminíferos planctônicos associados à ambientes com maiores temperaturas) e diminuição progressiva dos valores de isótopos de oxigênio. A CP2 apresenta valores máximos entre 11 e 5 mil anos A.P. e coincidem com os mínimos de razões de $\mathrm{Fe} / \mathrm{Ca}$ e $\mathrm{Ti} / \mathrm{Ca}$, indicando menor produtividade devido à diminuição da fertilização das águas superficiais por aporte continental e possivelmente maior estratificação da coluna de água que favorece as espécies de foraminíferos planctônicos associados a essa componente. A partir de 5 mil anos A.P. até o final do registro, observa-se novamente menores valores da CP2 e razões crescentes $\mathrm{Fe} / \mathrm{Ca}$ e Ti/Ca, sugerindo condições mais úmidas e de maior produtividade no Holoceno superior. 


\section{Referências Bibliográficas}

ALLABY, A. ; ALLABY, M. 1990. The Concise Oxford dictionary of Earth Sciences. Oxford University Press, New York. 410 p.

ANDREASEN, D.J.; RAVELO, A.C. 1997 Tropical Pacific Ocean thermocline depth reconstructions for the last glacial maximum. Paleoceanography, 12(3), 395-413.

ANTUNES, R.L.; MELO, J.H.G. 2001. Micropaleontologia e estratigrafia de seqüências. In: RIBEIRO, H.J.P.S. (Ed) Estratigrafia de Sequências - fundamentos e aplicações. São Leopoldo/RS Editora Unisinos, p. 137-218.

BAKER, P.A.; SELTZER, G.O.; FRITZ, S.C.; DUNBAR, R.B.; GROVE, M.J.; TAPIA, P.M.; CROSS, S.L.; ROWE, H.D.; BRODA, J.PL. 2001. The History of South American Tropical Precipitation for the Past 25000 Years. Science, v. 291, p. 640-643

BARIANI, L. M. 2009. Variações da sedimentação ao longo dos últimos 15.000 anos em um testemunho da Bacia de Santos. Trabalho de Graduação. Universidade de São Paulo. 39 p.

BASTOS, C.C.; FERREIRA, N.J. 2000. Análise climatológica da Alta Subtropical do Atlântico Sul. Anais do XI Congresso Brasileiro de Meteorologia, Rio de Janeiro. Sociedade Brasileira de Meteorologia, p. 612-619.

BÉ, A. W. H; MCINTYRE, A.; BREGER, D.L. 1966. The shell microsctucture of a planktonic foraminifer, Globorotalia menardii (d' Orbigny). Eclogae Geologicae Helvetiae 59, (2), p. 885896.

BÉ, A.W.H.; TOLDERLUND, D.S. 1971. Distribution and Ecology of Living Planktonic Foraminifera in surface waters of the Atlanic and Indian oceans. In: Funnell, B.M.; Riedel, W.R. (Eds) Micropaleontology of Oceans. Cambridge University Press, London, p. 105-149.

BÉ, A.W.H.; DAMUTH, J.E.; LOTT, L.; FREE, R.. 1976. Late Quaternary Climatic Record in Western Equatorial Atlantic Sediment. In: Geological Society of America. Investigations of Late Quaternary Paleoceanography and Paleoclimatology. Geological Society of America Memoir 145, Boulder, Co., p.162-200.

BÉ, A.W.H. 1977. An ecological, zoogeographic and taxonomic review of recent planktonic foraminifera. In: Oceanic Micropaleontology, Ramsay, A.T.S. Ed., Academic Press, London, p. $1-100$ 
BEHLING, H. 1997 Late Quaternary vegetation, climate and fire history from the tropical mountain region of Morro de Itapeva, SE Brazil. Palaeogeography, Palaeoclimatology, Palaeoecology, 129, p. 407-422

BEHLING, H.; KEIM, G.; IRION, G.; JUNK, W.; NUNES DE MELLO, J. 2001. Holocene environmental changes in the Central Amazon Basin inferred from Lago Calado (Brazil). Palaeogeography, Palaeoclimatology, Palaeoecology, 173, p. 87-101

BEHLING, H. 2002. Late Quaternary vegetational and climate dynamics in southeastern Brazil, inferences from marine cores GeoB 3229-2 and GeoB 3202-1. Palaeogeography, Palaeoclimatology, Palaeoecology, 179, p. 227-243

BENNETT, A.F. 1978. Poleward heat fluxes in the southern hemisfer oceans. Journal of Physical Oceanography, v. 8, p. 785-798.

BERGER, W.H 1968. Planktonic Foraminifera: selective solution and paleoclimatie interpretation. Deep-Sea Research, 1968, v. 15, p. 31-43.

BERGER, A. (Ed.) 1981. Climatic Variations and Variability: Facts and Theories, NATO ASI, D. Reidel Publishing Company, Dordrecht, Holland, 795 p.

BERGER, W.H. ; DIESTER-HAASS, L. 1988. Paleoproductivity: The benthic/planktonic ratio in foraminifera as a productivity index. Marine Geology, v. 81, p. 15-25.

BERGER, W.H.; WEFER, G. 1996. Expeditions into the past: Paleoceanographic studies in the South Atlantic. In: WEFER, G.; BERGER, W.H.; SIEDLER, G. ; WEBB, D.J. (eds.), The South Atlantic: Present and Past Circulation. Springer-Verlag, p. 363-410.

BIANCHI, G.G., MCCAVE, I.N. 1999. Holocene periodicity in North Atlantic climate and deepocean fow south of Iceland. Nature v. 397, p. 515-517.

BIGG, G. R. 1996. The Oceans and Climate. Cambridge University Press. 266 p.

BOERSMA, A. 1978. Foraminifera. In: HAQ, B.U.; BOERSMA, A. (eds), Introduction to Marine Micropaleontology. New York: Elsevier/North Holland, p. 19-77.

BOLTOVSKOY, E. 1962. Planktonic foraminifera as indicators of different water masses in the South Atlantic. Micropaleontology, v. 8, (3), p. 403- 408. 
BOLTOVSKOY, E. 1981. Foraminífera. In: Boltovskoy, D. Atlas Del Zooplâncton Del Atlântico Sudoccidental y métodos de trabajo con el zooplancton marino. Publicación especial Del INIDEP, Mar del Plata, Argentina. p. 317-352.

BOND, G.,SHOWERS,W., CHESEBY, M., LOTTI, R., ALMASLI, P., DEMENOCAL, P., PRIORE, P., CULLEN,H., HAJADAS, I., BONANI, G. 1997. A Pervasive Millennial-Scale Cycle in North Atlantic Holocene and Glacial Climates Science 278, 1257 p.

BRADLEY, R. S. 1999. Paleoclimatology: Reconstructing Climates of the Quaternary. Second Edition Academic Press, San Diego, 610 p.

BROECKER, W.S.; PETEET, D.M.; RIND, D. 1985. "Does the Ocean-Atmosphere System Have More Than One Stable Mode of Operation?" Nature, v. 315, p. 21-25.

BROECKER, W.S. 1994 Massive iceberg discharge as triggers for global climate change. Nature, v. 372, p. 421-424.

BUTZIN, M., PRANGE, M.; LOHMANN, G. 2005. Radiocarbon simulations for the glacial ocean: The effects of wind stress, Southern Ocean sea ice and Heinrich events. Earth Planetary Sciences Letters, 235, p. 45-61.

CAME, R.E.; OPPO, D.W.; CURRY, W.B., 2003. Atlantic Ocean circulation during the Younger Dryas: Insights from a new $\mathrm{Cd} / \mathrm{Ca}$ record from the western subtropical South Atlantic. Paleoceanography, v. 18, (4), 1086.

CAMPOS, E.J.D.; GONÇALVES, J.E.; IKEDA, Y. 1995. Water mass characteristics and geostrophic circulation in the South Brazil Bight: Summer of 1991. Journal of Geophysics Research, v. 100, (C9), p. 18537-18550.

CAO, L., FAIRBANKS, R.G.; BUTZIN, M.; NAIK, N., em prep. The marine radiocarbon reservoir age. Radiocarbon

CAPOTONDI, L.; VIGLIOTTI, L. 1999. Magnetic and microfaunal characterization of late quaternary sediments from the western mediterranean: inferences about sapropel formation and paleoceanographic implications. In: ZAHN, R., COMAS, M.C., KLAUS, A. (Eds.), Proceedings of the Ocean Drilling Program, Scientific Results, v. 161, p. 505-518.

CARON D. A.; BÉ, A.W.H.; ANDERSON, O.R. 1981. Effects of variations in light intensity on life processes of the planktonic foraminifer Globigerinoides sacculifer in laboratory culture. Journal of the Marine Biological Association of the United Kingdom, v. 62, p. 435-452. 
CHIESSI, C. M.; ULRICH, S., MULITZA, S.; PATZOLD, J.; WEFER 2007. Signature of BrazilMalvinas Confluence Argentine Basin in the isotopic composition of planktonic foraminifera form surface sediments. Marine Micropaleontology v. 64, p. 52-66

ChIESSI, C. M.; MUlitZA, S.; PÄTZOLD, J.; Wefer, G.; MARENGO, J.A. 2009. Possible impact of the Atlantic Multidecadal Oscillation on the South American summer monsoon. Geophysical Research Letters, v. 36, p. L21707, doi:10.1029/2009GL039914.

CIFELLI, R.; BENIÉR, C.S. 1976. Planktonic foraminifera from near the west African coast and a consideration of faunal parcelling in the North Atlantic. Journal Foraminiferal Research, v. 6, p. 258-273.

CIOTTI, A. M.; ODEBRECHT, C.; FILLMANN, G.; MöLLER, O., O., Jr. 1995. Freshwater outflow and Subtropical Convergence Influence on phytoplankton biomass on the southern Brazilian continental Shelf. Continental Shelf Research, v. 15, p. 1737-1756

CIRANO, M; MATA, M. M.; CAMPOS, E. J. D., DEIRÓ, N.F.R. 2006. A circulação oceânica de larga-escala na região oeste do atlântico sul com base no modelo de circulação global OCCAM. Revista Brasileira de Geofísica v. 24, 2, p. 209-230

CLIMAP Project Members 1976. The surface of ice-age earths. Science, v. 191, p. 11311137

COOKE, S.; ROHLING, E.J. 2001. Stable isotopes in foraminiferal carbonate. Southampton Oceanography Centre Internal Document, v. 72, 56 p.

COSTA, K.B. ; TOLEDO, F. A. L. 2003. Zoneamento Bioestratigráfico do Quaternário superior com base em foraminíferos Planctônicos. Relatório $n^{\circ}$. 5, Laboratório de geologia isotópica, Universidade federal do Rio Grande do Sul UFRGS. 115p

CRAIG, H. 1961. Standard for reporting concentrations of $D$ and ${ }^{18} \mathrm{O}$ in natural waters. Science, v. 133 , p. $1833-1834$

CRUZ, F. W.; Vuille, M.; Burns, S. J.; Wang, X.; Cheng, H.; Werner, M.; Edwards, R. L.; Karmann, I.; Auler, A. S. e Nguyen, H. 2009. Orbitally driven east-west antiphasing of South American precipitation. Nature Geosciences, 2, pp 210-214.

DAHL, K.A.; BROCCOLI, A.J.; STOUFFER, R.J. 2005. Assessing the role of North Atlantic freshwater forcing in millennial scale climate variability: A tropical Atlantic perspective. Climate Dynamics, v. 24, p. 325-346. 
DAMUTH, J.E. 1977. Late Quaternary sedimentation in the western equatorial Atlantic. Geological Society of America Bulletin, v. 88, (5), p. 695-710.

DE ABREU, L.; ABRANTES, F.F.; SHACKLETON, N.J.; TZEDAKIS, P.C.; MCMANUS, J.F.; OPPO, D. W.; Hall, M. A 2005. Ocean climate variability in the eastern North Atlantic during interglacial marine isotope stage 11: A partial analogue to the Holocene ?, Paleoceanography, v. 20, PA3009, doi:10.1029/2004PA001091.

DE MENOCAL, P.; ORTIZ, J.; GUILDERSON,T.; SARNTHEIN,M. 2000. Coherent High- and Low-Latitude Climate Variability During the Holocene Warm Period. Science, v. 288, p. 21982202.

DE VILLIERS, S. 2005. Foraminiferal shell- weight evidence for sedimentary calcite dissolution above the lysocline. Deep- Sea Research I, v. 52, p. 671-680.

DEUSER, W.G.; ROSS, E.H. 1989. Seasonally abundant planktonic foraminifera of the Sargasso Sea: succession, deep-water fluxes, isotopic compositions and paleoceanographic implications. Journal Foraminiferal Research, v. 19, p. 268-293.

EMERSON, S.; BENDER, M.L., 1981. Carbon fluxes at the sediment water interface of the deep-sea: calcium carbonate preservation. J. Mar. Res. v. 39, p. 139-162

EMIG, M. 1967. Heat transport by ocean currents, Journal of Geophysical Research., v.72, (10), p. $2519-2529$.

EMILIANI, C. 1955. Pleistocene Temperatures. Journal of Geology, v. 63, p. 538-578.

EMILSON, I. 1961 The shelf and coastal waters off southern Brazil. Boletim do Instituto Oceanográfico, São Paulo, v. 11, 2, p.101-112.

ERICSON, D.B.; WOLLIN, G. 1968. Pleistocene climates and chronology in deep-sea sediments. Science, v. 162, p. 1227-1234.

FAIRBRIDGE, R. W. 1966 Continental Slope. In: Encyclopedia of Oceanography. New York, Reinhold Publishing Co, v. 1, p. 205-207.

FARMER, E.C.; DEMENOCAL, P.B.; MARCHITTO, T.M. 2005 Holocene and deglacial ocean temperature variability in the Benguela upwelling region: Implications for low-latitude atmospheric circulation. Paleocenaography, 20, doi:10.1029/2004PA001049. 
FAWCETT, J., ÁGÚSTSDÓTTIR, A.M., ALLEY, R.B., SHUMAN, C.A., 1997. The Younger Dryas termination and North Atlantic Deep Water formation: insights from climate model simulations and Greenland ice cores. Paleoceanography, v.12, p. 23-28.

FELDBERG, M.J.; MIX, A. 2002 Sea-surface temperature estimates in the Southeast Pacific based on planktonic foraminiferal species; modern calibration and Last Glacial Maximum. Marine Micropaleontology, v.44, p. 1-29

FU, L.L. 1981. The general circulation and meridional heat transport of the Subtropical South Atlantic determined by inverse methods, Journal of Physical Oceanography, v. 11, p.11711193.

GAETA, S. A.; Brandini, F. P. 2006. Produção primária do fitoplâncton na região entre o Cabo de São Tomé (RJ) e o Chuí (RS). In: Wongtschowski, C. L. B.; Madureira, L.S.P. (Eds). O ambiente Oceanográfico da Plataforma Continental e do Talude na Região Sudeste-Sul do Brasil. São Paulo. Ed. Edusp, p. 219-264.

GARREAUD, R. D.; VUILLE, M.; COMPAGNUCCI, R.; MARENGO, J. 2009 Present- day South America climate. Palaeogeography, Palaeoclimatology, Palaeoecology $\quad$ v. 281, p. 180195.

GIRAUDEAU, J., PIERRE, C.; HERVE, L. 2001. A late Quaternary, high resolution record of planktonic foraminiferal species distribution in the southern Benguela region: Site 1087. In: WEFER, G., BERGER, W.H.; RICHTER, C. (Eds) Proc. ODP, Sci. Results, v. 175, p. 1-26

GONI, G.; KAMHOLZ, S.; GARZOLI, S.; OLSON, D. 1996. Dynamics of the Brazil-Malvinas Confluence based on inverted eccho sounders and altimetry. Journal of Geophysical Research, v. 101, (C7), p.16273-16289.

GONZAGA, F.G. 2005 Simulação geoquímica 1D ao longo de uma seção geológica da Bacia de Campos. Dissertação de Mestrado Rio de Janeiro, UFRJ/COPPE, 79 p.

GOODAY, A.J. 2002 Biological Responses to Seasonally Varying Fluxes of Organic Matter to the Ocean Floor: A Review. Journal of Oceanography, v. 58, p. 305-332.

GORDON, A.L. 1986. Inter-Ocean Exchange of Thermocline Water. Journal of Geophysical Research-Oceans, v. 91, C4, p.5037-5046 
GORDON, A. L. 1989. Brazil Malvinas Confluence - 1984 Deep-Sea Research Part aOceanographic Research Papers, Mar, v. 36, 3, p.359-384.

GRIMSDALE, T.F.; VAN MORKHOVEN, F.P.C.M., 1955. The ratio between pelagic and benthonic foraminifera as a means of estimating depth of deposition of sedimentary rocks. Proc. World Pet. Congr., 4th (Rome) Sect. l/D4, p 473-491

GUPTHA, M.V.S.; MOHAN, R.; MURALINATH, A.S. 1994 Living planktonic foraminifera during the late summer monsoon period in the Arabian Sea. Marine Geology, v. 120, p. 365-371.

HALD, M.; ANDERSSON, C.; EBBESEN, H.; JANSEN, E.; KLITGAARD-KRISTENSEN, D.; RISEBROBAKKEN, B.; SALOMONSEN, G.; SARNTHEIN, M.; SEJRUP, H.P.; TELFORD, R.J. 2007 Variations in temperature and extent of Atlantic Water in the northern North Atlantic during the Holocene. Quaternary Science Reviews v. 26, p. 3423-3440.

HASTENRATH, S. 1980. Heat budget of tropical ocean and atmosphere, Journal of Physical Oceanography, v. 10, p. 159-170.

HASTENRATH, S. 1991. Climate Dynamics of the Tropics. 2a. Ed. Kluwer Academic Publishers, New York, $488 \mathrm{p}$.

HEMLEBEN, C.; SPINDLER, M.; BREITINGER, I.; OTT, R. 1987. Morphological and physiological responses of Globigerinoides sacculifer (Brady) under varying laboratory conditions. Marine Micropaleontology, v. 12, p. 305-324.

HEMLEBEN, C., SPINDLER, M.; ANDERSON, O. R. 1989. Modern planktonic foraminifera: Berlin, Heidelberg, New York, Springer, 363 p.

HENDERSON, G.M. 2002. New oceanic proxies for paleoclimate. Earth and Planetary Science Letters, v. 203, p. 1-13.

HILBRECHT, H. 1996. Extant planktic foraminifera and the physical environment in the Atlantic and Indian Oceans. Mitteilungen aus dem Geologischen Institut der Eidgen. Technischen Hochschule und der Universität Zürich, Neue Folge. No. 300, Zürich

IPCC 2007. Climate Change 2007: The physical science basis. Summary for policymakers, intergovernmental panel on climate change. Fourth Assessment Report, Geneva, IPCC Secretariat, p. 1-18. 
ITO, E. R. K. ; AMBRIZZI, T. 2000 Climatologia da posição da alta subtropical do atlântico sul para os meses de inverno.. In: XI Congresso LatinoAmericano e Iberico de Meteorologia, 2000, Rio de Janeiro. A Meteorologia Brasileira além do ano 2000. Rio de Janeiro : Sociedade Brasileira de Meteorologia, p. 860-865

JENKINS, R.; GOULD; R.W.; GEDCKE, D. 1995. Quantitative X-ray Spectrometry. 2. ed. : Marcel Dekker, Inc., New York. 484p.

JONES, J.J. 1967. Significance of distribution of planktonic foraminifera in the Equatorial Atlantic Undercurrent. Micropaleontology, v. 13, p. 489-501.

KEMLE-VON MüCKE, S.; HEMLEBEN, C. 1999. Foraminifera. In: Boltovskoy, D. Ed., South Atlantic Zooplankton. Backhuys Publishers, Leiden, Netherlands, p. 43-73.

KENNETT. J.P.; HUDDLESTUN, P. 1972. Late pleistocene paleoclimatology, foraminiferal biostratigrafy and tephrochronology, western Gulf of México. Quaternary Research, v. 2, p. 38-69.

KLITGAARD-KRISTENSEN,D., SEJRUP H.P., HAFIIDASON,H. 2001. The last $18 \mathrm{kyr}$ fluctuations in Norwegian Sea surface conditions and implications for the magnitude of climatic change: Evidence from the North Sea. Paleoceanography, v. 16, 5, p. 455-467.

KOWSMANN, R.O. ; VICALVI, M.A. 2003. Descrição e datação dos furos da campanha Bucentaur 2003 na área de Jubarte/Cachalote (Bloco BC-60). PDEXP/PETROBRAS. Relatório interno RT GEOF n008/2003, 17 p.

KUCERA, M., WEINELT,M. KIEFER,T., PFLAUMANN, U., HAYES, A., WEINELT, M., CHEN,M., MIX, A.C., BARROWS, T.T., CORTIJO,E., DUPRAT, J., JUGGINS,S., WAELBROECK, C. 2005 Reconstruction of sea-surface temperatures from assemblages of planktonic foraminifera: multi-technique approach based on geographically constrained calibration data sets and its application to glacial Atlantic and Pacific Oceans. Quaternary Science Reviews, v. 24, p. 951-998.

LE, J.; SHACKLETON, N. J. 1992 Carbonate Dissolution Fluctuations in the Western Equatorial Pacific During the Late Quaternary. Paleoceanography, v. 7, p. 21-42

LE, J.; MIX, A.C.; SHACKLETON, N.J 1995. Late Quaternary Paleoceanography in the Eastern Equatorial Pacific Ocean from Planktonic Formaminifers: A High-Resolution Record from Site 846. Procedings of the Ocean Drilling Program, Scientific Results, v. 138, p. 1-19 
LE, N.; THUNELL, R.C. 1996. Modelling planktic foraminiferal assemblage changes and application to sea surface temperature estimation in the western equatorial Pacific Ocean, Marine Micropaleontology 28 (3-4), p. 211-229.

LEA, D.W. 2003. Elemental and Isotopic Proxies of Marine Temperatures. In : ELDERFIELD, H. (Ed.) The Oceans and Marine Geochemistry, Vol. 6 Treatise on Geochemistry (HOLLAND, H.D., TUEREKIAN, K.K., Eds.). Elsevier-Pergamon (Oxford), p.365-390.

LEDRU M.P; MOURGUIART, P.; CECCANTINI,G.;TURCQ B. ; SIFEDDINE, A. 2002 Tropical climates in the game of two hemispheres revealed by abrupt climatic change. Geology, v. 30, p. $275-278$.

LENTINI, C.A.D.; CAMPOS, E.J.D.; PODESTÁ, G. 2000 The annual cycle of satellite derived sea surface temperature on the western South Atlantic shelf, Brazilian Journal of Oceanography, v. 48, (2), p. 93-105.

LOHMANN. G.P. 1992. Increasing seasonal upwelling in the subtropical South Atlantic over the past 700000 yrs: Evidence from deep-living planktonic foraminifera. Marine Micropaleopntology, v. 19, p. 1-12

LOWE, J.J; WALKER, M.J.C. 1997 Reconstructing Quaternary Environments. London, Longmam Group Ltd. Londres, 446 p.

LUTJEHARMS, J.R.; VAN BALLEGOOYEN, R. 1988. The Retroflection of the Agulhas Current. Journal of Physical Oceanography, v. 18, p. 1570-1583.

LUTZE, G.F.; COULBOURN, W.T. 1983/84. Recent benthic foraminifera from the continental margin of northwest africa: community structure and distribution. Marine Micropaleontology, v. $8(5)$, p. $361-401$

MACDONALD, A.; WUNSCH, C.1996. The global ocean circulation and heat fux. Nature, v. 382, p. 436-439.

MADUREIRA, L.A.S.; CONTE, M., EGLINGTON, G., 1997. Early diagenesis of lipid biomarker compounds in North Atlantic sediments. Paleoceanography v. 10, p. 627-642.

MAHIQUES, M.M., TESSLER, M. G., CIOTTI, A.M.; SILVEIRA, I.C.A.; SOUSA, S.H.M; FIGUEIRA, R.C.L, TASSINARI, C.C.G, FURTADO, V.V, PASSOS, R.F. 2004 Hydrodynamically driven patterns of recent sedimentation in the shelf and upper slope off Southeast Brazil. Continental Shelf Research v. 24, p. 1685-1697 
MARTINEZ, J.I.; TAYLOR, L.; DE DECKKER, P.; BAROOWS, T. 1998 Planktonic foraminifera from the eastern Indian Ocean: distribution and ecology in relation to the Western Pacific Warm Pool (WPWP). Marine Micropaleontology, v. 34, p. 121-151.

MARTINSON, D.G.; PISIAS, N.G.; HAYS, J.D.; IMBRIE, J.; MOORE, T.C.; SHACKLETON, N.J. 1987. Age dating and the orbital theory of the ice ages: development of a high resolution 0 to 300,000-year chronostratigraphy. Quaternary Research, v. 27 ,p. 1-29.

MELGUEN, M.; THIEDE, J. 1974. Facies distribution and dissolution depths of surface sediment compoments from the vema channel and The Rio Grande Rise (Southwest Atlantic Ocean) Marine Geology, v. 17, p. 341-353

MELO, M. L. D. e MARENGO, J. A. 2008. Simulações do clima do Holoceno médio na América do Sul com modelo de circulação geral da atmosfera do CPTEC. Revista Brasileira de Meteorologia, v. 23, (2), p. 191-205.

MENDONÇA, F.; DANNI-OLIVEIRA, I. M.; 2007. Climatologia: noções básicas e climas do Brasil. São Paulo. Oficina de texto. 208p.

MESQUITA, A.R.; LEITE, J.B.A.; RIZZO, R. 1993. Note on the shelfbreak upwelling off the southeast coast off Brazil (Lat. 26 30'S). Boletim do Instituto Oceanográfico, v. 32, p.193-198.

MEYERS, P.A. 1994. Preservation of elemental and isotopic source identification of sedimentary organic matter. Chemical Geology v. 114, p. 289-302.

MEYERS, P.A., 1997. Organic geochemical proxies of paleoceanographic, paleolimnologic, and paleoclimatic processes. Organic Geochemistry v. 27, p. 213-250.

MIRANDA, L. B. 1985 Forma de Correlação T-S de massas de água das regiões costeiras e oceânicas entre o cabo de São Tomé RJ e a llha de São Sebastião. Boletim do Instituto Oceanográfico, São Paulo, v. 33 (2) p. 105-119.

MOREIRA, J, L. P.; NALPAS, T., ; JOSEPH, P.; GUILLOCHEAU, F. 2001 Stratigraphie sismique de la marge éocène du Nord du bassin de Santos Brésil : relations plateforme/ systèmes turbiditiques ; distorsion des sequences de depot. Earth and Planetary Sciences v. 332, p. 491-498

MOREY, A.E.; MIX, A.C.; PISIAS, N.G. 2005 Planktonic foraminiferal assemblages preserved in surface sediments correspond to multiple environment variables. Quaternary Science Reviews, v. 24, p. 925-950 
MULITZA, S.; DURKOOP, A.; HALE, W.; WEFER, G.; NIEBLER, H. S. 1997. Planktonic foraminifera as recorders of past surface-water stratification. Geology v. 25, 4, p. 335-338

MULLER, T. J.; IKEDA, Y.; ZANGENBERG, N.; NONATO, L. 1998 Direct measurements of western boundary currents off Brazil between $20^{\circ} \mathrm{S}$ and $28^{\circ} \mathrm{S}$ Journal of Geophysical Research, v. 103, C3, p. 5429-5437.

NACSN (North American Commission on Stratigraphic Nomenclature) 2005 North American Stratigraphic Code . 45 p. DOI:10.1306/07050504129

NAIDU, P. D. ; MALMGREN, B. A. 1996. Relationship between late quaternary upwelling history and coiling properties of Neogloboquadrina pachyderma e Globigerina bulloides in the Arabian sea. Journal of Foraminifeal Research, v. 26,1,p. 64-70.

NIMER, E. 1989. Climatologia do Brasil. Secretaria de Planejamento e Coordenação da Presidência da Republica e IBGE, Rio de Janeiro, 421p.

ODEBRECHT, C.; CASTELLO, J. P. 2001. The convergence ecosystem in Southwest Atlantic. In: SEELIGER, U.; KJERFVE, B. (eds). Costal marine ecosystems of Latin America, v. 144, p. 147-165.

OBERHANSLI, H. 1992. Planktonic Foraminifers as Tracers of Ocean Currents in the Eastern South Atlantic. Paleoceanography, v. 7, p. 607-632

PAILLARD, D.; LABEYRIE, L.; YIOU, P. 1996. Macintosh program performs time-series analysis, Eos Transactions AGU 77 (39) (1996), p. 379.

PARKER, F.L. 1967. Distribution of planktonic foraminifera in Recent deep-sea sediments. In: SCOR Symposium on Micropaleontology of Marine Bottom Sediments. Cambridge University Press, London.

PARKER, W. C.; ARNOLD, A.J. 1999 Quantitative methods of data analysis in foraminiferal ecology. In: SEN GUPTA, B.K (Ed.) Modern Foraminifera. Kluwer Academic Publishers. London, p. 71-89.

PERRY, A.H.; WALKER, J.M., 1977. The Ocean- Atmosphere System, Longman, London, 160 p.

PETERSON, R.G.; STRAMMA, L. 1991. Upper-level circulation in the South Atlantic Ocean. Progress in Oceanography, v. 26, p. 1-73. 
PIOLA, A.R ; CAMPOS E.; DONNERS, J.; GORDON, A.L ; NOF, D. 2003. The South Atlantic contribution to the global thermohaline circulation. In: The South Atlantic Climate Observing System Workshop, 2003, Angra dos Reis. Report of the SACOS Workshop, 2003. p. 30-37.

PICKARD, G.L.; EMERY, W.J.1992 Descriptive Physical Oceanography, 6th edition, Pergamon Press, Oxford, England, $241 \mathrm{p}$.

PODESTÁ, G.P.; BROWN, O.B.; EVANS, R.H 1991. The annual cycle of satellite derived sea surface temperature in the southwestern Atlantic ocean. Journal of Climate, v. 4, p. 457-466.

PRELL, W.L.; DAMUTH, J.E. 1978 The climate- related diachronous disapperance of Pulleniatina obliquiloculata in the Late Quaternary sediments of the Atlantic and Caribbean. Marine Micropaleontology, v. 3, p. 267-277.

RAVELO, A.C.; FAIRBANKS, R.G.; PHILANDER, S.G.H. 1990. Reconstructing Tropical Atlantic Hydrography Using Planktonic Foraminifera and an Ocean Model. Paleoceanography, v. 5 (3) p. 409-431

ROBERTSON, A.W.; MECHOSO, C.R. 2000. Interannual and interdecadal variability of the South Atlantic Convergence Zone. Mon. Weather Rev., v. 128, p. 2947-2957

RÖGL, F.; BOLLI, H. M. 1973. Holocene to Pleistocene Planktonic Foraminifera of Leg 15, site 147 (Cariaco Basin (Trench), Caribbean Sea) and their climatic interpretation. Initial Reports of the Deep Sea Drilling Project. Washington, v. 15, p. 553-614

ROHLING, E.J.; JORISSEN, F.J.; GRAZZINI, V.C.; ZACHARIASSE, W.J. 1993. Northern Levantine and Adriatic Quaternary planktic foraminifera; Reconstruction of paleoenvironmental gradients. Marine Micropaleontology, v. 21, p. 191-218.

ROHLING, E.J.; COOKE, S. Stable 1999. Oxygen and carbon isotope ratios in foraminiferal carbonate, cap. 14 In: B.K. Sen Gupta (ed.) Modern Foraminifera, Kluwer Academic, Dordrecht, The Netherlands, p. 239-258.

RÜHLEMANN, C.; MUILITZA, S.; MÜLLER, P.J.; WEFER, G.; ZAHN, R. 1999. Warming of the Tropical Atlantic Ocean and Slowdown of Thermohaline Circulation During the Last Deglaciation. Nature v. 402, p. 511-514.

RUHLemANN, C.; MUlitZA, S.; LOHMANN, G.; PAUL, A.; PRANGE, M.; WefER, G. 2004. Intermediate depth warming in the tropical Atlantic related to weakened thermohaline 
circulation: Combining paleoclimate data and modeling results for the last deglaciation. Paleoceanography, v. 19 PA1025, doi:10.1029/2003PA000948.

SELLERS, W.D. Physical climatology, The Univ. of Chicago Press, 272 p., 1966.

SEN GUPTA, B.K. 1999. Introduction to Modern Foraminifera. In: SEN GUPTA, B.K ed.. Modern Foraminifera. Kluwer Academic Publishers. London, p. 3-6.

SILVEIRA, I.C.A.; SCHMIDT, A.C.K.; CAMPOS, E.J.D.; GODOI, S.S.; IKEDA, Y. 2000. A Corrente do Brasil ao largo da costa Leste Brasileira. Revista Brasileira de Oceanografia, v. 48, 2, p. 171-183.

SORANO, M.R.G.S. 2006. Distribuicao de Foraminiferos Planctonicos (0-100 M na Coluna d'Agua) e se registro no sediment na margem continental sudeste brasileira, entre Sao Sebastiao, SP, e Cabo de Sao Tome, RJ

STEIN, R. 1991. Accumulation of Organic Carbon in Marine Sediments. Results from the Deep Sea Drilling Project/ Ocean Drilling Program. Springer, Berlin, 217 p.

STRAMMA, L.; ENGLAND, M. 1999. On the water masses and mean circulation of the South Atlantic Ocean. Journal of Geophysical Research, v. 104, C9, p. 20.863-20.883.

SVERDRUP, H. U., JOHNSON M. W.; FLEMING R. H. 1942 The Oceans: their physics, chemistry and general biology. Englewood Cliffs, Prentice- Hall Inc. 1087 p.

SWANSON, K.; VAN DER LINGEN, G. 1997. Late Quaternary ostracod and planktonic foraminiferal dissolution signals from the eastern Tasman Sea - palaeoenvironmental implications. Palaeogeography, Palaeoclimatology, Palaeoecology, v. 131, p. 303-314.

THOMPSON, P. R., BE, A.W.H., DUPLESSY, J. C, and SHACKLETON, N. J., 1979.

Disappearence of pink-pigmented Globigerinoides ruber at 120,000 yr BP in the Indian and Pacific oceans. Nature, v. 280, p. 554-558.

THUNELL, R.C. 1976. Calcium carbonate dissolution history in Late Quaternary deep-sea sediments, western Gulf of Mexico, Quaternary Research.v. 6, p. 281-297.

THUNELL, R.C.; WILLIAMS, D.F.; KENNETT, J.P. 1977. Late quaternary paleoclimatology, stratigraphy and sapropel history in eastern mediterranean deep-sea sediments. Marine Micropaleontology, v. 2, p. 371-388. 
THUNELL, R. C., 1984. Pleistocene planktonic foraminiferal biostratigraphy and paleoclimatology of the Gulf of Mexico. In: HEALY-WILLIAMS, N. (ed.) Principles of Pleistocene Stratigraphy Applied to the Gulf of Mexico. International Human Resources Development Corporation, p. 25-64.

THUNELL, R.C.; REYNOLDS, L. 1984. Sedimentation of planktonic foraminifera: Seasonal changes in species flux in the Panama Basin. Micropaleontology, v. 30, p. 241-260.

TOLEDO, F.A.L. 2000 Variações Paleoceanográficas nos últimos 30.000 anos no oeste do Atlântico Sul: isótopos de oxigênio, assembléia de foraminíferos planctônicos e nanofósseis calcários. Tese de doutorado. Universidade federal do Rio Grande do Sul. 245 p.

TOLEDO, F.A.L.; Costa, K.B.; QUADROS, J.P.; SANTOS, E.C. 2005. Variações Paleoceanográficas Observadas em Testemunhos do Atlântico Sudoeste nos Últimos 20.000 anos. Anais da II Conferência regional Sobre Mudanças Globais: América do Sul. São Paulo, Brasil. 06 - 10 de novembro de 2005.

TRIANTAPHYLLOU, M.V.; ANTONARAKOU, A.; DIMIZA, M.; ANAGNOSTOU, C. 2009 Calcareous nannofossil and planktonic foraminiferal distributional patterns during deposition of sapropels S6, S5 and S1 in the Libyan Sea (Eastern Mediterranean). Geo-Marine Letters, DOI 10.1007/s00367-009-0145-7.

TURCQ, B.; VINCENS, A.; ABSY, M.L.; BERTAUX, J.; LEDRU, M.P.; SERVANT, M.; SIFFEDINE, A. ; YBERT, J.P. ; ELENGA, H. ; MALEY, J. ; SCHWARTZ, D. 1996 Evolution des forets tropicales d'Amerique du Sud et D'Afrique Centrale Atlantique a L'Echelle des 20000 dernieres annees. Dynamique a long Terme des Ecosystemes Forestiers Intertropicaux, v. 20, p. 277-280.

VAN Der ZWAAN, G.J., JORISSEN, F.J., De STIGTER, H.C. 1990. The depth dependency of planktnic/benthic foraminiferal ratios: Constraints and applications. Marine Geology, v. 95, p. $1-16$

VELLINGA, M.; WOOD, R.A. 2002. Global climatic impacts of a collapse of the Atlantic thermohaline circulation. Climatic Change, v. 54, p. 251-267.

VIANELLO, R.L.; ALVES, A .R. 1991. Meteorologia Básica e Aplicações.Universidade Federal de Viçosa, Minas Gerais, MG

VICALVI, M.A. 1997. Zoneamento bioestratigráfico e paleoclimático dos sedimentos do Quaternário Superior do Talude da Bacia de Campos. Boletim de Geociências da PETROBRÁS, v. 11, (1/2), p. 132-165. 
VICALVI, M.A., 1999. Zoneamento bioestratigráfico e paleoclimático do QuaternárioSuperior do talude da Bacia de Campos e Platô de São Paulo adjacente, com base em foraminíferos planctônicos. Tese de Doutorado - Curso de Pós-Grauação em Geologia, Universidade Federal do Rio de Janeiro, $183 \mathrm{p}$.

VIDAL, L.; SCHNEIDER, R. R.; MARCHAL, O.; BICKERT, T.; STOCKER, T. F.; WEFER, G. 1999. Link between the North and South Atlantic during the Heinrich events of the last glacial period. Climate Dynamics, v. 15, p. 909-919.

VINCENT, E.; BERGER, W.H., 1981. Planktonic foraminifera and their use in palaeoceanography. In: Emiliani, C., (Ed.), The Sea, v. 7, Wiley-Interscience, New York, p. 1025-1119.

WATKINS, J.M.; MIX, A.C.; WILSON, J. 1996 Living planktic foraminifera: tracers of circulation and productivity regimes in the central equatorial Pacific. Deep-Sea Research, v. 43, p. 12571282

WEFER, G.; BERGER, W.H.; BIJMA, J.; FISCHER, G. 1999. Clues to Ocean History: a Brief Overview of Proxies. In: FISCHER, G; WEFER, G. (eds), Use of Proxies in Paleoceanography : Examples from the South Atlantic. Berlin ; New York, Springer 735 p.

WEIJER, W.; DE RUIJTER, W.P.M.; STERL, A.; DRIJFHOUT, S.S. 2002. Response of the Atlantic overturning circulation to South Atlantic sources of buoyancy. Global and Planetary Change, v. 34, p. 293-311.

XIE, P., ARKIN, P.A., 1997. Global precipitation: a 17-year monthly analysis based on gauge observations, satellite estimates, and numerical model outputs. Bulletin of the American Meteorological Society, v. 78, p. 2539-2558.

ZEMBRUSCKI, S. G. 1979. Geomorfologia da margem continental sul brasileira e das bacias oceânicas adjacentes. In: CHAVES, H. A. F. (Ed.) Geomorfologia da margem continental sul brasileira e das áreas oceânicas adjacentes. Rio de Janeiro, PETROBRAS. CENPES. DINTEP Série Projeto REMAC NUM. 7 
ANEXOS 


\section{Anexo I - Pranchas}

\section{Prancha 1}

1 Globigerinoides ruber (pink) (d'Orbigny, 1839)

Vista espiral ; \# $20 \mathrm{~cm}$

2 Globigerinoides ruber (pink) (d'Orbigny, 1839)

Vista umbilical; \# $20 \mathrm{~cm}$

3 Globigerina bulloides (d'Orbigny, 1826)

Vista umbilical; \# $20 \mathrm{~cm}$

4 Globigerina bulloides (d'Orbigny, 1826)

Vista espiral; \# $20 \mathrm{~cm}$

5 Globigerinoides sacculifer com saco (Brady, 1877)

Vista umbilical; \# $20 \mathrm{~cm}$

6 Globigerinoides sacculifer com saco (Brady, 1877)

Vista espiral; \# $20 \mathrm{~cm}$

7 Globigerinoides sacculifer sem saco (= Globigerinoides trilobus) (Brady, 1877)

Vista umbilical; \# $20 \mathrm{~cm}$

8 Orbulina universa (d'Orbigny, 1839)

\# $20 \mathrm{~cm}$

9 Globigerinoides conglobatus (Brady, 1879)

Vista umbilical; \# $20 \mathrm{~cm}$

10 Globigerinoides conglobatus (Brady, 1879)

Vista espiral; \# $20 \mathrm{~cm}$

11 Globigerinoides ruber (white) (d'Orbigny, 1839)

Vista umbilical; \# $20 \mathrm{~cm}$

12 Globigerinoides ruber (white) (d'Orbigny, 1839)

Vista espiral; \# $20 \mathrm{~cm}$ 


\section{Prancha 2}

1 Globorotalia menardii (d'Orbigny, 1865)

Vista umbilical; \# $20 \mathrm{~cm}$

2 Globorotalia menardii (d'Orbigny, 1865)

Vista espiral; \# $20 \mathrm{~cm}$

3 Globorotalia crassaformis (Galloway e Wissler, 1927)

Vista umbilical; \# $470 \mathrm{~cm}$

4 Globorotalia fimbriata (Brady, 1884)

Vista espiral; \# $55 \mathrm{~cm}$

5 Globorotalia fimbriata (Brady, 1884)

Vista umbilical; \# $55 \mathrm{~cm}$

6 Globorotalia truncatulinoides (dex) (d'Orbigny, 1839)

Vista umbilical; \# $398 \mathrm{~cm}$

7 Pulleniatina obliquiloculata (Parker e Jones, 1865)

Vista apertural; \# $478 \mathrm{~cm}$

8 Pulleniatina primalis (Parker e Jones, 1865)

Vista apertural; \# $478 \mathrm{~cm}$

9 Neogloboquadrina dutertrei (= Globoquadrina dutertrei) (d'Orbigny, 1839)

Vista umbilical; \# $486 \mathrm{~cm}$

10 Neogloboquadrina dutertrei (= Globoquadrina dutertrei) (d'Orbigny, 1839)

Vista espiral; \# $486 \mathrm{~cm}$

13 Globigerinita glutinata (= Globigerina glutinata ) (Egger, 1893)

Vista espiral; \# $240 \mathrm{~cm}$

14 Globorotalia inflata (d'Orbigny, 1839)

Vista apertural; \# $486 \mathrm{~cm}$ 